\title{
(ब)
}

ipen

INSTITUTO DE PESQUISAS ENERGÉTICAS E NUCLEARES

Autarquia Associada à Universidade de São Paulo

\section{APLICAÇÃO DO MÉTODO DE MONTE CARLO NA PADRONIZAÇÃO DE RADIONUCLÍDEOS EMISSORES DE PÓSITRONS}

MARGARETH LIKA ONISHI TONGU

Dissertação apresentada como parte dos requisitos para obtenção do grau de Mestre em Ciências na Área de Tecnologia Nuclear - Aplicações.

Orientador:

Dr. Mauro da Silva Dias

São Paulo 
Ao meu esposo Shinji

Aos meus pais, Toru e Sumie

Aos meus irmãos Eduardo, Wilson e Marly Aos meus cunhados Érica, Taisa e Pedro Aos meus sobrinhos Victor e Sophie 


\section{Agradecimentos:}

Ao Dr. Mauro da Silva Dias, orientador deste trabalho, pela oportunidade, dedicação e apoio durante o desenvolvimento desta dissertação.

À Dra. Marina Fallone Koskinas, pelas discussões, sugestões e apoio durante todo o desenvolvimento do trabalho.

Aos colegas Fábio de Toledo, Vanderlei Cardoso, Denise Simões Moreira, Franco Brancaccio, Cláudio Domienikan, pela amizade, apoio e estímulo.

Ao meu esposo Shinji, pelo apoio, carinho, incentivo e compreensão, durante a realização deste trabalho.

Aos meus sobrinhos Sophie e Victor, que após seus nascimentos, proporcionaram-me grande alegria e incentivo para a realização do meu trabalho.

Aos meus pais que sempre apoiaram e incentivaram os meus estudos, com carinho e dedicação.

Ao pessoal da Comissão de Pós-Graduação do IPEN-CNEN/SP pelo apoio oferecido.

Ao IPEN-CNEN/SP, na pessoa de seu superintendente, Dr. Nilson Dias Vieira Junior, pela oportunidade de realização deste trabalho.

A todos que diretamente ou indiretamente colaboraram na execução e realização deste trabalho. 


\title{
APLICAÇÃO DO MÉTODO DE MONTE CARLO NA PADRONIZAÇÃO DE RADIONUCLÍDEOS EMISSORES DE PÓSITRONS.
}

\author{
Margareth Lika Onishi Tongu
}

\section{Resumo}

O Laboratório de Metrologia Nuclear do IPEN (LMN) desde 1967 desenvolve métodos de padronização de radionuclídeos e medidas de probabilidades de emissão gama por decaimento, utilizando o sistema de coincidência $4 \pi \beta-\gamma$, que é um método primário de alta exatidão para a determinação da taxa desintegração dos radionuclídeos de interesse. A partir de 2001, o LMN iniciou uma linha de pesquisa relacionada com a modelagem, por meio do método de Monte Carlo, de todo o sistema de coincidências, incluindo os detectores de radiação e o processo de decaimento do radionuclídeo. Esta metodologia permite simular o processo de detecção no sistema $4 \pi \beta-\gamma$, determinando teoricamente a atividade observada em função da eficiência do detector $4 \pi \beta$. Com isso, torna-se possível prever o comportamento da curva de extrapolação, possibilitando um planejamento detalhado do experimento antes do início das medidas. O presente trabalho tem como um dos objetivos o aperfeiçoamento da modelagem do detector proporcional $4 \pi$, introduzindo uma descrição detalhada do suporte e do material da fonte radioativa, além de absorvedores colocados em torno da fonte. $O$ programa utilizado nas simulações de transporte de radiação nos detectores é o MCNPX. O foco principal do presente trabalho reside na modelagem por Monte Carlo da padronização de radionuclídeos com emissão de pósitrons, associados (ou não) com captura eletrônica e acompanhados (ou não) por emissão de radiação gama. Uma das dificuldades nesta modelagem é simular a detecção dos gamas de aniquilação, que são produzidos no processo de absorção dos pósitrons no interior do detector $4 \pi$. A metodologia foi aplicada aos radionuclídeos ${ }^{18} \mathrm{Fe}{ }^{22} \mathrm{Na}$. 


\title{
APPLICATION OF MONTE CARLO SIMULATION TO THE STANDARDIZATION OF POSITRON EMITTING RADIONUCLIDES
}

\author{
Margareth Lika Onishi Tongu
}

\begin{abstract}
Since 1967, the Nuclear Metrology Laboratory (LNM) at the Nuclear and Energy Research (IPEN) in São Paulo, Brazil, has developed radionuclide standardization methods and measurements of the Gamma-ray emission probabilities per decay by means of $4 \pi \beta-\gamma$ coincidence system, a high accuracy primary method for determining disintegration rate of radionuclides of interest. In 2001 the LNM started a research field on modeling, based on Monte Carlo method, of all the system components, including radiation detectors and radionuclide decay processes. This methodology allows the simulation of the detection process in a $4 \pi \beta-\gamma$ system, determining theoretically the observed activity as a function of the $4 \pi \beta$ detector efficiency, enabling the prediction of the behavior of the extrapolation curve and optimizing a detailed planning of the experiment before starting the measurements. One of the objectives of the present work is the improvement of the $4 \pi$ proportional counter modeling, presenting a detailed description of the source holder and radioactive source material, as well as absorbers placed around the source. The simulation of radiation transport through the detectors has been carried out using code MCNPX. The main focus of the present work is on Monte Carlo modeling of the standardization of positron emitting radionuclides associated (or not) with electron capture and accompanied (or not) by the emission of Gamma radiation. One difficulty in this modeling is to simulate the detection of the annihilation Gamma ray, which arise in the process of positron absorption within the $4 \pi$ detector. The methodology was applied to radionuclides ${ }^{18} \mathrm{~F}$ and ${ }^{22} \mathrm{Na}$.
\end{abstract}




\section{SUMÁRIO}

INTRODUÇÃO

1 FUNDAMENTOS TEÓRICOS 4

1.1 Leis da Desintegração radioativa 4

1.2 Desintegração alfa 7

1.3 Desintegração beta 7

1.4 Captura Eletrônica 9

1.4.1 Emissão de Elétrons Auger 12

1.4.2 Emissão de Raio-X 12

1.5 Transições Gama 13

1.5.1 Emissão de Radiação Gama 14

$\begin{array}{ll}\text { 1.5.2 Conversão Interna } & 14\end{array}$

1.6 Interação da Radiação com a Matéria 16

1.6.1 Elétrons e Pósitrons 16

$\begin{array}{ll}1.6 .2 \text { Fótons } & 18\end{array}$

1.6.2.1 Coeficiente de Atenuação Linear 19

1.6.2.2 Coeficiente de Atenuação de massa 20

1.6.2.2.1 Efeito Fotoelétrico 21

1.6.2.2.2 Efeito Compton 22

1.6.2.2.3 Produção de Pares 23

2 METODOLOGIA 25

2.1 Medida Absoluta da Atividade pelo Método de Coincidência 26

2.1.1 Formalismo geral 26

2.1.2 Técnica da extrapolação linear da eficiência 30

2.2 Arranjo experimental do sistema de coincidência $4 \pi(P C) \beta-\gamma \quad 33$

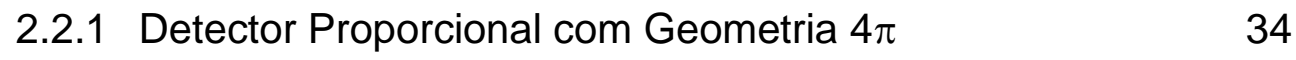

2.2.2 Cristal Cintilador de $\mathrm{Nal}(\mathrm{TI})$

2.2.3 Sistema Eletrônico Associado 35

2.3 Padronização de Radionuclídeos por meio de sistemas de $\begin{array}{ll}\text { Coincidência } & 37\end{array}$

2.3.1 Padronização do ${ }^{60} \mathrm{Co} \quad 37$ 
2.3.2 Padronização do ${ }^{18} \mathrm{~F}$

2.2.4 Padronização do ${ }^{22} \mathrm{Na}$

2.4 Modelagem do Método de Coincidências pela técnica de Monte Carlo

2.4.1 Introdução

2.4.2 Programa VISED

2.4.3 Geometria Original

2.4.4 Geometria Modificada

2.4.5 Programas Desenvolvidos para Análise de Dados

Programas ELETRONX E FOTONX

2.4.5.2 Programas MCOUT1 E MCOUT2

2.4.5.3

Programa DGAMA

2.4.5.4

Programa EALUM

3 RESULTADOS OBTIDOS E DISCUSSÃO

3.1 Padronização do ${ }^{60} \mathrm{Co}$

3.2 Padronização do ${ }^{18} \mathrm{~F}$

3.3 Padronização do ${ }^{22} \mathrm{Na}$

4 CONCLUSÕES

5 PERPECTIVAS FUTURAS 78

$\begin{array}{lll}\text { APÊNDICE A Código do Programa ESQPOS1 } & 79\end{array}$

APÊNDICE B Código do Programa ELETRONX 81

APÊNDICE C Código do Programa FOTONX 82

APÊNDICE D Código do Programa EALUM 83

APÊNDICE E Código do Programa DGAMA $\quad 89$

APÊNDICE F Código do Programa MCOUT1 85

APÊNDICE G Código do Programa MCOUT2 86

$\begin{array}{lll}\text { APÊNDICE H Código do Programa MCOUT3 } & 87\end{array}$

$\begin{array}{lll}\text { APÊNDICE I } & \text { Arquivo Efibeta.dat. } & 88\end{array}$

$\begin{array}{lll}\text { APÊNDICE J Arquivo Efigama.dat. } & 89\end{array}$ 
APÊNDICE K Código do Programa ESQPOS2 90

APÊNDICE L $\quad$ Código do Programa ESQPOS3 91

REFERÊNCIAS BIBLIOGRÁFICAS 93 


\section{INTRODUÇÃO}

Em Metrologia Nuclear o método de medida absoluta de radionuclídeos por coincidência $4 \pi \beta-\gamma$ tem sido considerado um padrão primário, em razão de seu alto grau de exatidão e por depender apenas de grandezas observáveis para obtenção de seus resultados ${ }^{[1-10]}$. A atividade da fonte radioativa, pelo método primário é determinada pela observação das taxas de contagem para o radionuclídeo de interesse, sem a necessidade de padrões, dispensando assim, diversos parâmetros nucleares e/ou parâmetros do sistema de calibração utilizado.

O Laboratório de Metrologia Nuclear (LMN) do IPEN tem desenvolvido padronizações pelo sistema de coincidência $4 \pi \beta-\gamma$, desde 1967. Atualmente, o LMN possui três sistemas de medida deste tipo: dois, que utilizam um detector proporcional em geometria $4 \pi^{[10-14]}$ e um terceiro, que utiliza um cintilador plástico em geometria $4 \pi^{[15]}$. Todos estes sistemas são acoplados a cintiladores de $\mathrm{Nal}(\mathrm{TI})$ ou detectores semicondutores de HPGe, para a detecção da radiação gama.

Os sistemas de coincidência do LMN que utilizam detectores proporcionais em geometria $4 \pi$ são denominados: sistema I (que possui um detector de $\mathrm{Nal}(\mathrm{TI})$ acoplado) e sistema II (que possui dois detectores de $\mathrm{Nal}(\mathrm{TI})$ acoplados). Os detectores proporcionais são preenchidos com uma mistura composta de $10 \%$ de metano e $90 \%$ de argônio (mistura P-10). A pressão para o sistema I pode variar entre 0,1 e 1,0 MPa e, para o sistema II, o detector funciona a gás fluente, com pressão próxima de $0,1 \mathrm{MPa}^{[10-14]}$.

A partir de 2001, o LMN iniciou uma linha de pesquisa relacionada com a modelagem, por meio do método de Monte Carlo, de todo o sistema de coincidências, incluindo os detectores de radiação e o processo de desintegração do radionuclídeo, definido pelo seu esquema de desintegração ${ }^{[16-18]}$. Esta metodologia permite simular 0 processo de detecção no sistema $4 \pi \beta-\gamma$, determinando teoricamente a atividade observada em função da eficiência do 
detector $4 \pi \beta$. Com isso, torna-se possível prever o comportamento da curva de extrapolação, possibilitando um planejamento detalhado do experimento, antes do início das medidas.

Para esquemas de desintegração simples, os resultados são facilmente previsíveis, entretanto, para esquemas mais complexos, deve-se levar em consideração uma série de fatores, tais como: detecção de elétrons de conversão, superposição de eventos provenientes de outras transições no intervalo de energia gama de interesse, etc. Deste modo, foi necessário desenvolver uma metodologia teórica, que simulasse de modo abrangente todo o experimento.

Neste tipo de enfoque o LMN é pioneiro, tendo recebido incentivo por parte da comunidade internacional, para a aplicação desta metodologia. Esta linha de pesquisa foi inicialmente desenvolvida por Takeda ${ }^{[16-18]}$, considerando uma modelagem relativamente simples para o sistema de coincidência e aplicando a técnica para emissores $\beta^{-}-\gamma$ ou captura eletrônica (CE)- $\gamma$. Recentemente ${ }^{[19]}$, Takeda introduziu diversas melhorias na modelagem da geometria do sistema de coincidências, além de incluir o processo de detecção da radiação gama no detector beta. $O$ novo programa de simulação do esquema de desintegração, modificado a partir do programa original ESQUEMA ${ }^{[18]}$ foi denominado ESQPOS ${ }^{[19]}$.

O presente trabalho tem como um dos objetivos o aperfeiçoamento da modelagem do detector proporcional $4 \pi$, introduzindo uma descrição detalhada do suporte e do material da fonte radioativa, além de absorvedores colocados em torno da fonte. Além disso, o programa utilizado no presente trabalho para as simulações de transporte de radiação nos detectores é o MCNPX ${ }^{[19]}$. Este programa possui recursos melhores de visualização da geometria e bibliotecas de seções de choque mais atualizadas, quando comparado à versão anterior MCNP4C ${ }^{[21]}$, utilizada por Takeda.

O objetivo principal do presente trabalho reside na modelagem por Monte Carlo da padronização de radionuclídeos com emissão de pósitrons, associados (ou não) com captura eletrônica e acompanhados (ou não) por emissão de radiação gama. Uma das dificuldades nesta modelagem é simular a detecção dos gamas de aniquilação, que são produzidos no processo de absorção dos pósitrons no interior do detector $4 \pi$. 
Esta aniquilação de pósitrons pode ocorrer próxima ou distante da fonte radioativa, dependendo dos absorvedores utilizados na calibração, dificultando a determinação da eficiência dos gamas de aniquilação no detector gama. Uma limitação da atual versão do programa desenvolvido por Takeda, é a impossibilidade de simular dois modos de desintegração do tipo $\beta^{+} / C E$, como é o caso do ${ }^{22} \mathrm{Na}$. Neste caso, a presença de pósitrons juntamente com elétrons Auger ou de conversão interna, necessitaria da utilização de duas tabelas de resposta, na simulação do esquema de desintegração: uma para pósitrons e outra para elétrons. No presente trabalho, esta dificuldade foi contornada utilizando-se um esquema de desintegração alternativo para o ${ }^{22} \mathrm{Na}$ e não foi necessária uma tabela para elétrons, porque a energia dos elétrons Auger deste radionuclídeo é menor do que $1 \mathrm{keV}$, acarretando a absorção completa destes elétrons nos absorvedores colocados nas fontes radioativas. 


\section{FUNDAMENTOS TEÓRICOS}

Neste capítulo são abordados conceitos sobre estabilidade, desintegração radioativa e os tipos de desintegrações. A maior parte dos núcleos é instável, ou seja, as respectivas combinações de prótons e nêutrons não originam configurações nucleares estáveis. Para alcançar a estabilidade, os núcleos instáveis desintegram-se por meio da emissão de partículas alfa, elétrons, pósitrons, neutrinos e radiação eletromagnética (fótons $\gamma$ ), para outra espécie que poder ser estável ou radioativa. Neste último caso, o núcleo produzido continua o processo de emissão de radiação, até que um núcleo estável seja obtido ${ }^{[22,23]}$.

\subsection{Leis da Desintegração Radioativa}

Os processos radioativos seguem uma lei de desintegração exponencial, primeiramente formulada por Rutherford e Soddy em 1902. Após a descoberta da fissão nuclear verificou-se a existência de uma série de decaimentos radioativos sucessivos, explicados pelas equações de Bateman (1910), que são utilizadas até hoje, para a devida compreensão destes processos de desintegrações radioativas ${ }^{[22]}$.

Neste capítulo são abordados os vários tipos de radiações com diferentes características provenientes destes processos, além das interações da radiação com a matéria.

As diferentes propriedades do radionuclídeo e os parâmetros característicos de sua desintegração são normalmente descritos por diagramas, denominados Esquemas de Desintegração, conforme exemplo da figura 1.1 Estes diagramas apresentam a energia liberada pela desintegração, a meia-vida, as energias e spins dos níveis excitados e as transições entre níveis excitados. 


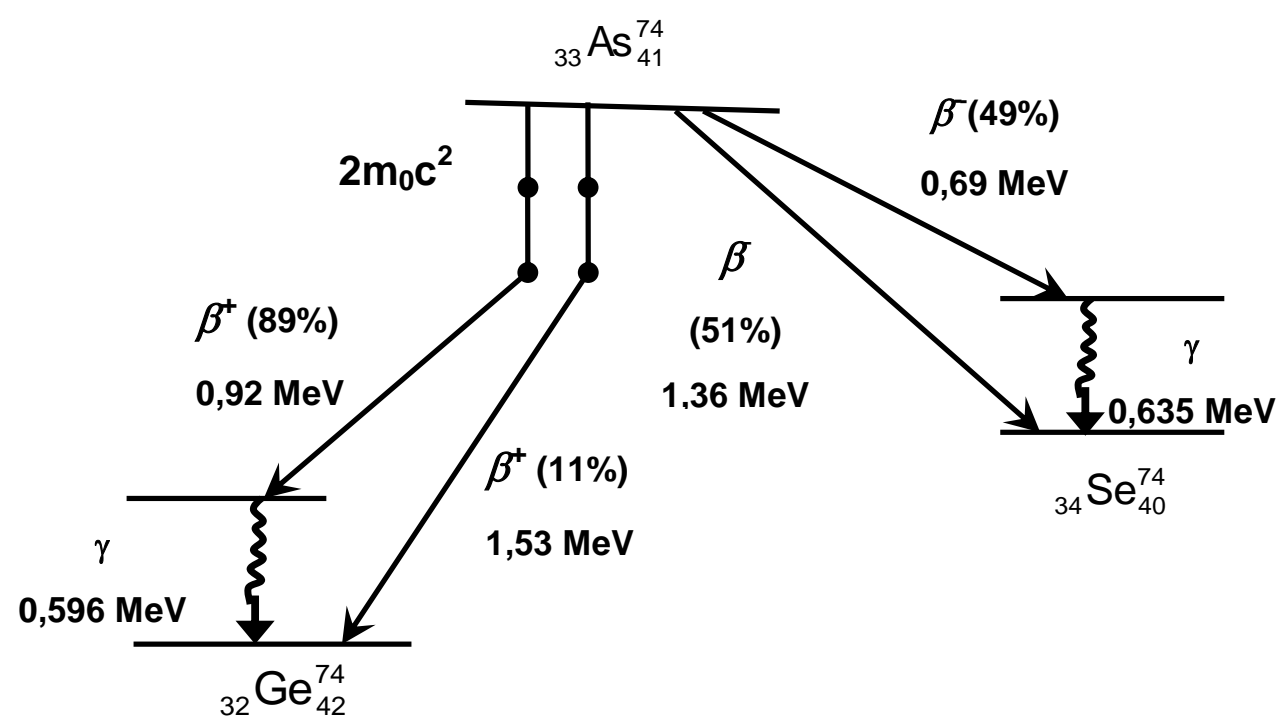

Figura 1.1 - Exemplo de um esquema de desintegração ${ }^{[22]}$. As intensidades apresentadas referem-se a cada um dos modos de desintegração, tratados separadamente.

A desintegração radioativa que ocorre por diferentes processos atômicos ou nucleares dão origem a radiações que são classificadas em quatro tipos gerais a seguir ${ }^{[23]}$.

Radiação de partículas carregadas $\left\{\begin{array}{l}\text { partículas leves } \\ \text { partículas carregadaspesadas }\end{array}\right.$

Radiação sem carga $\left\{\begin{array}{l}\text { radiação eletromagnética } \\ \text { nêutrons }\end{array}\right.$

Em nosso trabalho o que nos interessa são as radiações das partículas carregadas leves: partículas betas positivas, denominadas pósitrons, que são emitidas na desintegração nuclear, quando o núcleo possui um excesso de prótons. Este processo concorre com a captura eletrônica que, por sua vez, pode ser acompanhada por emissão de elétrons Auger, raios- $\mathrm{X}$, ou transições gama.

Para um radionuclídeo isolado, à medida que a amostra radioativa se desintegra, há um decréscimo no número de átomos do pai e um conseqüente aumento no número de átomos do filho no decorrer do tempo. 
Para obtermos a atividade da fonte, suponhamos que a amostra radioativa contenha $\mathrm{N}_{0}$ núcleos radioativos no instante $\mathrm{t}=0$. O número provável de núcleos que se desintegrarão no intervalo de tempo dt é dado por:

$$
\frac{\mathrm{dN}}{\mathrm{dt}}=-\lambda \mathrm{N}
$$

O sinal negativo aparece em virtude do número de átomos radioativos decrescerem com 0 tempo. O termo $\lambda \mathbf{N}$ corresponde ao número de desintegrações por unidade de tempo, que é denominado atividade da amostra e é fornecido pela equação abaixo;

$$
A=\lambda N
$$

Verifica-se que a lei de variação do número de átomos radioativos com o tempo é do tipo exponencial,

$$
\mathrm{N}=\mathrm{N}_{0} \mathrm{e}^{-\lambda t}
$$

Onde:

$\mathrm{N}=$ número de átomos radioativos presentes na amostra no instante t;

$\mathrm{N}_{0}=$ número de átomos radioativos no instante inicial;

$\lambda=$ constante de desintegração, é característica do núcleo pai e independe de qualquer condição físico-química em que a amostra radioativa estiver submetida. Multiplicando-se a equação (1.3) em ambos os lados por $\lambda$, obtém-se a equação seguinte:

$$
A=A_{0} e^{-\lambda t}
$$

Onde

$A=$ Atividade da fonte no instante te $A_{0}$ no instante $t=0$. 
A unidade no Sistema Internacional de Unidades (SI) é o Bq (Bequerel)

$$
1 \mathrm{~Bq}=1 \mathrm{~s}^{-1}
$$

Que é definido como uma desintegração por segundo.

\subsection{Desintegração Alfa}

Alguns radionuclídeos podem emitir espontaneamente partículas alfa (ou núcleos de hélio ${ }^{4} \mathrm{He}$ ). $\mathrm{O}$ processo deste tipo de desintegração pode ser esquematizado, conforme relação abaixo ${ }^{[23]}$ :

$$
{ }_{\mathrm{Z}}^{\mathrm{A}} \mathrm{X} \rightarrow{ }_{\mathrm{Z}-2}^{\mathrm{A}-4} \mathrm{Y}+{ }_{2}^{4} \alpha
$$

Onde $\mathrm{X}$ (núcleo pai) e $\mathrm{Y}$ (núcleo filho), correspondem respectivamente ao estado inicial e final da transição nuclear.

A desintegração alfa é característica dos núcleos pesados (em geral, $Z$ maior que 82). As partículas alfa, por serem partículas pesadas, possuem um alto poder de ionização, portanto elas interagem intensamente com a matéria, perdendo rapidamente a sua energia e penetrando muito pouco na matéria.

\subsection{Desintegração Beta}

Denomina-se desintegração beta a emissão de elétrons negativos ou positivos, provenientes do núcleo atômico. As partículas betas negativas possuem as mesmas características dos elétrons atômicos, com a diferença que as partículas betas têm origem nuclear e espectro contínuo de energia, variando de zero até um valor máximo, característico do núcleo pai.

Apesar dos núcleos apresentarem energias discretas, o beta é emitido com um espectro contínuo de energia, pois uma segunda partícula é emitida, que é o neutrino (ou anti-neutrino), carregando a diferença de energia existente entre a energia da partícula beta e a energia disponível, dada pela diferença de massa entre o núcleo pai e os produtos de desintegração. 
A interação da força fraca é uma das quatro interações fundamentais da natureza (força nuclear forte, eletromagnética e gravitacional), e a força nuclear fraca que é a responsável, pelo decaimento beta nuclear, negativos $\left(\beta^{-}\right)$ positivos $\left(\beta^{+}\right)$e a captura eletrônica, conforme a figura 1.2. As descrições para esses processos são apresentadas a seguir ${ }^{[23]}$.

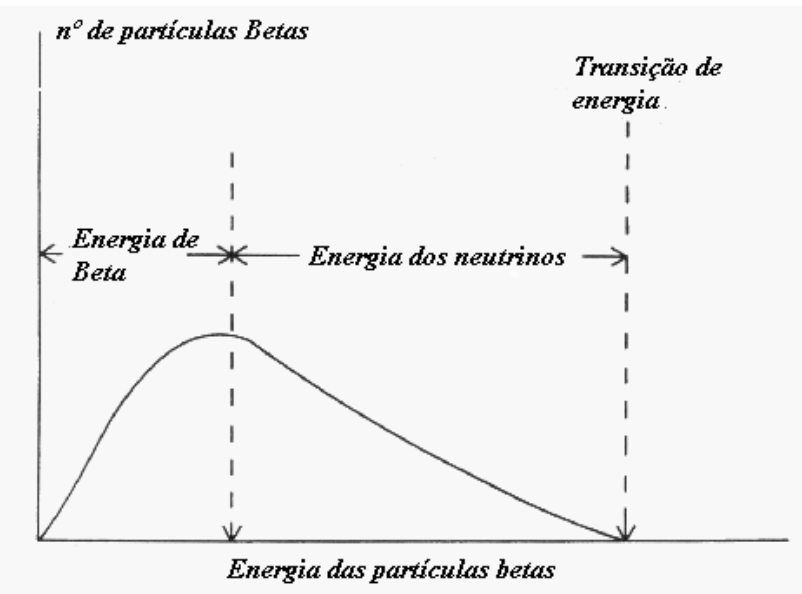

Figura 1.2 - Espectro de um decaimento beta típico ${ }^{[23]}$.

Na desintegração beta negativa, um nêutron se converte em um próton emitindo uma partícula negativamente carregada e outra desprovida de massa, sendo tais partículas a partícula beta e o anti-neutrino, respectivamente, mantendo desta forma a conservação de energia, do momento linear e angular. Esse processo pode ser escrito esquematicamente, conforme a relação abaixo ${ }^{[23]}$ :

$$
{ }_{\mathrm{Z}}^{\mathrm{A}} \mathrm{X} \rightarrow{ }_{\mathrm{Z}+1}^{\mathrm{A}} \mathrm{Y}+\beta^{-}+\overline{\mathrm{v}}
$$

Onde $\mathrm{X}$ e $\mathrm{Y}$ são respectivamente os núcleos do processo inicial e final, da transição nuclear, e $\bar{v}$ representa o anti-neutrino. O núcleo filho tem o mesmo número de massa que o núcleo pai, mas um número atômico com uma unidade a mais.

Este processo é mais provável quando o número de nêutrons é grande comparado ao número de prótons, o núcleo correspondente pode ser instável e o número de nêutrons pode ser diminuído pela transformação de um nêutron num 
próton. Essa transformação é acompanhada da emissão de um elétron e de um anti-neutrino, pela seguinte relação ${ }^{[24]}$ :

$$
{ }_{0}^{1} \mathrm{n} \rightarrow{ }_{1}^{1} \mathrm{p}+{ }_{-1}^{0} \mathrm{e}+\overline{\mathrm{v}}
$$

A desintegração beta positiva $\left(\beta^{+}\right)$pode ser representada pela relação:

$$
{ }_{Z}^{A} X \rightarrow{ }_{Z-1}^{A} Y+\beta^{+}+v
$$

Este processo ocorre quando o número de prótons é relativamente grande comparado ao número de nêutrons, o núcleo correspondente pode ser instável e o número de prótons pode ser diminuído pela transformação de um próton num nêutron. Essa transformação é acompanhada da emissão de um pósitron (partícula idêntica ao elétron, exceto pela carga, que é positiva) e de um neutrino ${ }^{[24]}$ :

$$
{ }_{1}^{1} \mathrm{p} \rightarrow{ }_{0}^{1} \mathrm{n}+{ }_{+1}^{0} \mathrm{e}+\mathrm{v}
$$

A partícula beta positiva (pósitron) possui a mesma massa do elétron e sua carga tem valor absoluto igual à do elétron, porém com sinal positivo. Analogamente às partículas betas negativas, as partículas betas positivas são emitidas com um espectro contínuo de energia ${ }^{[24]}$.

Para alguns radionuclídeos, tanto a emissão $\beta^{-}$como $\beta^{+}$, podem ocorrer por mais de um ramo de desintegração, decaindo para diferentes níveis de energias de estados excitados dos núcleos filhos, que então se desexcitam por emissão gama e/ou elétrons de conversão interna.

\subsection{Captura Eletrônica}

É um processo que compete com a desintegração beta positiva, ocorrendo quando o núcleo possui um excesso de prótons. Em certos casos, o mesmo núcleo pode possuir probabilidades comparáveis de se desintegrar por 
qualquer um dos dois processos. A captura de elétron pode ser acompanhada por decaimento $\beta^{+}$, quando a energia disponível no decaimento ultrapassar o valor de $1,022 \mathrm{MeV} \cdot{ }^{[24]}$.

A captura eletrônica é seguida pela emissão de radiação eletromagnética (raios- $X$ ) pelo núcleo filho, resultante da passagem de um dos elétrons das camadas mais externas à vacância da camada interior deixada pelo elétron capturado. $O$ efeito da captura eletrônica é a mudança de um próton em um nêutron e, nesse sentido, o seu efeito sobre o núcleo é idêntico ao efeito produzido pela emissão $\beta^{+}$.

Representação do processo de captura eletrônica ${ }^{[24]}$ :

$$
{ }_{Z}^{A} \mathrm{X}+\mathrm{e}^{-} \rightarrow{ }_{Z-1}^{A} \mathrm{Y}+v
$$

Os elétrons das camadas mais internas dos átomos podem se aproximar bastante do núcleo. Em particular, aqueles da camada $\mathrm{K}$, que é a mais interna; porém este processo pode ocorrer também com elétrons de camadas mais externas. Um próton do núcleo pode capturar um desses elétrons neste processo convertendo-se em um nêutron e liberando um neutrino monoenergético, o qual carrega a energia disponível no processo ${ }^{[24]}$ :

$$
{ }_{1}^{1} \mathrm{p}+{ }_{1}^{0} \mathrm{e} \rightarrow{ }_{1}^{0} \mathrm{n}+\mathrm{v}
$$

Este processo deixa uma vacância na camada atômica que é preenchido por um elétron. No processo de desexcitação, o preenchimento da vacância ocasionado pela captura eletrônica é acompanhado da emissão de elétrons Auger ou raios- $X$.

A Teoria de Fermi é válida tanto para decaimentos $\beta^{-}$e $\beta^{+}$. Esta teoria foi proposta para explicar a forma da distribuição de energia das partículas beta emitidas, e as relações entre a energia cinética máxima da partícula beta e a vidamédia do núcleo emissor. Além disto, a teoria estabelece regras de seleção e explica as mudanças de momento angular esperadas nas transições beta. A teoria de Fermi usa a teoria de perturbação, fornecida pela equação abaixo ${ }^{\text {[24]. }}$ 


$$
\mathrm{T}=\frac{2 \pi}{\hbar}\left|\mathrm{H}_{\mathrm{if}}\right|^{2} \rho(\mathrm{E})
$$

Onde

$\mathrm{H}_{\text {if }}=$ elemento de matriz da interação perturbadora $\mathrm{H}^{\prime}$

$\hbar=$ constante de Planck

$\rho(E)=$ densidade de energia dos estados finais do sistema.

Para compor o espectro de beta emitido do radionuclídeo, aplicou-se a teoria de Fermi para desintegração $\beta$, levando-se em conta as características de energia e regras de seleção de momento angular para a transição nuclear considerada. Para o caso não-relativístico a probabilidade de que um beta seja emitido com momento entre $p$ e $(p+d p)$ é dado pela equação abaixo ${ }^{\text {[22]: }}$

$$
\frac{d_{n}}{d_{E_{o}}}=\left(\frac{16 \pi^{2} m_{0}^{5} c^{4} d p}{h^{6}}\right) \eta^{2}\left(W_{0}-W\right)^{2} F_{N}(Z, \eta) d \eta
$$

na qual:

$$
\begin{aligned}
& \eta=\frac{p}{m_{0} c}=\text { momentoreduzido } \\
& W \equiv \frac{E+m_{0} c^{2}}{m_{0} c^{2}}=\text { energiareduzida } \\
& F_{N}(Z, \eta) \cong \frac{2 \pi y}{1-e^{-2 \pi y}} ; \text { e o valor de y é dado por: } \\
& y \equiv \frac{ \pm Z}{137 \beta}= \pm Z \alpha \frac{W}{\eta} \quad\left\{\begin{array}{l}
+Z \text { para decaimento } \beta^{-} \\
-Z \text { para decaimento } \beta^{+}
\end{array}\right.
\end{aligned}
$$




\subsubsection{Emissão de Elétrons Auger}

A emissão de elétrons Auger ocorre quando uma vacância é criada nas camadas eletrônicas, por exemplo, através de um processo de captura eletrônica. A ejeção de elétrons ocorre devido ao processo fotoelétrico criando a vacância na camada. Em alguns casos, entretanto, a energia disponível no átomo, devida ao aparecimento da vacância, pode ser transferida diretamente a um dos outros elétrons orbitais, o qual é ejetado do átomo. Este processo é denominado efeito Auger ${ }^{[24]}$.

Portanto, a energia do elétron Auger-K é dada por:

$$
E_{A K}=E_{K}-E_{X}-E_{Y}-\Delta E
$$

Onde:

$E_{k}, E_{x}$ e $E_{Y}=$ são as energias de ligação dos elétrons nas camadas $K, X$ e $Y$.

$\Delta \mathrm{E}=$ é um termo corretivo para o caso em que a energia de ligação do átomo excitado seja muito maior do que do átomo em seu estado fundamental.

\subsubsection{Emissão de Raio-X}

O processo de captura de um elétron cria uma vacância em uma das camadas eletrônicas do átomo, dando origem a uma série de raios- $X$ e elétrons que podem ser emitidos como conseqüência da captura inicial de um elétron. Esta vacância poderá, então, ser preenchida por um elétron de uma camada na qual ele tenha uma menor energia de ligação, como a camada L. No caso da vacância ocorrer na camada $\mathrm{K}$ e o elétron Auger ser originário da camada $\mathrm{L}$, sua energia será $E_{K}-E_{L}$, podendo assim ser emitido como raio- $X$, existindo outra vacância na camada $L$, esta vacância pode ser preenchida por um elétron da camada $M$, e assim mais um raio-X poderá então aparecer, fazendo surgir uma cascata de raios- $X^{[25]}$. 


\subsection{Transições Gama}

Quase todos os estados excitados dos núcleos podem decair para estados menos excitados por emissão espontânea de radiação eletromagnética, cuja energia pertence à parte do espectro eletromagnético chamada de radiação gama.

Uma transição gama ocorre quando um núcleo atômico, desexcita-se para um estado de energia mais baixo, podendo ou não ser o estado fundamental. Ela manifesta-se espontaneamente pela emissão de um fóton gama ou um elétron de conversão. Em casos mais raros, pode haver a emissão de um par elétron-pósitron.

De um modo geral, além da origem, a diferença entre a radiação gama e os fótons atômicos é a energia ou comprimento de onda entre eles. No caso nuclear, as forças de ligação são intensas, de modo que transições entre estados nucleares freqüentemente envolvem fótons com misturas multipolares, em contraste com o caso atômico, em que o valor pequeno da constante de estrutura fina $(\alpha)$, determina a predominância da emissão de fótons do tipo dipolo elétrico. No caso nuclear, como no atômico, observa-se a conservação da paridade e do momento angular total. Essas leis de conservação impõem regras de seleção aos tipos de radiação emitida em qualquer transição nuclear ${ }^{[25]}$. Entretanto, há diversos casos onde a energia do gama pode ser menor que a dos raios-X.

A Intensidade da transição gama é dada por:

$$
\mathrm{T}_{\gamma}=\mathrm{I}_{\gamma}+\mathrm{I}_{\mathrm{EC}}+\mathrm{I}_{\beta^{ \pm}}
$$

Onde

$\mathrm{I}_{\gamma}=$ intensidade de emissão gama

$\mathrm{I}_{\mathrm{EC}}=$ intensidade de emissão de elétrons de conversão

$\mathrm{I}_{\beta^{ \pm}}=$intensidade de emissão de par elétron - pósitron

Normalmente a emissão elétron-pósitron é muito pequena e será desconsiderada. 


\subsubsection{Emissão de Radiação Gama}

Em muitos casos, após ocorrer um dos tipos de desintegração descritos anteriormente, o processo radioativo se completa. Em outros casos, entretanto, o núcleo filho é formado em um de seus estados excitados, contendo ainda uma quantidade de energia armazenada temporariamente. Quando isto ocorre, o núcleo filho pode emitir esta energia sob a forma de fótons denominados "raios gamas", estes raios- $\gamma$ são ondas eletromagnéticas, que são emitidos dos núcleos radioativos com energias bem definidas, correspondentes á diferença entre os níveis de energia de transição que se desexcita. A transição pode ocorrer entre dois níveis excitados ou entre um nível excitado e o nível fundamental. Deste modo, pode haver a emissão de um ou mais raios-gama em cada desintegração. Como qualquer onda eletromagnética, os raios-gama se propagam com a velocidade da luz e sua energia é dada em função da freqüência da onda, por meio da relação ${ }^{[22]}$ :

$$
E=h v=h \frac{c}{\lambda}
$$

Onde:

$\mathrm{E}=$ energia da radiação

$\mathrm{h}=$ constante de Planck

$v=$ freqüência da radiação

$\mathrm{C}=$ velocidade da luz

$\lambda=$ comprimento de onda

\subsubsection{Conversão Interna}

O processo de emissão de elétron de conversão interna compete com a emissão de raios gama, oferecendo uma alternativa ao decaimento gama quando a emissão de fótons é estritamente proibida pela impossibilidade de se originar um fóton sem nenhuma unidade de momento angular em uma dada 
transição ${ }^{[22]}$. Neste caso, o elétron é ejetado do átomo com uma energia $E_{e}$ dada por:

$$
E_{e}=E_{\gamma}-E_{i}
$$

$E_{i}=$ é a energia de ligação do elétron na órbita $i$.

Como este processo compete com a emissão de raios gama, a probabilidade de que ocorra a emissão de elétrons é descrita pelo coeficiente de conversão interna $(\alpha)$, que é definido por $^{[24]}$ :

$$
\alpha=\frac{\text { probabilicade de conversão }}{\text { probabilidade de emissão- } \gamma}=\frac{\lambda_{e}}{\lambda_{\gamma}}=\frac{N_{e}}{N_{\gamma}}
$$

Em que $\lambda_{e}$ e $\lambda_{\gamma}$ são, respectivamente, as probabilidades de emissão de elétron e de raio gama, e $\mathrm{N}_{\mathrm{e}}$ e $\mathrm{N}_{\gamma}$ são os números de elétrons de conversão e fótons, respectivamente, observados por unidade de tempo. Os coeficientes de conversão interna para as outras camadas são definidas como:

$$
\alpha_{\mathrm{K}}=\frac{\mathrm{N}_{\mathrm{K}}}{\mathrm{N}_{\gamma}}, \alpha_{\mathrm{L}}=\frac{\mathrm{N}_{\mathrm{L}}}{\mathrm{N}_{\gamma}}, \alpha_{\mathrm{M}}=\frac{\mathrm{N}_{\mathrm{M}}}{\mathrm{N}_{\gamma}}
$$

Como os elétrons emitidos podem ser de qualquer órbita eletrônica, a soma total do coeficiente de conversão interna $\alpha_{T}$ é a representação da contribuição total das diferentes probabilidades de cada órbita, ou seja:

$$
\alpha_{T}=\alpha_{K}+\alpha_{L}+\alpha_{M}+\cdots=\frac{N_{e}}{N_{\gamma}}
$$

Observa-se que a conversão interna é importante apenas quando a transição é de baixa energia e para elétrons da camada $K(n=1)$ em núcleos pesados ( $Z$ elevado). 


\subsection{Interação da Radiação com a Matéria}

Como resultado das interações da radiação com a matéria produz-se uma transferência de energia da radiação para os átomos e moléculas do meio através do qual a radiação está passando. A transferência da energia de uma partícula ou fóton para os átomos do material absorvedor pode ocorrer principalmente por meio de dois mecanismos: ionização e excitação, em colisões que podem ser elásticas ou inelásticas. Qualquer processo do qual resulta a remoção de um elétron, de um átomo ou molécula, deixando-o com uma carga positiva, denomina-se ionização, enquanto que a adição de energia para o sistema atômico ou molecular ocorre o processo de excitação. Pode ocorrer ainda a interação da partícula carregada com o núcleo, onde ocorre a perda de energia por emissão de radiação (Bremsstrahlung).

\subsubsection{Elétrons e Pósitrons}

A interação de elétrons e pósitrons com a matéria é ocasionada por dois processos: colisão e radiação ${ }^{[23]}$. Para o caso de colisão, tem-se:

$>\quad$ Colisões elásticas com elétrons atômicos: a energia incidente é menor que 100 eV, existindo a conservação de energia e quantidade de movimento a energia transferida é menor que o potencial de ionização dos elétrons.

> Colisões inelásticas com elétrons atômicos: mecanismo dominante na diminuição da energia ( $d E / d X)$, para cada colisão; um ou mais elétrons, sofrem o processo de ionização ou de excitação.

$>\quad$ Colisões elásticas com núcleos atômicos: ocorre a perda de energia apenas por conservação de quantidade de movimento entre as duas partículas e ocorre a deflexão, mas não a ionização e excitação.

$>\quad$ Perda de energia apenas por colisões inelásticas com núcleos atômicos (perdas de energia por Radiação), para partículas leves com energias elevadas ocorrem deflexões, mas em algumas interações, quando ocasiona as deflexões é emitido um quantum de radiação, perda de energia cinética por radiação, ocorrendo o fenômeno Bremsstrahlung. 
As expressões para a perda de energia total podem ser dadas conforme segue $^{[23]}$.

Para Colisão;

$$
\begin{aligned}
-\left(\frac{d E}{d x}\right)_{c}=\frac{2 \pi e^{4} N Z}{m_{0} v^{2}}\left(\begin{array}{rl}
\ln \frac{m_{0} v^{2} E}{2 l^{2}\left(1-\beta^{2}\right)}- & (\ln 2)\left(2 \sqrt{1-\beta^{2}}\right)-1+\beta^{2} \\
+\left(1-\beta^{2}\right)+\frac{1}{8}\left(1-\sqrt{1-\beta^{2}}\right)^{2}
\end{array}\right]
\end{aligned}
$$

Onde: $\beta=v / c$

E para Radiação (Bremsstrahlung ${ }^{[23]}$.

$$
-\left(\frac{d E}{d x}\right)_{r}=\frac{N E Z(Z+1) e^{4}}{137 m_{0}^{2} c^{4}}\left[4 \ln \left(\frac{2 E}{m_{0} c^{2}}\right)-\frac{4}{3}\right]
$$

Portanto a perda total de energia das partículas carregadas leves será dada $\operatorname{por}^{[23]}$ :

$$
\left(\frac{d E}{d X}\right)_{\text {tot }}=\left(\frac{d E}{d X}\right)_{\text {col }}+\left(\frac{d E}{d X}\right)_{r a d}
$$

Conforme indicado pelas relações 1.22 e 1.23 , existe uma relação entre a perda de energia Os dois mecanismos possuem uma energia relativa em função da e a energia do elétron incidente. Em baixas energias (abaixo de 1 $\mathrm{MeV}$ ), a perda de energia por colisão é mais significativa do que por radiação.

A perda de energia por Radiação se dá quando uma partícula carregada passa perto do núcleo e interage com o seu campo coulombiano. Há uma mudança na sua trajetória e ocorre a desaceleração, ao qual denominamos "Bremsstrahlung" e, como conseqüência, radiação é emitida na forma de raios-X.

A perda de energia por radiação é proporcional a $\left(\frac{Z}{m}\right)^{2} E$, onde $m$ é a massa e E a energia dos elétrons incidentes. 
A razão entre a perda de energia por radiação e colisão para elétrons, é dada aproximadamente por $^{[23]}$ :

$$
\frac{\left(\frac{d E}{d x}\right)_{\mathrm{rad}}}{\left(\frac{\mathrm{dE}}{d x}\right)_{\mathrm{col}}}=\frac{E Z}{700}
$$

Onde (E em MeV)

O alcance da radiação beta é muito maior que da radiação alfa de mesma energia, pois o poder de ionização das partículas betas é bem menor do que das alfas. Isto significa que elas deverão atravessar uma espessura maior de material para perder toda a sua energia por ionização.

A trajetória dos elétrons na matéria, após as colisões com os elétrons atômicos, sofrem grandes deflexões. Por esta razão observa-se que elétrons de uma mesma energia não possuem o mesmo alcance em um dado meio absorvedor. Como o poder de penetração das partículas betas é bem maior, a espessura de material sólido para deter partículas betas com energia de alguns $\mathrm{MeV}^{[24]}$ é da ordem de vários $\mathrm{mm}$.

Em todo o processo de ionização são produzidos dois íons, um negativo e outro positivo. Esses dois íons recebem o nome de par de íons, e a ionização está associada à produção de pares de íons. O número de pares de íons produzidos por unidade de comprimento ao longo do percurso de uma partícula carregada chama-se ionização específica. Para partículas betas, o valor deste parâmetro é da ordem de 50 a 500 pares de íons por centímetro no ar.

\subsubsection{Fótons}

Os mecanismos de interação dos fótons com a matéria são independentes de sua origem, sendo função apenas de sua energia.

Nas partículas carregadas, vimos que sua energia era perdida em conseqüência de um grande número de colisões, a maioria dos quais com elétrons orbitais. Este processo de interação múltipla não acontece na interação 
da radiação gama, sendo que os fótons são absorvidos ou desviados de sua trajetória original por meio de uma única interação. Como conseqüência, um feixe de fótons bem colimado apresenta uma atenuação exponencial na matéria.

Existem doze processos diferentes para cada raio gama ser absorvido ou espalhado, portanto doze maneiras de combinar a coluna $1 \mathrm{com}$ a $2^{[22]}$ conforme a tabela 1.1.

Tabela 1.1 - Processos de interação de fótons com a matéria.

\begin{tabular}{ll}
\hline \multicolumn{1}{c}{ Tipos de Interação } & \multicolumn{1}{c}{ Efeito da interação } \\
\hline 1 - Interação com elétrons atômicos & (a) absorção completa \\
2 - Interação com os núcleons & (b) espalhamento elástico (coerente) \\
3 - Interação com o campo elétrico ao & (c) espalhamento inelástico (incoerente) \\
redor do núcleo ou do elétron & \\
$\begin{array}{l}\text { 4.Interação com o campo nuclear ao } \\
\text { redor dos núcleos }\end{array}$ & \\
\hline
\end{tabular}

\subsubsection{Coeficiente de Atenuação Linear}

Um feixe de raios- $X$ sofre uma redução de sua intensidade ao se propagar através da matéria. Esta redução fracional constante é chamada de coeficiente de atenuação linear. Este coeficiente é representado pela letra $\mu$ (unidade $\mathrm{cm}^{-1}$ ). Fisicamente, $\mu$ representa a probabilidade de um fóton ser removido do feixe por $\mathrm{cm}$ de material.

Supondo que uma espessura $\Delta \mathbf{x}$ de material absorvedor reduza a intensidade de um feixe de uma quantidade $\Delta \mathbf{I}$, esta quantidade será proporcional à intensidade $\mathbf{I}$, á espessura $\Delta \mathbf{x}$, e ao coeficiente de atenuação linear $\mu$ que depende do número atômico do material absorvedor $(Z)$ e da energia do feixe $\left(\mathbf{E}_{\mathbf{x}}\right)$. Portanto a equação será ${ }^{[22]}$ :

$$
\Delta \mathrm{I}=-\mathrm{I} \Delta \mathrm{x} \mu
$$

Onde:

$\mu=\mu\left(Z, E_{x}\right)$ 
O sinal negativo representa o decréscimo da intensidade do feixe com o aumento da espessura. Utilizando as equações das leis de desintegração, obtém-se:

$$
I=I_{0} e^{-\mu x}
$$

Onde

$\mathrm{I}_{0}=$ intensidade do feixe incidente.

\subsubsection{Coeficiente de atenuação de massa}

Este coeficiente independe da densidade do absorvedor, e representa a redução fracional da intensidade do feixe de radiação produzida por um absorvedor de densidade unitária. É determinado pelo quociente entre o coeficiente de atenuação linear e a densidade do material $(\mu / \rho)$.

O coeficiente de atenuação é composto principalmente por três processos de interação que os fótons sofrem com a matéria, a saber:

$>\quad$ Efeito fotoelétrico

$>\quad$ Efeito Compton

$>\quad$ Produção de pares

Eles podem ocorrer simultaneamente, para diferentes fótons de um mesmo feixe. Cada um destes fenômenos atenua a intensidade do feixe de fótons incidente, ocorrendo absorção de toda ou parte da energia de cada fóton. Quando é apenas parte da energia do fóton incidente que é absorvida, a outra parte é considerada energia espalhada. Para o efeito fotoelétrico e para a produção de pares não há espalhamento. 


\subsection{Efeito Fotoelétrico}

O efeito fotoelétrico, conforme a figura 1.3, ocorre para baixas energias, aproximadamente de $0,1 \mathrm{MeV}$, e a interação é predominante em materiais de alto $Z$.

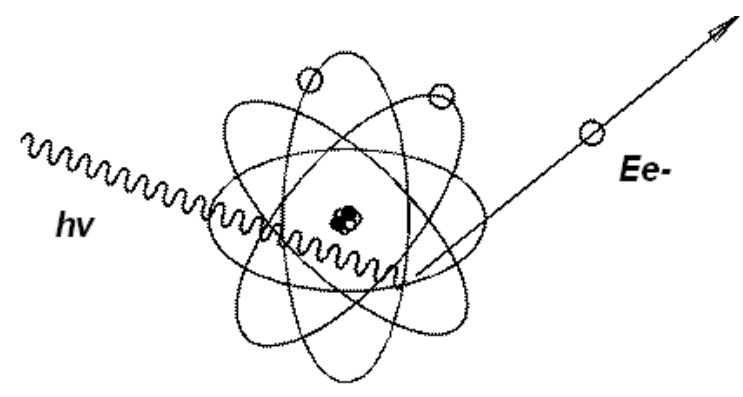

Figura 1.3 - Efeito Fotoelétrico

Neste processo o fóton interage com uma energia $h v$ que é absorvida por um elétron das camadas atômicas (geralmente da camada $\mathrm{K}$ ou $\mathrm{L}$ ), resultando na ejeção do elétron. A energia cinética deste elétron é dada por ${ }^{[22]}$ :

$$
\mathrm{hv}-\mathrm{W}=\frac{1}{2} \mathrm{~m} \mathrm{v}^{2}
$$

Onde

$\mathrm{h} v$ = energia do fóton incidente;

W = energia de ligação do elétron e

$\frac{1}{2} m v^{2}=$ energia cinética transferida ao elétron.

Haverá ionização e o átomo ficará num estado excitado. Esta excitação é eliminada pelo preenchimento da vaga criada pelo elétron de outra camada e assim sucessivamente.

O coeficiente total de atenuação para 0 efeito fotoelétrico é representado pela letra $\tau$. E o coeficiente de atenuação de massa $\tau / \rho$ é diretamente proporcional a $Z^{3}$ ou $Z^{4}$ e proporcional a $1 /(h v)^{3}$. Podemos observar 
que, os elétrons mais ligados têm a maior probabilidade de absorção por efeito fotoelétrico.

\subsection{Efeito Compton}

Um fóton ao interagir com um átomo pode transferir parte de sua energia a um dos elétrons orbitais, através do espalhamento incoerente inelástico, conhecido como efeito Compton, conforme a figura 1.4. Este processo ocorre preferencialmente com os elétrons localizados nas camadas mais externas, embora possa também ocorrer com os demais elétrons do átomo ${ }^{[24]}$.

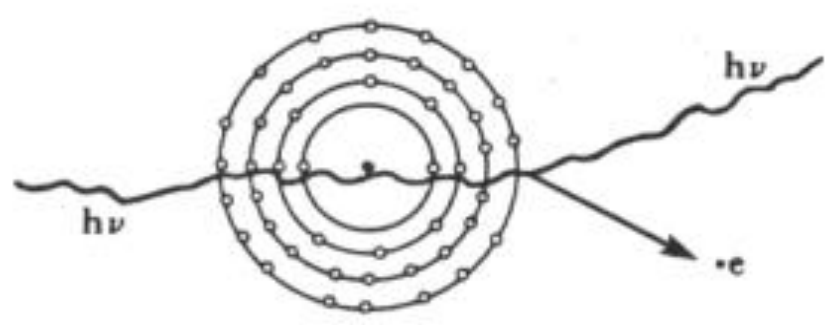

Figura 1.4 - Efeito Compton

Compton deduziu a equação da variação de comprimento de onda do fóton desviado, que é escrita da seguinte maneira:

$$
\lambda^{\prime}-\lambda=\frac{\mathrm{h} v}{\mathrm{~m}_{0} \mathrm{c}^{2}}
$$

Onde a energia dos elétrons depende do ângulo com o qual ele é espalhado. Para um ângulo $\phi=0^{0}$, teremos o elétron com energia nula. Para $\phi=$ $180^{\circ}$, teremos o elétron Compton com energia máxima:

$$
E_{\max }=h v \frac{2 \alpha}{(1+2 \alpha)}
$$

Onde: $\alpha=h v / m_{0} c^{2}$. 
A colisão Compton ocorre entre fótons e elétrons orbitais. A probabilidade desta ocorrência vai depender da densidade eletrônica do meio onde se propagam os fótons e da energia do fóton. Como a densidade eletrônica do meio (número de elétrons/grama) é aproximadamente constante para os diferentes materiais, segue que a probabilidade de ocorrer o efeito Compton praticamente independe do número atômico do material.

\subsection{Produção de Pares}

Quando um fóton com energia superior a 1,022 MeV interage nas vizinhanças do núcleo de um átomo, pode desaparecer e em seu lugar surgir um par de elétrons, sendo um negativo e outro positivo, cada um com massa equivalente a uma energia de $0,511 \mathrm{MeV}$. A outra parte é dividida como energia cinética destas partículas ${ }^{[22]}$, conforme a figura 1.5 .

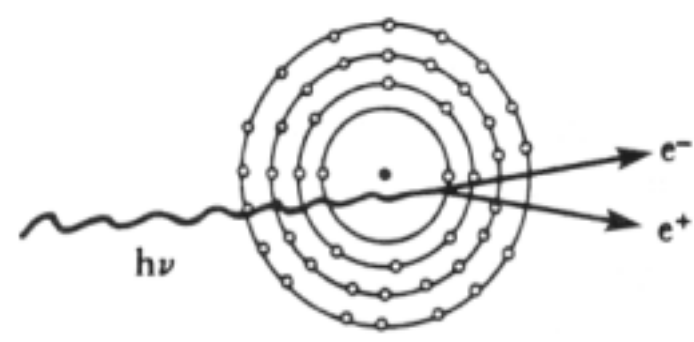

Figura 1.5 - Produção de Pares

Para que o processo seja possível, a energia do raio gama deve ser maior do que o equivalente em energia das massas do elétron e pósitron (maior que 1,022 MeV). A energia cinética total do par é dada por:

$$
E_{c}=h v-2 m_{0} c^{2}
$$

A presença do campo coulombiano do núcleo na produção de pares tem como principal função a de permitir a conservação da quantidade de movimento. Algumas vezes a produção de pares pode ocorrer no campo de um elétron em vez de no campo nuclear. A energia mínima necessária para que isso ocorra é: 


$$
4 \mathrm{~m}_{0} \mathrm{c}^{2}=2,044 \mathrm{MeV}
$$

Se essa condição não for satisfeita, não haverá conservação do momento e o processo é impossível. A probabilidade de ocorrência do efeito de produção de pares aumenta com $Z^{2}$.

Tanto o pósitron como o elétron perdem suas energias, por ionização e excitação. Quando atingem o repouso, o elétron permanece na matéria, onde existem outros elétrons. Entretanto os pósitrons não existem na matéria. Assim, sofrem aniquilação, ou seja, juntam-se com outros elétrons e em seguida ambos desaparecem, produzindo dois raios gama de 0,511 MeV. Por outro lado, pode ocorrer aniquilação, quando o pósitron ainda não está em repouso, a probabilidade desse efeito é tanto maior quanto maior for a, energia do pósitron. Nessas condições, os raios gamas emitidos terão energias mais altas do que 511 keV. Esse é o princípio que permite utilizar o processo de "Bremsstahlung" para produzir fótons monoenergéticos: estes fótons espectro contínuo sofrem interação por produção de pares. Os pósitrons são acelerados até uma energia conhecida e são arremessados a um alvo para sofrerem aniquilação, havendo com isso, a emissão da radiação gama monoenergética.

A atenuação total de um feixe de raios-X ou gama é dada pela soma das atenuações causadas por cada um dos processos:

$$
\mu=\tau+\sigma+\pi
$$

Onde

$\mu=$ coeficiente de atenuação total

$\tau=$ coeficiente de atenuação para fotoelétrons

$\sigma=$ coeficiente de atenuação para elétrons Compton

$\pi=$ coeficiente de atenuação para produção de pares 


\section{METODOLOGIA}

O presente trabalho foi realizado em diversas etapas. Inicialmente foi elaborado o aperfeiçoamento da modelagem para a geometria do detector $4 \pi$ proporcional, incluindo detalhes do suporte da fonte radioativa, possibilitando um cálculo por Monte Carlo mais realista.

Em seguida, procedeu-se ao desenvolvimento de programas por computador, utilizando a linguagem FORTRAN, para a geração de arquivos de entrada para o código MCNPX, para todas as radiações envolvidas, a saber: fótons, nos detectores $4 \pi \mathrm{e} \mathrm{Nal}(\mathrm{TI})$; elétrons no detector $4 \pi$ e pósitrons nos detectores $4 \pi \mathrm{e} \mathrm{Nal}(\mathrm{Tl})$. Estes cálculos foram ser feitos para uma ampla faixa de energia, desde keV até $\mathrm{MeV}$.

A seguir, fez-se o desenvolvimento de programas por computador, utilizando a linguagem FORTRAN, para a leitura dos resultados do código MCNPX, gerando as tabelas de resposta necessárias para a operação do código ESQPOS, para fótons, elétrons e pósitrons. Em seguida, foi aplicada a metodologia para um radionuclídeo emissor $\beta^{-}-\gamma$ com esquema de desintegração simples $\left({ }^{60} \mathrm{Co}\right)$, com o objetivo de validar os programas desenvolvidos. Esta parte incluiu uma nova determinação da eficiência do detector $4 \pi$ para fótons.

$\mathrm{Na}$ etapa seguinte, procedeu-se a uma determinação experimental da curva de extrapolação da eficiência, comparação com a previsão teórica e aplicação da modelagem por Monte Carlo para o radionuclídeo ${ }^{22} \mathrm{Na}$. Este radionuclídeo foi utilizado pelo $L M N$ em uma comparação internacional efetuada com o PTB (Physikalisch Technische Bundesanstalt) da Alemanha, em 1972 ${ }^{[26]}$. Nesta ocasião, os dois sistemas de coincidência I e II foram utilizados, em geometrias idênticas às simuladas atualmente por Monte Carlo. No sistema I foi utilizado o Método do Pico Nuclear e no sistema II foi utilizado o Método do Pico Soma, que serão descritos na seção 2.3.3.

O presente trabalho teve como objetivos: efetuar uma nova análise destas medidas, aplicando o método de Monte Carlo, o que possibilitou um novo 
resultado da atividade da solução radioativa e também a obtenção de um parâmetro nuclear, que não foi determinado anteriormente pelo LMN: a intensidade de emissão de pósitrons por desintegração. Este parâmetro foi comparado com determinação recente efetuada pelo $\mathrm{PTB}^{[29]}$. Por fim, foi aplicada a modelagem por Monte Carlo do radionuclídeo ${ }^{18} \mathrm{~F}$, que é um emissor $\beta^{+}$ acompanhado de captura eletrônica. Esta parte inclui a determinação experimental da curva de extrapolação da eficiência em comparação com a previsão teórica, os resultados deste radionuclídeo foram realizados, pelo LMN em uma comparação internacional organizado pelo NPL (National Physical Laboratory), em Tenddington, Middlesex, UK em 2001 ${ }^{[30]}$ A seguir são descritos os procedimentos seguidos para as determinações teóricas e experimentais, referentes ao presente trabalho.

\subsection{Medida Absoluta da Atividade pelo Método de Coincidência}

Trata-se de medida absoluta ou método primário, métodos que se baseiam somente nas taxas de contagens medidas da fonte em questão. Tais medidas necessitam apenas do tempo como uma referência e desta forma, a taxa de desintegração pode ser determinada sem o conhecimento prévio dos parâmetros do detector ou do valor de uma grandeza auxiliar.

O método da coincidência é um método fundamental que é aplicado na padronização de fontes radioativas que desintegram pela emissão de radiações distintas como as desintegrações entre, $\alpha-\gamma, \beta-\gamma$ e CE- $\gamma$, amplamente utilizado no Laboratório de Metrologia Nuclear - IPEN ${ }^{[10,15]}$, que possibilita a obtenção de resultados de taxa de desintegração com grande exatidão por meio das taxas de contagens.

\subsubsection{Formalismo geral}

Para uma fonte radioativa puntiforme, em uma situação ideal, esquema de desintegração simples e com emissão de $\beta^{-}$seguida de emissão de radiação $\gamma$, a atividade $N_{0}$ e as eficiências $\varepsilon_{\beta}$ e $\varepsilon_{\gamma}$ podem ser determinadas por meio das taxas de contagens beta $\left(N_{\beta}\right)$, gama $\left(N_{\gamma}\right)$ e de coincidência $\left(N_{c}\right)$ : 


$$
\begin{aligned}
& \mathrm{N}_{\beta}=\varepsilon_{\beta} \mathrm{N}_{0} \\
& \mathrm{~N}_{\gamma}=\varepsilon_{\gamma} \mathrm{N}_{0} \\
& \mathrm{~N}_{\mathrm{C}}=\varepsilon_{\beta} \varepsilon_{\gamma} \mathrm{N}_{0}
\end{aligned}
$$

Multiplicando as equações 2.1 e 2.2 e dividindo-se pela equação 2.3, tem-se:

$$
\begin{gathered}
\frac{\mathrm{N}_{\beta} \mathrm{N}_{\gamma}}{\mathrm{N}_{\mathrm{C}}}=\frac{\varepsilon_{\beta} \mathrm{N}_{0} \varepsilon_{\gamma} \mathrm{N}_{0}}{\varepsilon_{\beta} \varepsilon_{\gamma} \mathrm{N}_{0}} \\
\frac{\mathrm{N}_{\beta} \mathrm{N}_{\gamma}}{\mathrm{N}_{\mathrm{C}}}=\mathrm{N}_{0}
\end{gathered}
$$

Dividindo-se 2.3 por 2.2, obtém-se a eficiência de beta $\left(\varepsilon_{\beta}\right)$

$$
\begin{aligned}
& \frac{\mathrm{N}_{\mathrm{C}}}{\mathrm{N}_{\gamma}}=\frac{\varepsilon_{\beta} \varepsilon_{\gamma} \mathrm{N}_{0}}{\varepsilon_{\gamma} \mathrm{N}_{0}} \\
& \frac{\mathrm{N}_{\mathrm{C}}}{\mathrm{N}_{\gamma}}=\varepsilon_{\beta}
\end{aligned}
$$

Incluindo-se as contribuições de fótons $\left(\varepsilon_{\beta \gamma}\right)$ e de elétrons de conversão $\left(\varepsilon_{\mathrm{EC}}\right)$ no detector beta, tem-se:

$$
\mathrm{N}_{\beta}=\varepsilon_{\beta} \mathrm{N}_{0}+\left(1-\varepsilon_{\beta}\right) \mathrm{N}_{0}\left[\varepsilon_{\beta \gamma}+\alpha \varepsilon_{\mathrm{EC}}\right] \frac{1}{(1+\alpha)}
$$




$$
\mathrm{N}_{\beta}=\mathrm{N}_{0}\left\{\varepsilon_{\beta}+\left(1-\varepsilon_{\beta}\right)\left[\frac{\varepsilon_{\beta \gamma}+\alpha \varepsilon_{\mathrm{EC}}}{(1+\alpha)}\right]\right\}
$$

Onde $\alpha$ é o coeficiente de conversão interna para a transição gama:

$$
\alpha=\frac{\mathrm{N}_{\mathrm{EC}}}{\mathrm{N}_{\gamma}} \quad \mathrm{N}_{\mathrm{T}}=\mathrm{N}_{\gamma}+\mathrm{N}_{\mathrm{EC}} \quad \mathrm{N}_{\mathrm{EC}}=\alpha \mathrm{N}_{\gamma}
$$

$\mathrm{N}_{\mathrm{T}}, \mathrm{N} \gamma$ e $\mathrm{N}_{\mathrm{EC}}$ são, respectivamente, os números de transições gama, de gamas emitidos e de elétrons de conversão emitidos na transição.

A equação para as contagens gama é dada por:

$$
\mathrm{N}_{\gamma}=\frac{\varepsilon_{\gamma} \mathrm{N}_{0}}{(1+\alpha)}
$$

As contagens de coincidência são dadas por:

$$
\mathrm{N}_{\mathrm{C}}=\frac{\varepsilon_{\beta} \varepsilon_{\mathrm{Y}} \mathrm{N}_{0}}{(1+\alpha)}
$$

Onde:

$\varepsilon_{\beta}=$ eficiência beta,

$\varepsilon_{\beta \gamma}=$ eficiência do detector beta para as radiações gama,

$\varepsilon_{\mathrm{EC}}=$ eficiência do detector beta para elétrons de conversão,

$\varepsilon_{\gamma}=$ eficiência gama

Multiplicando 2.6 por 2.7 e dividindo-se o resultado por 2.8, obtém-se: 


$$
\frac{\mathrm{N}_{\beta} \mathrm{N}_{\gamma}}{\mathrm{N}_{\mathrm{C}}}=\frac{\mathrm{N}_{0} \varepsilon_{\beta}\left\{1+\frac{\left(1-\varepsilon_{\beta}\right)}{\varepsilon_{\beta}}\left[\frac{\varepsilon_{\beta \gamma}+\alpha \varepsilon_{\mathrm{EC}}}{(1+\alpha)}\right]\right\} \frac{\varepsilon_{\gamma} \mathrm{N}_{0}}{(1+\alpha)}}{\frac{\varepsilon_{\beta} \varepsilon_{\gamma} \mathrm{N}_{0}}{(1+\alpha)}}
$$

Ou

$$
\frac{\mathrm{N}_{\beta} \mathrm{N}_{\gamma}}{\mathrm{N}_{\mathrm{C}}}=\mathrm{N}_{0}\left\{1+\frac{\left(1-\varepsilon_{\beta}\right)}{\varepsilon_{\beta}}\left[\frac{\varepsilon_{\beta \gamma}+\alpha \varepsilon_{\mathrm{EC}}}{(1+\alpha)}\right]\right\}
$$

Para um esquema de $n$ grupos de desintegração beta e considerando $a_{r}$ a abundância relativa do r-ésimo do grupo com eficiência beta $\left(\varepsilon_{\beta r}\right)$, provavelmente um dos grupos pode produzir uma ou mais radiações gama $\left(\gamma_{\mathrm{rs}}\right)$, a eficiência no detector gama, pode ser representada pela equação ${ }^{[10]}$ :

$$
\varepsilon_{\gamma_{r s}}^{\prime}=\frac{\varepsilon_{\gamma_{r s}}}{\left(1+\alpha_{r s}\right)}
$$

Onde

$\alpha_{\text {rs }}=$ coeficiente de conversão interna da s-ésima transição gama, correspondente a r-ésimo ramo beta.

As taxas de contagens para as vias, beta, gama e de coincidência, serão:

$$
\begin{gathered}
\mathrm{N}_{\beta}=\mathrm{N}_{0} \sum_{\mathrm{r}=1}^{\mathrm{n}} \mathrm{a}_{\mathrm{r}}\left[\varepsilon_{\mathrm{r}}+\left(\left(1-\varepsilon_{\beta \mathrm{r}}\right)\right] \sum_{\mathrm{s}=1}^{\mathrm{pr}} \mathrm{b}_{\mathrm{rs}}\left(\frac{\alpha_{\mathrm{s}} \varepsilon_{\mathrm{ECS}}+\varepsilon_{\beta \gamma \mathrm{s}}}{\left(1+\alpha_{\mathrm{s}}\right)_{\mathrm{r}}}\right)\right. \\
\mathrm{N}_{\gamma}=\mathrm{N}_{0} \sum_{\mathrm{r}=1}^{\mathrm{n}} \mathrm{a}_{\mathrm{r}} \sum_{\mathrm{s}=1}^{\mathrm{p}_{\mathrm{r}}} \mathrm{b}_{\mathrm{rs}} \varepsilon_{\gamma_{\mathrm{rs}}}^{\prime}
\end{gathered}
$$




$$
\mathrm{N}_{\mathrm{c}}=\mathrm{N}_{0} \sum_{\mathrm{r}=1}^{\mathrm{n}} \mathrm{a}_{\mathrm{r}} \varepsilon_{\beta r}\left[\sum_{\mathrm{s}=1}^{\mathrm{p}_{\mathrm{r}}} \mathrm{b}_{\mathrm{rs}} \varepsilon_{\gamma_{\mathrm{rs}}}^{\prime}+\left(1-\varepsilon_{\beta r}\right) \sum_{\mathrm{s}=1}^{\mathrm{p}_{\mathrm{r}}} \mathrm{b}_{\mathrm{rs}} \varepsilon_{\mathrm{c}_{\mathrm{rs}}}\right]
$$

Onde:

$\mathrm{a}_{\mathrm{r}}=$ abundância do r-ésimo ramo beta;

$\varepsilon_{\mathrm{r}}=$ eficiência do r-ésimo ramo beta;

$\varepsilon_{\beta r}$ e eficiência beta associada ao r-ésimo ramo beta;

$b_{\mathrm{rs}}=$ intensidade relativa da s-ésima transição gama relacionada com o $r$-ésimo ramo beta;

$\mathrm{p}_{\mathrm{r}}=\mathrm{n}^{\circ}$ de radiações gama associadas a r-ésimo transição beta;

$\varepsilon_{\mathrm{ECs}}=$ eficiência de detecção para elétrons de conversão associado, a s-ésima transição gama;

$\varepsilon_{\beta \gamma s}=$ eficiência gama para detector beta associado, a s-ésima transição gama;

$\varepsilon_{\mathrm{Crs}}=$ eficiência de detecção da coincidência gama-gama.

As equações gerais tornam-se:

$$
\begin{gathered}
\frac{N_{\beta} N_{\gamma}}{N_{c}}=\frac{N_{0} \sum a_{r}\left[\varepsilon_{\beta r}+\left(1-\varepsilon_{\beta r}\right)\left(\alpha \varepsilon_{E C}+\varepsilon_{\beta \gamma}\right)_{r} /(1+\alpha)_{r}\right] N_{0} \sum a_{r} \varepsilon_{\gamma_{r}^{\prime}}^{\prime}}{N_{0} \sum a_{r}\left[\varepsilon_{\beta r} \varepsilon_{\gamma_{r}^{\prime}}^{\prime}+\left(1-\varepsilon_{\beta r}\right) \varepsilon_{\mathrm{C}_{r}}\right]} \\
N_{0}=\frac{N_{\beta} N_{\gamma}}{N_{C}} \times \frac{\sum a_{r}\left[\varepsilon_{\beta \beta} \varepsilon_{\gamma_{r}}^{\prime}+\left(1-\varepsilon_{\beta r}\right) \varepsilon_{\mathrm{c}_{r}}\right]}{\sum a_{r}\left[\varepsilon_{\beta r}+\left(1-\varepsilon_{\beta r}\right)\left(\alpha \varepsilon_{\mathrm{EC}}+\varepsilon_{\beta \gamma}\right)_{r} /(1+\alpha)_{r}\right] \sum a_{r} \varepsilon_{\gamma_{r}}^{\prime}} \\
\frac{N_{c}}{N_{\gamma}}=\frac{\sum a_{r}\left[\varepsilon_{\beta r} \varepsilon_{\gamma_{r}}^{\prime}+\left(1-\varepsilon_{\beta r}\right) \varepsilon_{\mathrm{c}_{r}}\right]}{\sum a_{r} \varepsilon_{\gamma_{r}}^{\prime}}
\end{gathered}
$$

\subsubsection{Técnica da Extrapolação Linear da Eficiência}

A técnica de extrapolação linear é utilizada para a padronização de radionuclídeos que apresentam um esquema de desintegração complexo, envolvendo algumas vezes mais de dois tipos de radiações. 
Para os radionuclídeos com um esquema de desintegração mais complexo, em princípio, seria necessário o conhecimento dos parâmetros do esquema de desintegração e as probabilidades de detecção, para a obtenção da atividade, $\mathrm{N}_{0}$, a partir da equação (2.9).

Para solucionar este problema, e manter a principal característica do método que consiste na sua independência do conhecimento da eficiência de detecção e dos parâmetros do esquema de desintegração, aplica-se a Técnica de Extrapolação Linear da Eficiência ${ }^{[1,6]}$. Segundo esta técnica, a determinação de $N_{0}$ só será possível se houver uma relação funcional entre $N_{\beta}$ e o parâmetro de eficiência $\frac{N_{c}}{N_{\gamma}}$, tal que $N_{\beta} \rightarrow N_{0}$, quando $\frac{N_{c}}{N_{\gamma}} \rightarrow 1$. Tal condição pode ser obtida quando houver uma relação biunívoca entre a eficiência de um dado ramo beta, $\varepsilon_{b r}$, por meio de uma função $f_{r}\left(\varepsilon_{b s}\right)$ que relacione as eficiências dos diversos ramos beta do decaimento do radionuclíde ${ }^{[10]}$. A eficiência dos diferentes ramos beta $\varepsilon_{\beta r}$ passa a ser interpretada como uma função de uma eficiência unitária $\varepsilon_{\beta s}$.

$$
\varepsilon_{\beta r}=f_{r}\left(\varepsilon_{\beta s}\right)
$$

Em que, $f_{r} \rightarrow 1$ quando $\varepsilon_{\beta s} \rightarrow 1$.

$\mathrm{Na}$ prática o parâmetro $\varepsilon_{\beta s}$ é extrapolado para 1 a partir de uma discriminação gradual em energia das partículas betas emitidas pelo radionuclídeo. Com isso pode-se escrever a equação de coincidência generalizada $^{[1,6]}$, dada por:

$$
\mathrm{N}_{\beta}=\mathrm{N}_{0} \mathrm{~F}\left(\frac{\mathrm{N}_{\mathrm{C}}}{\mathrm{N}_{\gamma}}\right)
$$

Segundo Campion ${ }^{[1]}$ a equação de coincidência generalizada pode ser escrita de forma mais conveniente para a sua solução gráfica, relacionando $\frac{\mathrm{N}_{\beta} \mathrm{N}_{\gamma}}{\mathrm{N}_{\mathrm{C}}}$ 
e o parâmetro de ineficiência $\left(\frac{1-N_{C} / N_{\gamma}}{N_{C} / N_{\gamma}}\right)$ por meio de uma relação funcional $G$, cuja variação é mais lenta que a da equação 2.18 .

Deste modo, quando o parâmetro de ineficiência $\left(\frac{1-N_{C} / N_{\gamma}}{N_{C} / N_{\gamma}}\right)$ tender a zero, a função G tenderá a 1 e $\frac{\mathrm{N}_{\beta} \mathrm{N}_{\gamma}}{\mathrm{N}_{\mathrm{C}}}$ tenderá a $\mathrm{N}_{0}$.

Logo a equação de coincidência é dada por:

$$
\frac{\mathrm{N}_{\beta} \mathrm{N}_{\gamma}}{\mathrm{N}_{\mathrm{C}}}=\mathrm{N}_{0} \mathrm{G}\left(\frac{1-\mathrm{N}_{\mathrm{C}} / \mathrm{N}_{\gamma}}{\mathrm{N}_{\mathrm{C}} / \mathrm{N}_{\gamma}}\right)
$$

Usando-se a razão $\frac{\mathrm{N}_{\beta} \mathrm{N}_{\gamma}}{\mathrm{N}_{\mathrm{C}}}$ como a variável dependente e o parâmetro de ineficiência $\left(\frac{1-N_{C} / N_{\gamma}}{N_{C} / N_{\gamma}}\right)$ como a variável independente, pode-se obter a taxa de desintegração $N_{0}$ a partir do gráfico $\frac{N_{\beta} N_{\gamma}}{N_{C}}$ versus $\left(\frac{1-N_{C} / N_{\gamma}}{N_{C} / N_{\gamma}}\right)$ de modo que $\frac{\mathrm{N}_{\beta} \mathrm{N}_{\gamma}}{\mathrm{N}_{\mathrm{C}}}$ é dependente da função $\mathrm{G}$.

O valor extrapolado obtido por ajuste polinomial dos dados experimentais fornece a taxa de desintegração $\mathrm{N}_{0}$.

A variação do parâmetro de eficiência pode ser obtida pelo uso de absorvedores externos, por auto-absorção na fonte, por discriminação eletrônica, ou qualquer outro método que possibilite a variação da eficiência beta, desde que as probabilidades de detecção $\varepsilon_{\beta \gamma}$, $\varepsilon_{\mathrm{EC}}$ e $\varepsilon_{\gamma}$ sejam constantes ou nulas no intervalo de variação da eficiência beta ${ }^{[10]}$.

Pela técnica da extrapolação linear da eficiência é ajustada uma reta onde o coeficiente angular corresponde ao produto da atividade da fonte pela constante de correção devido ao esquema de desintegração e ao sistema de detecção utilizado, e o coeficiente linear à taxa de desintegração procurada. 
A medida de coincidência é feita selecionando-se o pico de absorção total de uma energia gama que esteja em coincidência com a radiação beta. $A$ escolha recai nos gamas mais intensos e que apresentem menor coeficiente de conversão interna, o que resultará numa reta com menor coeficiente angular e um coeficiente linear com menor incerteza

\subsection{Arranjo experimental do sistema de coincidência $4 \pi(P C) \beta-\gamma$}

Os sistemas de coincidência do LMN (Laboratório de Metrologia Nuclear) que foram utilizados, são detectores proporcionais em geometria $4 \pi$, denominados: sistema I (que possui um detector de $\mathrm{Nal}(\mathrm{TI})$ acoplado) e sistema II (possui dois detectores de $\mathrm{Nal}(\mathrm{TI})$ acoplados), conforme mostra a figura 2.1.

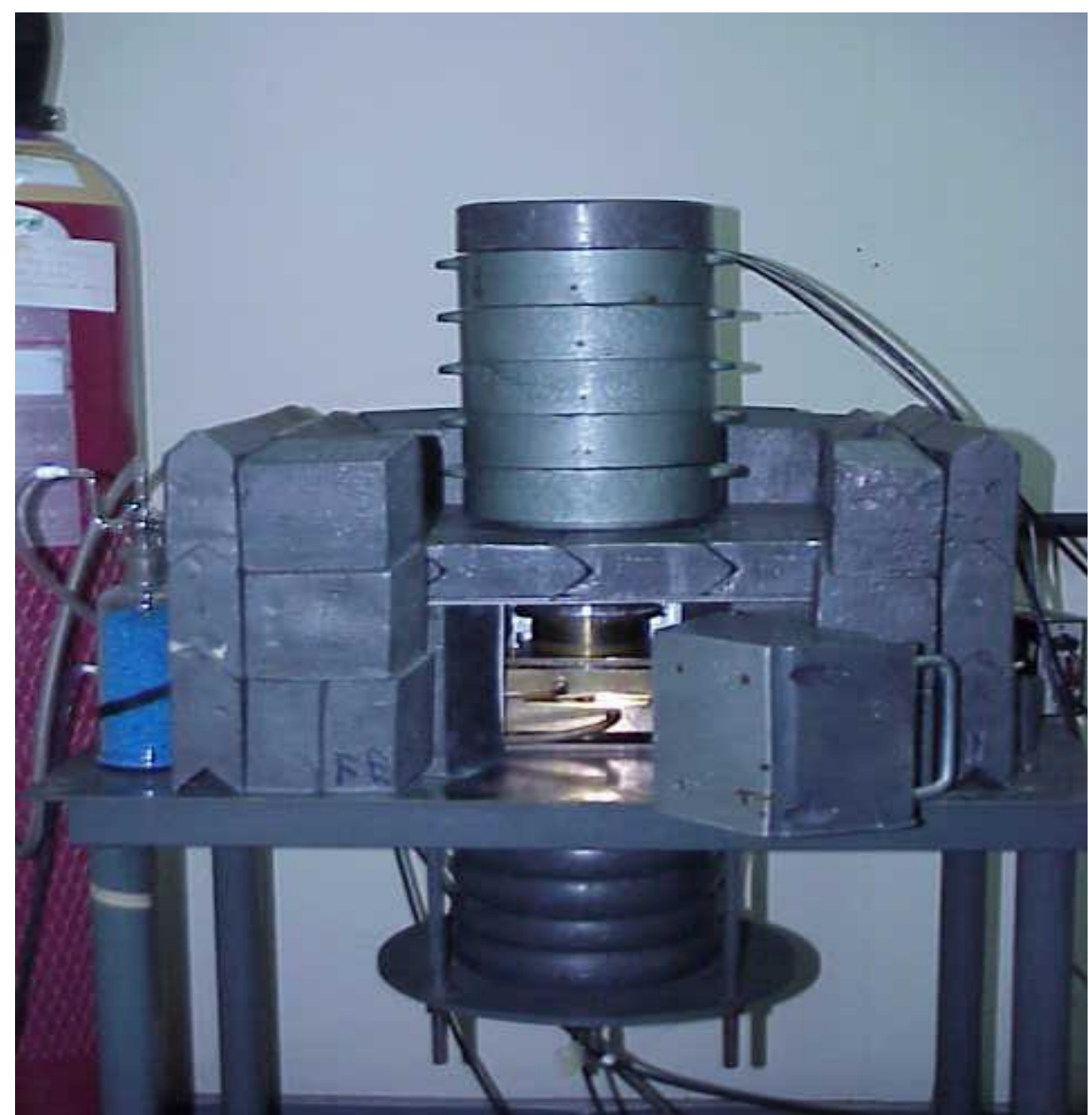

Figura 2.1 - sistema de coincidência $4 \pi(P C) \beta-\gamma$, do LMN do IPEN ${ }^{[18]}$ 


\subsubsection{Detector Proporcional com Geometria $4 \pi$}

Os detectores proporcionais são preenchidos com uma mistura composta de $10 \%$ de metano e $90 \%$ de argônio (mistura P-10). A pressão para o sistema I pode variar entre 0,1 e 1,0 MPa e, para o sistema II, o detector funciona a gás fluente, com pressão próxima de $0,1 \mathrm{MPa}{ }^{[10-14]}$.

Estes detectores são utilizados para a detecção da radiação $\beta$ (negativa e positiva), elétrons de conversão, raios X e elétrons Auger.

Este tipo de contador apresenta uma eficiência de detecção de partículas beta próxima de $100 \%$, e eficiência para detecção de radiação gama menor que $0,5 \%$, podendo detectar partículas alfa em presença de radiação beta, pois as partículas alfas são muito mais ionizantes. Os elétrons livres formados são acelerados pelo campo elétrico no interior do detector, ganhando energia no percurso e ionizando outras moléculas de gás. Este detector é apresentado na figura 2.2 .

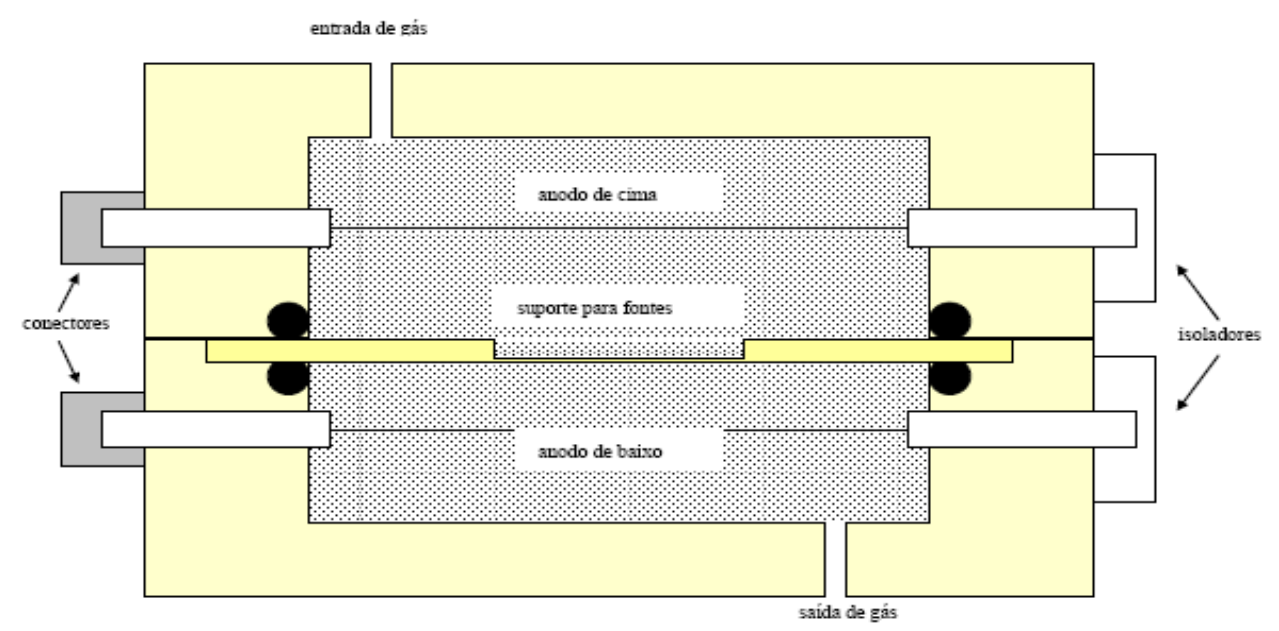

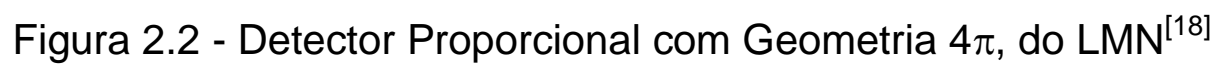

\subsubsection{Cristal Cintilador $\mathrm{Nal}(\mathrm{TI})$}

Este detector é utilizado para a detecção da radiação gama possui janelas de alumínio, com espessura de 0,3 $\mathrm{mm}$ com dois cristais cintiladores de lodeto de Sódio (Nal) ativado com Tálio (TI), com diâmetro de 76 mm e 76 mm de 
altura. Os cristais cintiladores estão, acoplados nas faces, superior e inferior do contador proporcional. O sistema está inserido dentro de uma torre cilíndrica de chumbo, que protege o cristal de iodeto de sódio das radiações de fundo.

O processo de detecção nos cristais inorgânicos, como é o caso do $\mathrm{Nal}(\mathrm{TI})$, ocorre pela interação dos fótons incidentes com as moléculas do cristal levando-as a uma configuração instável de energia o que acarreta em emissão de fótons no espectro do visível para voltar ao seu estado fundamental. Tais fótons são coletados pela fotomultiplicadora acoplada opticamente ao cristal, convertendo os sinais luminosos em pulsos elétricos.

\subsubsection{Sistema Eletrônico Associado}

O sistema Eletrônico básico é apresentado na figura 2.3. Este sistema é destinado para detectar as radiações, $\beta$ e $\gamma$, portanto possuem duas vias distintas, cada uma delas destinadas a um tipo de detector.

Para as partículas $\beta$, utiliza-se o detector $4 \pi$. A medida nesta via é feita selecionando-se a região do espectro beta acima no ruído eletrônico. A discriminação é efetuada em um módulo SCA (Analisador Monocanal com Atraso). Após esta discriminação, os pulsos são enviados a um módulo de porta e atraso e, em seguida, enviados para um módulo TAC (conversor de tempo em altura de pulso para registrar os eventos.

Os fótons $\gamma$, são detectados nos cintiladores de $\mathrm{Nal}(\mathrm{TI})$. Os pulsos provenientes de dois detectores distintos passam por amplificadores e depois são somados, gerando um único sinal. A discriminação gama é efetuada, selecionando-se os pulsos correspondentes ao pico de absorção total. Para isto utiliza-se o módulo SCA para a faixa de energia de interesse. Após serem discriminados, os pulsos são analisados de forma semelhante à via $\beta$. 


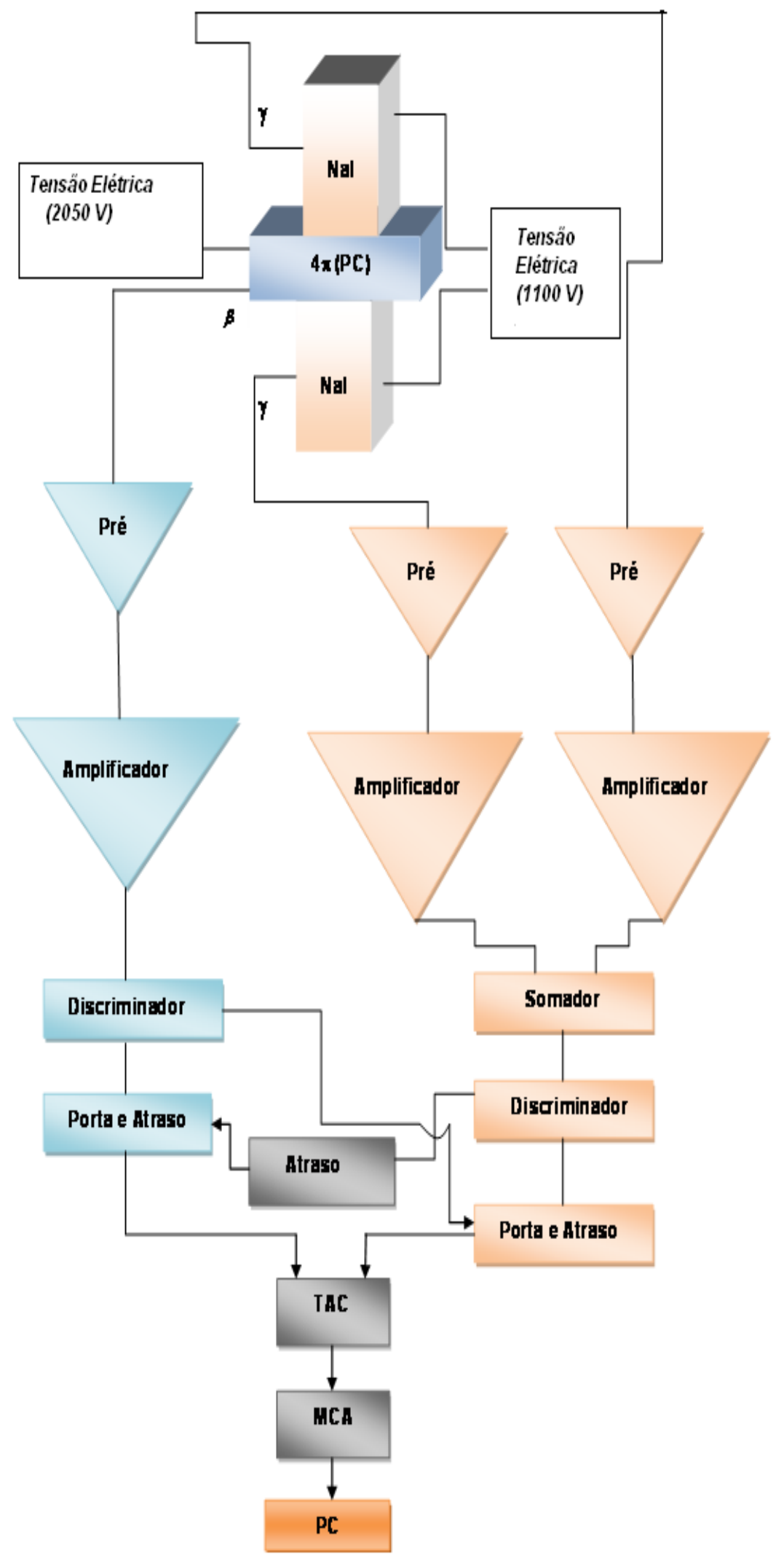

Figura 2.3 - Sistema Eletrônico associado ao Sistema II. 


\subsection{Padronização de Radionuclídeos por Meio de Sistemas de Coincidência}

Aplicou-se a metodologia desenvolvida no presente trabalho para padronização de radionuclídeos que se desintegram por emissão de $\beta^{-}-\gamma$ como o ${ }^{60} \mathrm{Co}$ o radionuclídeo emissor de $\beta+$ - EC como o ${ }^{18} \mathrm{~F}$ e o ${ }^{22} \mathrm{Na}$ que é um emissor de $\beta+$ - CE acompanhado de radiação gama.

Neste item foi incluído o formalismo geral das taxas de gama e coincidências dos respectivos radionuclìdeos acima.

\subsubsection{Padronização do ${ }^{60} \mathrm{Co}$}

Esta padronização foi realizada com o propósito de validar a metodologia de cálculo por Monte Carlo, uma vez que este radionuclídeo apresenta um esquema de desintegração simples, meia vida longa e já foi extensivamente calibrado nos sistemas de coincidência, apresentando resultados satisfatórios.

$\mathrm{O}^{60} \mathrm{Co}$, decai com meia-vida de 5,2714 anos ${ }^{[28]}$, por $\beta^{-}$, alimentando os estados excitados do ${ }^{60} \mathrm{Ni}$ (Figura 2.4). A equação aplicável a este radionuclídeo corresponde à equação (2.9). Por esta relação, conclui-se que, como os coeficientes de conversão, para as transições gamas consideradas, são muito pequenos $\left(\approx 10^{-4}\right)$, espera-se uma inclinação próxima de zero, para a curva de extrapolação da eficiência. 


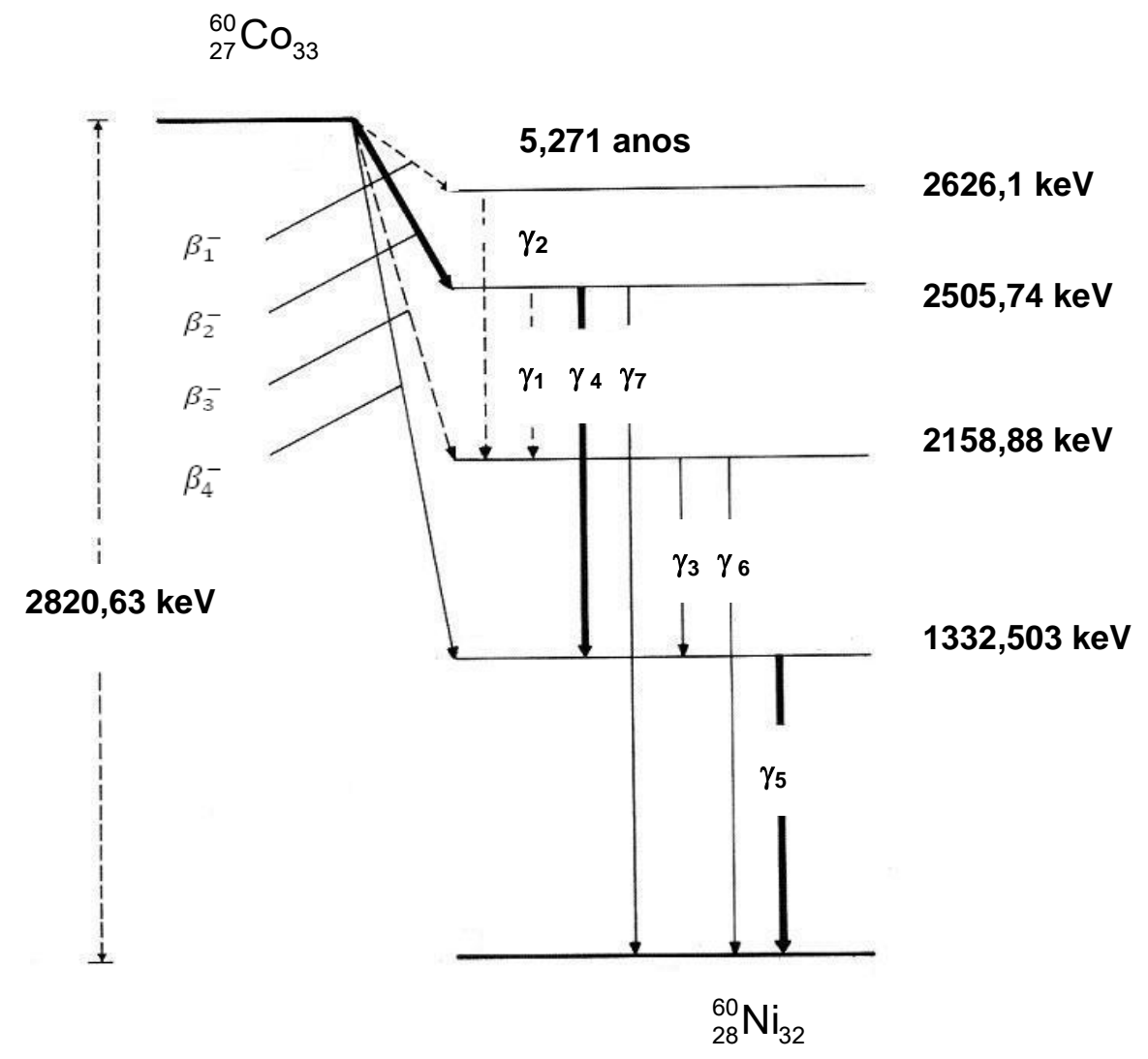

Figura 2.4 - Esquema de desintegração do ${ }^{60} \mathrm{Co}^{[22]}$.

A padronização do ${ }^{60} \mathrm{Co}$ foi realizada no sistema II de medida absoluta $4 \pi(\mathrm{PC})$ - Nal( $\mathrm{TI})$ com a aplicação do método de coincidências, utilizando-se à técnica da extrapolação linear para a eficiência, e variando-se a eficiência beta por meio de discriminação eletrônica. O sistema eletrônico aplica o método TAC $^{[14]}$, apresentado na seção 1.2, e as atividades foram determinadas através do programa CONTAC, versão $15^{[29]}$.

Para esse radionuclídeo as relações que apresentam as taxas de contagens beta, gama, coincidência e para $\frac{\mathrm{N}_{\beta} \mathrm{N}_{\gamma}}{\mathrm{N}_{c}}$ corresponde, respectivamente às equações (2.6), (2.7), (2.8) e (2.9).

\subsubsection{Padronização do ${ }^{18} \mathrm{~F}$}

$\mathrm{O}{ }^{18} \mathrm{~F}$ decai por emissão $\beta^{+}(96,80 \%)$ e captura eletrônica $(3,20 \%)$, com uma meia-vida de $1,829 \mathrm{~h}$, diretamente para o estado fundamental do ${ }^{18} \mathrm{O}^{[28]}$, 
conforme apresentado na figura 2.5. A energia dos elétrons Auger é inferior a $1 \mathrm{keV}$.

Para este radionuclídeo, o número de contagens beta é dado por ${ }^{[15]}$ :

$$
\mathrm{N}_{\beta}=\mathrm{aN}_{0} \varepsilon_{\beta}+\mathrm{bN}_{0} \varepsilon_{\mathrm{EC}}+\mathrm{aN}_{0}\left(1-\varepsilon_{\beta}\right)\left(2 \varepsilon_{\beta \gamma}-\left(\varepsilon_{\beta \gamma}\right)^{2}\right)
$$

Considerando-se que $\varepsilon_{\mathrm{EC}}$ é próxima de zero, tem-se:

$$
\mathrm{N}_{\beta}=\mathrm{aN}_{0} \varepsilon_{\beta}+\mathrm{aN}_{0}\left(1-\varepsilon_{\beta}\right)\left(2 \varepsilon_{\beta \gamma}-\left(\varepsilon_{\beta \gamma}\right)^{2}\right)
$$
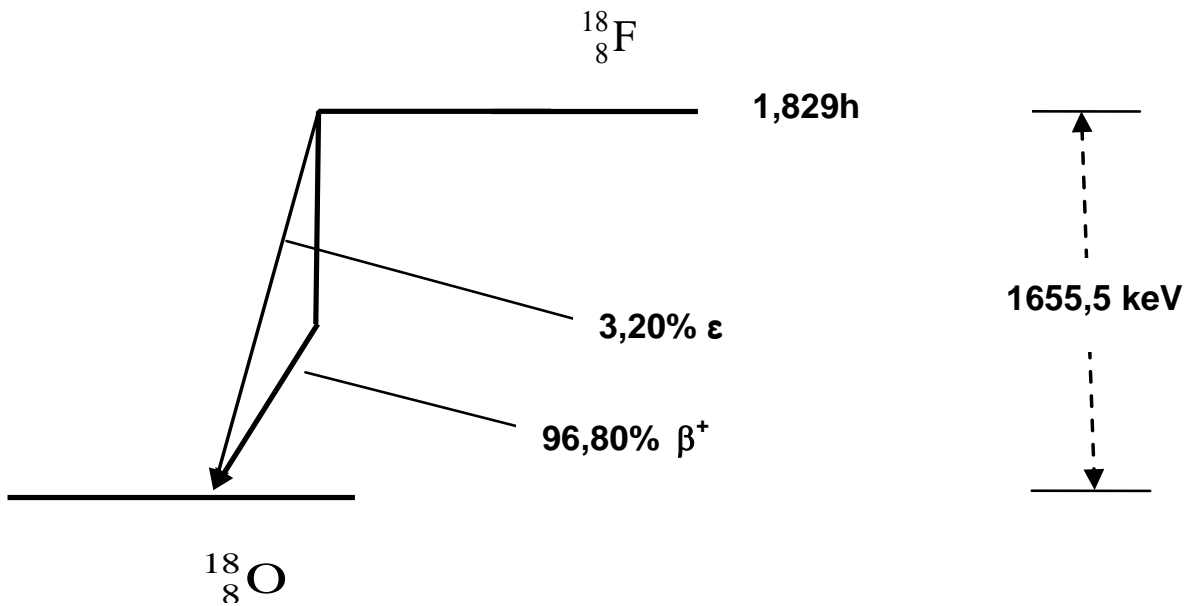

Figura 2.5 - Esquema de desintegração do ${ }^{18} \mathrm{~F}^{[28]}$.

Como complemento destes estudos a padronização do ${ }^{18} \mathrm{~F}$ foi realizada no sistema II de medida absoluta $4 \pi(\mathrm{PC})$-Nal(TI) com a aplicação do método de coincidências, utilizando-se à técnica da extrapolação linear para a eficiência, e variando-se a eficiência beta por meio de discriminação eletrônica, as medições foram realizadas pelo grupo do LMN - Laboratório de Metrologia Nuclear do IPEN, para uma comparação internacional para a (NPL) National Physical Laboratory, UK,em $2001^{[30]}$. O sistema eletrônico aplicado foi o método $\operatorname{TAC}^{[14]}$ e a atividade foi determinada por meio do programa CONTAC, versão $15^{[29]}$. Selecionando apenas o pico de absorção total produzido pelo ${ }^{18} \mathrm{~F}$, pelos raios gamas de aniquilação (511 keV), em nossos estudos comparou - se os resultados 
realizados pelo grupo do $\mathrm{LMN}$ do ${ }^{18} \mathrm{~F}$ com o resultado teórico gerado pelo método de Monte Carlo.

O número de contagens de gama é dado por:

$$
\mathrm{N}_{\gamma}=\mathrm{aN}_{0}\left(2 \varepsilon_{\gamma}-\varepsilon_{\gamma}^{2}\right)
$$

O número de contagens de coincidências é dado por:

$$
\mathrm{N}_{\mathrm{C}}=\mathrm{aN}_{0}\left(2 \varepsilon_{\gamma}-\varepsilon_{\gamma}^{2}\right)\left\{\varepsilon_{\beta}+\left(1-\varepsilon_{\beta}\right)\left[2 \varepsilon_{\beta \gamma}-\left(\varepsilon_{\beta \gamma}\right)^{2}\right]\right\}
$$

Onde:

$\mathrm{a}=$ é a probabilidade de emissão $\beta^{+}$;

b = é a probabilidade de emissão de captura eletrônica;

$\varepsilon_{\beta}=$ eficiência beta;

$\varepsilon_{\beta \gamma}=$ eficiência do detector beta para as radiações gama,

$\varepsilon_{\mathrm{EC}}=$ eficiência do detector beta para elétrons de conversão,

$\varepsilon_{\gamma}=$ eficiência gama.

Portanto,

$$
\frac{\mathrm{N}_{\beta} \mathrm{N}_{\gamma}}{\mathrm{N}_{\mathrm{C}}}=\frac{\mathrm{aN}_{0}\left\{1+\frac{\left(1-\varepsilon_{\beta}\right)}{\varepsilon_{\beta}}\left[2 \varepsilon_{\beta \gamma}-\left(\varepsilon_{\beta \gamma}\right)^{2}\right]\right\}}{\left\{1+\frac{\varepsilon_{\beta \gamma}\left(1-\varepsilon_{\beta}\right)}{\left(1-\frac{\varepsilon_{\gamma}}{2}\right) \varepsilon_{\beta}}\right\}}
$$

Para aplicar a modelagem por Monte Carlo a este radionuclídeo foi elaborado um esquema de desintegração alternativo, apresentado na figura 2.6 que.possibilitasse a reprodução do experimento, com a versão atual do programa ESQPOS (versão 2.0). Esta versão não permite o cálculo para um radionuclídeo que tenha dois modos de desintegração, como $\beta^{+}$e captura eletrônica, $0{ }^{18} \mathrm{~F}$, 
possui uma desintegração de $\beta^{+}$acompanhado de captura eletrônica, foi considerado o pico de aniquilação de $1022 \mathrm{keV}$, para a detecção dos pósitrons e a aniquilação dos fótons com os pósitrons, para esta transição a altura do espectro no detector $\mathrm{Nal}(\mathrm{TI})$ foi calculado através do código MCNPX, pela média de energia dos pósitrons igual a 215,6 keV e incluído na tabela de respostas no local em que ocorre o espectro dos raios gamas produzidos no detector $\mathrm{Nal}(\mathrm{TI})$ para uma energia de $1022 \mathrm{keV}$. A intensidade da captura eletrônica é fornecida através dos desvios dos raios, que estão incluídos com a transição dos pósitrons.

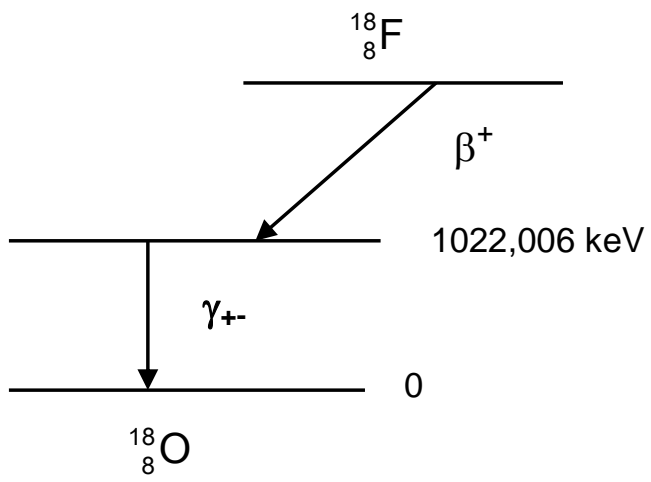

Figura 2.6 - Esquema de desintegração do ${ }^{18} \mathrm{~F}$ desenvolvido para aplicação na modelagem por Monte Carlo.

\subsubsection{Padronização do ${ }^{22} \mathrm{Na}$}

$\mathrm{O}{ }^{22} \mathrm{Na}$ decai com meia vida de 2,602 anos, por emissão $\beta^{+}(90,26 \%)$ e captura eletrônica $(9,74 \%)$, alimentando o estado excitado do ${ }^{22} \mathrm{Ne}^{[28]}$, conforme indicado pela figura2.7.

A transição $\beta^{+}$dominante $(90,20 \%)$ possui uma energia de $545,5 \mathrm{keV}$. Imediatamente após $\left(3,7 \times 10^{-12} \mathrm{~s}\right)$, tem-se uma transição gama de $1274,582 \mathrm{keV}$. As energias dos elétrons Auger e dos raios-X estão abaixo de $1 \mathrm{keV}$. 


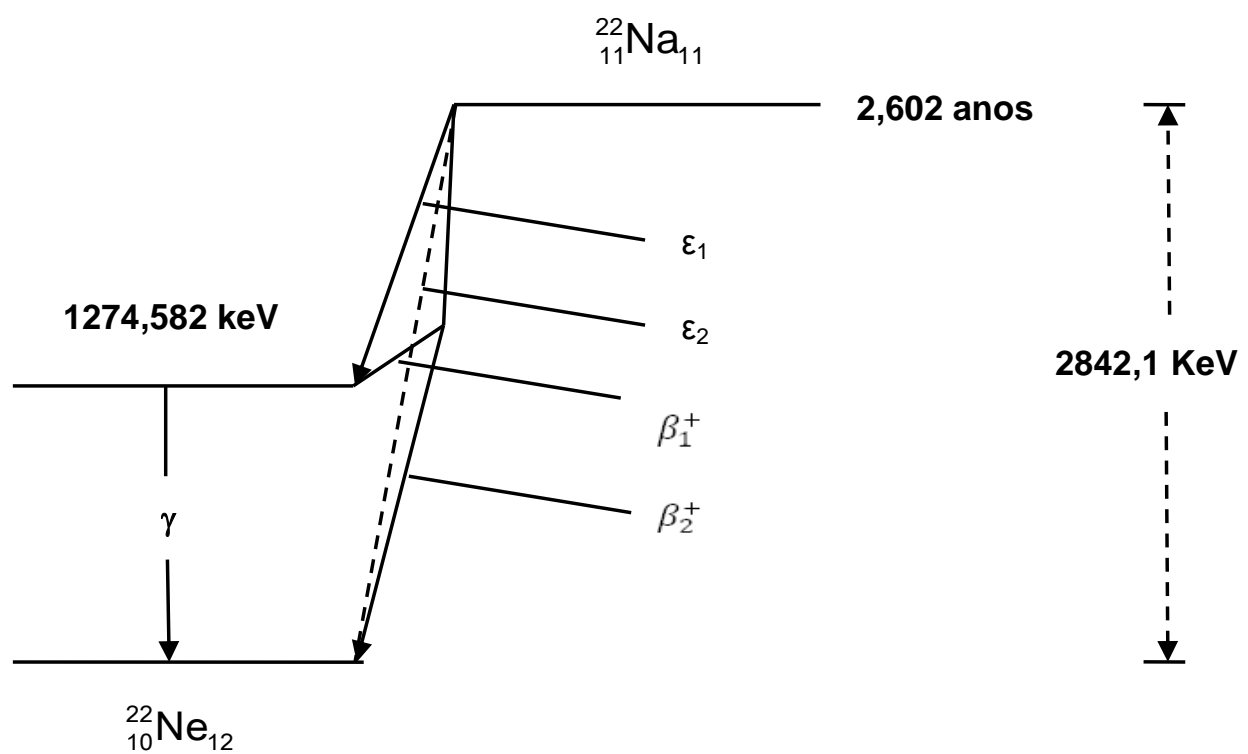

Figura 2.7 - Esquema de desintegração do ${ }^{22} \mathrm{Na}^{[28]}$.

O tratamento a seguir foi utilizado pelo PTB para a padronização do ${ }^{22} \mathrm{Na}^{[27]}$. O método utilizado pelo $\mathrm{LMN}$ é semelhante ${ }^{[26]}$ e segue as mesmas considerações.

Para este radionuclídeo, as taxas de contagens, com as devidas correções para contagem de fundo e coincidências espúrias, para os três canais do sistema coincidência, podem ser escritas como ${ }^{[27]}$ :

Contagens beta:

$$
\begin{gathered}
N_{\beta}=N_{0}\left|p_{\beta_{00}} \varepsilon_{\beta}+p_{\beta_{01}}(\underbrace{\varepsilon_{\beta}+\left(1-\varepsilon_{\beta}\right) \varepsilon_{\beta \gamma}^{\prime}}_{\varepsilon_{\beta}^{\prime}}]\right|+p_{E_{01}} \varepsilon_{\beta E}^{\prime} \\
N_{\beta}=N_{0}\left[h \varepsilon_{\beta}+p_{\beta_{01}}\left(1-\varepsilon_{\beta}\right) \varepsilon_{\beta \gamma}^{\prime}+p_{E_{01}} \varepsilon_{E C}^{\prime}\right]
\end{gathered}
$$

Onde: $\mathrm{h}=\mathrm{p}_{\beta_{00}}+\mathrm{p}_{\beta_{01}}$

Os índices 00 e 01 correspondem às transições que terminam no estado fundamental e no primeiro nível excitado do ${ }^{22} \mathrm{Ne}$, respectivamente.

As probabilidades de emissão beta e captura eletrônica são indicadas por $p_{\beta}$ e $p_{E C}$, respectivamente. 
Contagens gama:

$$
\begin{aligned}
\mathrm{N}_{\mathrm{Y}}=\mathrm{N}_{0} & {\left[\pi_{\beta_{00}} 2 \varepsilon_{\gamma_{(511)}}+\pi_{\beta_{01}} \|\left(\varepsilon_{\gamma_{(1275 \beta)}}+\varepsilon_{\gamma_{(1786)}}\right)\right.} \\
& \left.\left.+\left(1-\varepsilon_{\gamma_{(1275 \beta)}}-\varepsilon_{\gamma_{(1786)}}\right) 2 \varepsilon_{\gamma_{(511)}}\right\rfloor+\mathrm{p}_{\mathrm{EC}_{01}} \varepsilon_{\gamma_{(1275 \mathrm{EC})}^{\prime}}\right\rfloor
\end{aligned}
$$

Contagens de coincidências:

$$
\begin{aligned}
\mathrm{N}_{\mathrm{C}} & =\mathrm{N}_{0}\left[\mathrm{p}_{\beta_{00}} 2 \varepsilon_{\gamma_{(511)}} \varepsilon_{\beta}+\mathrm{p}_{\beta_{01}}\left[\left(\varepsilon_{\gamma_{(1275 \beta)}}+\varepsilon_{\gamma_{(1786)}}\right)\right.\right. \\
& \left.\left.+\left(1-\varepsilon_{\gamma_{(1275 \beta)}}-\varepsilon_{\gamma_{(1786)}}\right) 2 \varepsilon_{\gamma_{(511)}}\right\rfloor \varepsilon_{\beta}^{\prime}+\mathrm{p}_{\mathrm{EC}_{01}} \varepsilon_{\gamma_{(1275 \mathrm{EC})}^{\prime}} \varepsilon_{\mathrm{EC}}^{\prime}\right\rfloor
\end{aligned}
$$

Para uma discriminação do canal beta em $1 \mathrm{keV}$, tem-se $\varepsilon_{\mathrm{EC}_{01}}=0 \mathrm{e}$ $\varepsilon_{\mathrm{EC}_{00}}=0$ Para as taxas de contagens gama, pode-se considerar $\varepsilon_{\beta \gamma}=\varepsilon_{\beta \gamma(511)}$. Neste tratamento são utilizadas, para a transição do $\beta^{+}$, as seguintes condições: $\varepsilon_{\beta=} \varepsilon_{\beta 01} \approx \varepsilon_{\beta 00}$. O nível de discriminação para o canal gama nestas equações está colocado acima de $511 \mathrm{keV}$, resultando em $\varepsilon_{\gamma(511)}=0^{[13]}$.

Considerando-se $h$ a probabilidade de emissão $\beta^{+}$, tem-se: $\frac{p_{E C}}{p_{\beta^{+}}}=\frac{1-h}{h}$

Nas condições estabelecidas acima, as equações ficam reduzidas para

$$
\begin{gathered}
\mathrm{N}_{\beta}=\mathrm{N}_{0}\left[\mathrm{~h} \varepsilon_{\beta}+\mathrm{p}_{\beta_{01}}\left(1-\varepsilon_{\beta}\right) \varepsilon_{\beta \gamma}^{\prime}+\mathrm{p}_{\mathrm{EC}_{01}} \varepsilon_{\beta \gamma}\right] \\
\mathrm{N}_{\gamma}=\mathrm{N}_{0}\left[\mathrm{p}_{\beta_{01}}\left(\varepsilon_{\gamma_{(1275 \beta)}}+\varepsilon_{\gamma_{(1786)}}\right) \mathrm{p}_{\mathrm{EC}_{01}} \varepsilon_{\gamma_{(1275 \mathrm{EC})}}\right] \\
\mathrm{N}_{\mathrm{C}}=\mathrm{N}_{0}\left[\mathrm{p}_{\beta_{01}}\left(\varepsilon_{\gamma_{(1275, \beta)}}+\varepsilon_{\gamma_{(1786)}}\right) \varepsilon_{\beta}^{\prime}+\mathrm{p}_{\mathrm{EC}_{01}} \varepsilon_{\gamma_{(1275, \mathrm{EC})}} \varepsilon_{\beta \gamma}\right]
\end{gathered}
$$

Onde: 
$\mathrm{p}_{\beta_{00}}=$ a probabilidade de transição do $\beta^{+}$, para o estado fundamental;

$\mathrm{p}_{\beta_{01}}=$ a probabilidade de transição do $\beta^{+}$,para o primeiro nível excitado do ${ }^{22} \mathrm{Ne}$;

$\mathrm{p}_{\mathrm{EC}_{01}}=\mathrm{a}$ probabilidade da captura eletrônica no primeiro nível excitado do ${ }^{22} \mathrm{Ne}$;

$\varepsilon_{\beta}=$ eficiência beta;

$\varepsilon_{\mathrm{EC}}=$ eficiência do detector beta para captura eletrônica;

$\varepsilon_{\gamma(511)}=$ probabilidade da detecção de um gama, quando ocorre a aniquilação $\left(\beta^{+} \mathrm{e}\right.$ $\left.\beta^{-}\right)$;

$\varepsilon_{\gamma(1275, \beta)}=$ probabilidade da deteç̧ão de um gama , quando ocorre a transição do $\beta^{+}$para a energia de $1275 \mathrm{keV}$;

$\varepsilon_{\gamma(1275, \mathrm{EC})}=$ probabilidade da detecção de um gama , quando ocorre a transição da captura eletrônica,

$\varepsilon_{\gamma(1786)}=$ probabilidade da deteç̧ão do Pico Soma $(1275+511) \mathrm{keV}$;

$\varepsilon_{\beta \gamma}=$ eficiência do detector beta para as radiações gama;

$\varepsilon_{\beta}^{\prime}:=\varepsilon_{\beta}+\left(1-\varepsilon_{\beta}\right)=$ probabilidade de detectar, o total de pósitrons no detector beta;

$\varepsilon_{\mathrm{EC}}^{\prime}:=\varepsilon_{\mathrm{EC}}+\left(1-\varepsilon_{\mathrm{EC}}\right) \varepsilon_{\beta \gamma}=$ probabilidade de detectar, o total de captura eletrônica no contador beta;

$\varepsilon_{\beta \gamma}^{\prime}:=3 \varepsilon_{\beta \gamma}-3 \varepsilon_{\beta \gamma}^{2}+3 \varepsilon_{\beta \gamma}^{3}=$ probabilidade de detecção de pelo menos um dos três gamas (1275 keV e 511 keV (2 gamas)), na transição dos pósitrons para o detector beta.

Para a medida utilizando Método do Pico Soma o limiar para o canal gama, é colocado pouco abaixo do pico-soma em $(1275+511) \mathrm{keV}$. Neste caso tem-se: $\varepsilon_{\gamma(1275, \mathrm{EC})}=\varepsilon_{\gamma(1275, \beta)}=0$

Adicionando-se absorvedores de alumínio sobre a fonte radioativa, a eficiência do canal beta é reduzida, e pode-se equacionar conforme segue. A probabilidade $h$ para emissão de pósitrons pode ser calculada, e a correção $Y_{s}$ é pequena.

$$
\frac{\mathrm{N}_{\beta, S} \mathrm{~N}_{\gamma, \mathrm{S}}}{\mathrm{N}_{\mathrm{C}, \mathrm{S}}}=\mathrm{N}_{0}\left(\mathrm{~h}+\mathrm{p}_{\mathrm{EC}} \varepsilon_{01} \varepsilon_{\beta, \gamma}\right)=\mathrm{N}_{0}\left(\mathrm{~h}+\mathrm{Y}_{\mathrm{S}}\right)
$$


Onde:

$\mathrm{N}_{\beta, S}=$ taxa de contagens beta para o Pico Soma;

$\mathrm{N}_{\gamma, \mathrm{S}}=$ taxa de contagens gama para o Pico Soma;

$\mathrm{N}_{\mathrm{C}, \mathrm{S}}=$ taxa de contagens de coincidência para o Pico Soma;

A determinação da atividade da fonte pelo Método do Pico Nuclear (índice $D$ nas equações abaixo) é feita selecionando-se apenas o pico de absorção total para o gama de $1275 \mathrm{keV}$. Neste caso, a medida pode ser efetuada variando-se a distância $r$ entre a fonte e o cintilador de $\mathrm{Nal}(\mathrm{TI})$ e determinando-se a eficiência gama pela relação $\mathrm{N}_{c} \mathbb{N}_{\beta}$.

Extrapolando-se as medidas para uma distância infinita, o fator $Y_{s}$ torna-se insignificante, em razão: $\varepsilon_{\gamma(1786)} \rightarrow 0$. Assim $\varepsilon_{\gamma(1275, \beta)} \rightarrow \varepsilon_{\gamma(1275, \mathrm{EC})}=: \varepsilon_{\gamma(1275)}$. Neste caso, podemos efetuar a razão:

$$
\begin{gathered}
\frac{\mathrm{N}_{\beta, \mathrm{D}} \mathrm{N}_{\gamma, \mathrm{D}}}{\mathrm{N}_{\mathrm{C}, \mathrm{D}}}=\mathrm{N}_{0} \frac{\left[\mathrm{h}_{\beta}+\mathrm{p}_{\beta_{01}}\left(1-\varepsilon_{\beta}\right) \varepsilon_{\beta \gamma}^{\prime}+\mathrm{p}_{\mathrm{EC}_{01}} \varepsilon_{\beta \gamma}\right]\left(\mathrm{p}_{\beta_{01}}+\mathrm{p}_{\mathrm{EC}_{01}}\right) \varepsilon_{\gamma_{(1275)}}}{\mathrm{p}_{\beta_{01}} \varepsilon_{\gamma_{(1275)}} \varepsilon_{\beta}^{\prime}+\mathrm{p}_{\mathrm{EC}_{01}} \varepsilon_{\gamma_{(1275)}} \varepsilon_{\beta \gamma}} \\
\frac{\mathrm{N}_{\beta, \mathrm{D}} \mathrm{N}_{\gamma, \mathrm{D}}}{\mathrm{N}_{\mathrm{C}, \mathrm{D}}}=\mathrm{N}_{0}\left(1+\mathrm{Y}_{\mathrm{D}}\right)
\end{gathered}
$$

Onde

$\mathrm{N}_{\beta, \mathrm{D}}=$ taxa de contagens beta para o Pico Nuclear;

$\mathrm{N}_{\gamma, \mathrm{D}}=$ taxa de contagens gama para o Pico Nuclear;

$\mathrm{N}_{\mathrm{C}, \mathrm{D}}=$ taxa de contagens de coincidência para o Pico Nuclear;

Considerando $\mathrm{N}_{\beta, \mathrm{s}}=\mathrm{N}_{\beta, \mathrm{D}}$, pode-se determinar a probabilidade de emissão de pósitrons, h:

$$
\mathrm{h}=\frac{\mathbf{N}_{\gamma, \mathrm{S}} \mathrm{N}_{\mathrm{C}, \mathrm{D}}}{\mathbf{N}_{\mathrm{C}, \mathrm{S}} \mathrm{N}_{\gamma, \mathrm{D}}}\left(1+\mathrm{Y}_{\mathrm{D}}\right)-\mathrm{Y}_{\mathrm{S}}
$$


Outra metodologia que podemos utilizar para o ${ }^{22} \mathrm{Na}$, é o de Williams ${ }^{[31]}$ o qual, podemos encontrar o fator de correção $\Delta$, efetuando um estudo comparativo, conforme descrito abaixo.

Assumindo o esquema para o ${ }^{22} \mathrm{Na}$, na figura 2.7, procede-se a realização de medidas utilizando o método de coincidências $4 \pi \beta-\gamma$, por Willians, através de dois métodos ${ }^{[31]}$ :

(a) No método do Pico Soma, o intervalo de discriminação gama inclui apenas o pico de absorção total na energia correspondente à soma entre os raios- $\gamma$ nucleares de 1,28 MeV e um dos raios- $\gamma$ de 0,511 MeV, associados à aniquilação de pósitrons;

(b) No método do Pico Nuclear, o intervalo de discriminação gama inclui apenas o pico de absorção total para o gama nuclear de 1,28 MeV.

A taxa de contagens beta é dada por:

$$
\mathrm{N}_{\beta}=\mathrm{N}_{0} \mathrm{~h} \varepsilon_{\beta}
$$

$\mathrm{N}_{0}=$ taxa de desintegração na fonte;

$\mathrm{h}=$ é a fração de desintegração para 1,274 MeV, na qual existe a emissão de pósitrons;

$\varepsilon_{\beta}=$ eficiência no contador $\beta$ para emissão de pósitrons.

Taxa de contagens para gama;

$$
\mathrm{N}_{\gamma \mathrm{s}}=\mathrm{N}_{0} \mathrm{~h} \varepsilon_{\gamma \mathrm{s}}
$$

$\varepsilon_{\gamma s}=$ eficiência no contador gama para a soma de eventos

E a taxa de contagens $\beta-\gamma$ coincidência é determinada por,

$$
\mathrm{N}_{\mathrm{c}}=\mathrm{N}_{0} \mathrm{~h} \varepsilon_{\beta} \varepsilon_{\gamma \mathrm{s}}
$$

Onde

$$
\frac{\mathrm{N}_{\beta} \mathrm{N}_{\gamma \mathrm{s}}}{\mathrm{N}_{\mathrm{cs}}}=\mathrm{N}_{0} \mathrm{~h}
$$


Para medidas do item (b), a taxa de contagem $\beta$ é determinada da mesma forma que a equação (2.35), a taxa $\gamma$ é dada por:

$$
\mathrm{N}_{\gamma \mathrm{n}}=\mathrm{N}_{0} \varepsilon_{\gamma \mathrm{n}}
$$

$\varepsilon_{\gamma n}=$ é a eficiência do contador $\gamma$ para raios- $\gamma$ de $1,28 \mathrm{MeV}$

E a taxa de contagens de coincidências $\beta-\gamma$, é dada por:

$$
\mathrm{N}_{\mathrm{cn}}=\mathrm{N}_{0} \mathrm{~h} \varepsilon_{\beta} \varepsilon_{\gamma \mathrm{n}}
$$

Onde

$$
\frac{\mathrm{N}_{\beta} \mathrm{N}_{\gamma \mathrm{n}}}{\mathrm{N}_{\mathrm{cn}}}=\mathrm{N}_{0}
$$

Dividindo a equação (2.38) pela (2.41), obteremos o valor de h, de onde tem-se:

$$
\frac{e}{\beta^{+}}=\frac{(1-h)}{h}
$$

Em decorrência da equação (2.35) a sensibilidade para o contador $\beta$, tanto para os raios- $\gamma$ como para captura eletrônica são desprezadas, levando em conta os eventos citados, obteremos uma nova equação:

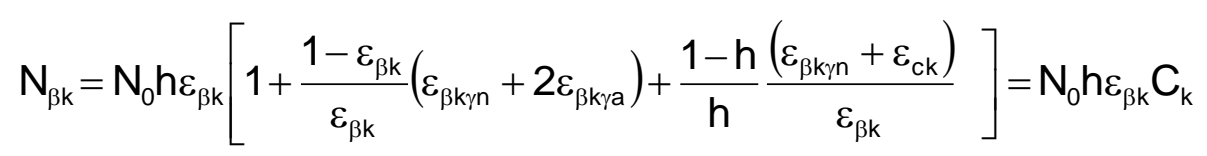

Onde:

$\mathrm{h}$ = probabilidade de emissão de pósitrons;

$\varepsilon_{\beta k \text { ’n }}=$ eficiência do contador $\beta$ para os raios- $\gamma$ nucleares; 
$\varepsilon_{\beta k \gamma a}=$ eficiência do contador $\beta$ para aniquilação dos raios- $\gamma$;

$\varepsilon_{\mathrm{ck}}=$ eficiência do contador $\beta$ para os eventos de captura eletrônica.

O sufixo $\mathrm{k}$ refere-se ao contador $\beta$ utilizado, quando $\mathrm{k}=1$ foi utilizado para o Pico Soma e quando $k=2$ para o Pico Nuclear.

$\mathrm{Na}$ equação (2.36) considera-se a contagem no contador $\gamma$ independente do ponto de ocorrência da aniquilação. Em decorrência da equação das taxas de contagem $\gamma$, assumimos uma probabilidade da detecção da aniquilação do Pico Soma ocorrer em um ponto $r$ da fonte $f\left(\varepsilon_{\gamma a} \varepsilon_{\gamma n} r\right)$, ou fora da fonte $\phi\left(\varepsilon_{\gamma a} \varepsilon_{\gamma n} r\right)$. Então se $x$ é a fração de aniquilação de pósitrons na fonte, as taxas de contagens $\gamma$, podem ser obtidas por:

$$
N_{\gamma s}=N_{0} h\left\{(1-x) \int \varphi\left(\varepsilon_{\gamma a} \varepsilon_{\gamma n} r\right) d r+x \int f\left(\varepsilon_{\gamma a} \varepsilon_{\gamma n} r\right) d r\right\}
$$

Onde

$\varepsilon_{\gamma a}=$ eficiência para o contador dos gamas para os raios gamas de 1,28 MeV;

Para as taxas de coincidência $\beta-\gamma$, temos a equação:

$$
N_{c s}=N_{0} h\left\{\int \phi\left(\varepsilon_{\gamma a} \varepsilon_{\gamma n} r\right) \varepsilon_{\beta}(r) d r+\frac{1}{2} \int\left[1-\varepsilon_{\beta}(r)\right] f\left(\varepsilon_{\gamma a} \varepsilon_{\gamma n} r\right) \varepsilon_{\beta \gamma} d r\right\}
$$

Onde:

$\varepsilon_{\beta}(r)$ é a probabilidade de detecção no contador $\beta$ para a aniquilação de pósitrons na posição $r$.

A eficiência no contador $\beta$ para pósitrons, se aniquilar fora da fonte independe de $r$, pois a geometria do contador é $4 \pi$ o que gera uma $\varepsilon_{\beta}(r)$ constante, e teremos as integrais da equação (2.44), que podem ser removidas e escritas como $\varepsilon_{\beta 1}$. Podemos ainda substituir (1-x) por $\varepsilon_{\beta 1}$.

Assim obtém-se: 


$$
\frac{\int f\left(\varepsilon_{\gamma a} \varepsilon_{\gamma n} r\right) d r}{\int \phi\left(\varepsilon_{\gamma a} \varepsilon_{\gamma n} r\right) d r}=1+\Delta
$$

Dado

$$
\frac{N_{\gamma s}}{N_{c s}}=\frac{\left\{1+\left(1-\varepsilon_{\beta 1}\right) \Delta\right\}}{\varepsilon_{\beta 1}\left\{1+\frac{1}{2}\left(\frac{\left(1-\varepsilon_{\beta 1}\right)}{\varepsilon_{\beta 1}}\right)(1+\Delta) \varepsilon_{\beta 1 \gamma \mathrm{a}}\right\}}
$$

O valor de $\varepsilon_{\beta 1 \gamma a}$, é pequeno, conseqüentemente o fator de correção $\Delta$ se torna pequeno, podendo ser negligenciado na equação (2.46). Assumindo que $\varepsilon_{c}$ é zero, podemos encontrar $\Delta$, variando $\varepsilon_{\beta 1}$ e graficando os seguintes parâmetros:

$$
\frac{\mathrm{N}_{\beta 1} \mathrm{~N}_{\gamma \mathrm{s}}}{\mathrm{N}_{\mathrm{cs}}} \frac{\left\{1+\left(\frac{\left(1-\varepsilon_{\beta 1}\right)}{\varepsilon_{\beta 1}}\right) \frac{1}{2} \varepsilon_{\beta 1 \gamma \mathrm{\gamma}}\right\}}{\left\{1+\left(\frac{\left(1-\varepsilon_{\beta 1}\right)}{\varepsilon_{\beta 1}}\right)\left(\varepsilon_{\beta \gamma \mathrm{n}}+2 \varepsilon_{\beta 1 \gamma \mathrm{a}}\right)+\frac{1-\mathrm{h}}{\mathrm{h}} \frac{\varepsilon_{\beta 1 \gamma \mathrm{n}}}{\varepsilon_{\beta 1}}\right\}} \text { em funçao de }\left(1-\varepsilon_{\beta 1}\right)
$$

Em decorrência da equação (2.42) a possibilidade dos raios- $\gamma$ nucleares e de aniquilação interagir simultaneamente no contador $\gamma$ é desprezada. Para efetuar a correção, considera-se uma provável perda de energia dos raios gama entre um intervalo de e e e +de, no detector gama, tanto para os raios gama nucleares de $\mathbf{f}_{n}(\mathbf{e})$ de como para os raios- $\gamma$ de aniquilação $\mathbf{f}_{n}(\mathbf{e})$ de. Portanto, os tipos de eventos que ocorrem acréscimo de contagens nas janelas do detector incluindo as energia de alcance $\mathbf{E}$ e E+dE, para o Pico Nuclear são considerados os itens (1) e (2), a seguir ${ }^{[31]}$ :

(1) raios- $\gamma$ nucleares absorvidos no contador- $\gamma$ através do efeito fotoelétrico, ou então os raios- $\gamma$ de aniquilação são detectados, com uma probabilidade dada por:

$$
\int_{E}^{E+\Delta E} f_{n}(e) d e\left[1-2 h \int_{0}^{E a} f_{a}(e) d e\right]=\varepsilon_{\gamma n}-2 h \varepsilon_{\gamma n} \bar{\varepsilon}_{\gamma a}
$$


Onde

$\mathrm{E}_{\mathrm{a}}=$ energia de aniquilação dos raios gamas;

$$
\boldsymbol{\varepsilon}_{\gamma \mathrm{n}}=\int_{\mathrm{E}}^{\mathrm{E}+\Delta \mathrm{E}} \mathrm{f}_{\mathrm{n}}(\mathrm{e}) \mathrm{de}, \quad \overline{\boldsymbol{\varepsilon}}_{\gamma \mathrm{a}}=\int_{0}^{\mathrm{E}_{\mathrm{a}}} \mathrm{f}_{\mathrm{a}}(\mathrm{e}) \mathrm{de}
$$

(2) os raios- $\gamma$ nucleares e aniquilação interagem simultaneamente, no contador $\gamma$ produzindo contagens no canal gama. A probabilidade desta ocorrência é dada por:

$$
2 h \int_{E}^{E+\Delta E} \int_{e=0}^{\infty} f_{n}(e) f(a)\left(E^{\prime}-e\right) d e d E^{\prime}=2 h \overline{\varepsilon_{\gamma a}} \overline{\varepsilon_{\gamma n}},
$$

Onde

$$
\overline{\varepsilon_{\gamma a}} \overline{\varepsilon_{\gamma n}}=\int_{E}^{E+\Delta E} \int_{e=0}^{\infty} f_{n}(e) f(a)\left(E^{\prime}-e\right) d e d E^{\prime},
$$

Portanto

$$
\mathrm{N}_{\gamma \mathrm{n}}=\mathrm{N}_{0} \varepsilon_{\gamma \mathrm{n}}\left[1-2 \mathrm{~h} \frac{\left(\varepsilon_{\gamma \mathrm{n}} \overline{\varepsilon_{\gamma \mathrm{n}}}\right)-\overline{\varepsilon_{\gamma \mathrm{a}} \varepsilon_{\gamma \mathrm{n}}}}{\varepsilon_{\gamma \mathrm{n}}}\right]
$$

Esta notação mostra que a probabilidade para a detecção simultânea de dois raios- $\gamma$ é proporcional ao produto das duas eficiências. Se a eficiência geométrica do contador $\gamma$ for reduzida a detecção simultâneas de dois raios gamas decrescem mais rapidamente para $\varepsilon_{\gamma \mathrm{n}}$, uma vez dependente do produto das eficiências, e conseqüentemente as taxas de contagens gama são reduzidas, assim tem-se $\mathrm{e}^{[31]}$ :

$$
\mathrm{N}_{\gamma \mathrm{n}}^{\prime}=\mathrm{N}_{0} \varepsilon_{\gamma \mathrm{n}}
$$

E esse limite $N^{\prime}$, é dado por:

$$
\mathrm{N}_{\mathrm{cn}}^{\prime}=\mathrm{N}_{0} \mathrm{~h} \varepsilon_{\beta 2} \varepsilon_{\gamma \mathrm{n}}\left\{1+\left(\frac{1-\varepsilon_{\beta 2}}{\varepsilon_{\beta 2}}\right) 2 \varepsilon_{\beta 2 \gamma \mathrm{a}}+\frac{1-\mathrm{h}}{\mathrm{h}} \varepsilon_{\mathrm{C} 2}\right\}
$$


Das equações (2.42), (2.45), (2.52) e (2.53), tem-se:

$$
\mathrm{h}=\frac{\mathrm{N}_{\beta 1} \mathrm{~N}_{\gamma \gamma} \mathrm{N}_{\mathrm{cn}}^{\prime}}{\mathrm{N}_{\beta 2} \mathrm{~N}_{\gamma \gamma}^{\prime} \mathrm{N}_{\mathrm{cs}}} \frac{\left[1+\left(\frac{1-\varepsilon_{\beta 1}}{\varepsilon_{\beta 1}}\right) \frac{1}{2} \varepsilon_{\beta 1 \gamma a}\right] \mathrm{C}_{2}}{\left[1+\left(\frac{1-\varepsilon_{\beta 2}}{\varepsilon_{\beta 2}}\right) 2 \varepsilon_{\beta 2 \gamma \mathrm{\gamma}}+\frac{1-\mathrm{h}}{\mathrm{h}} \varepsilon_{\mathrm{c} 2}\right] \mathrm{C}_{1}\left[1+\left(1-\varepsilon_{\beta 1}\right) \Delta\right]}
$$

Notou as diferenças entre as eficiências $\beta$, para os dois contadores com as correções correspondentes.

Utilizando os dados experimentais obtidos por Moura ${ }^{[26]}$, para o Pico Soma, determinamos as taxas de contagem $\mathrm{N}_{\beta 1}, \mathrm{~N}_{\gamma \mathrm{s}}$ e $\mathrm{N}_{\mathrm{cs}}$, descritas no item 2.3.3, por meio de um contador $4 \pi$ proporcional, para a detecção $\beta$, acoplado a dois cintiladores de $\mathrm{Nal}(\mathrm{TI})$ de $7,6 \mathrm{~cm} \times 7,6 \mathrm{~cm}$, para a detecção $\gamma$ (Sistema II). Foram utilizadas diversas fontes radioativas contendo absorvedores de alumínio nas partes superior e inferior do suporte, para reduzir o valor da eficiência para eventos de captura eletrônica $\left(\varepsilon_{c}\right)$ a um valor próximo de zero.

Para o Pico Nuclear, Medidas de contagem das taxas $N_{\beta 2}, N_{\gamma n}$ e $N_{c n}$, fornecidas por Moura ${ }^{[26]}$, foram efetuadas com um contador $\beta$ similar ao utilizado acima, porém acoplado apenas com um único $\mathrm{Nal}(\mathrm{TI})$ de 7,6 $\mathrm{cm} \times 7,6 \mathrm{~cm}$, para a detecção $\gamma$ (Sistema I). A eficiência geométrica do contador- $\gamma$ foi reduzida em cada etapa, variando-se a distância entre o $\mathrm{Nal}(\mathrm{TI})$ e o contador $4 \pi$ proporcional.

Para os dois casos, a eficiência do contador $\beta$ para os raios- $\gamma$ foi determinada previamente.

Para o ${ }^{22} \mathrm{Na}$, como no caso anterior do ${ }^{18} \mathrm{~F}$, foi elaborado um esquema de desintegração alternativo, efetuando-se uma nova modelagem para o Monte Carlo a este radionuclídeo o qual, possibilitasse a reprodução do experimento, com a versão atual do programa ESQPOS (versão 2.0). Esta versão não permite o cálculo para um radionuclídeo que tenha dois modos de desintegração, como $\beta^{+}$ e captura eletrônica, simultaneamente, como é o caso do ${ }^{22} \mathrm{Na}$. Desta forma, criou-se o esquema apresentado na figura 2.8 . 


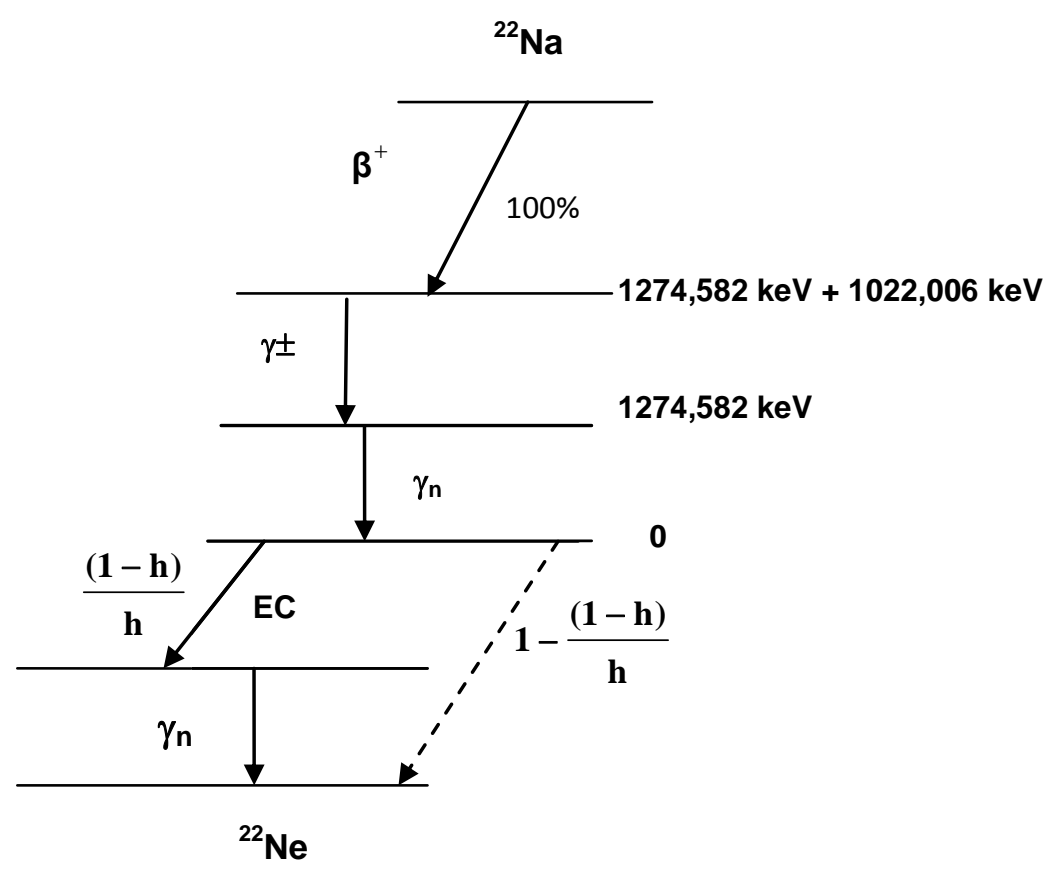

Figura 2.8 - Esquema de desintegração do ${ }^{22} \mathrm{Na}$ desenvolvido para aplicação na modelagem por Monte Carlo.

A simulação do ${ }^{22} \mathrm{Na}$, pelos dois métodos apresentados (Pico Soma e Pico Nuclear), foi realizada utilizando a modelagem, por meio do código ESQUEMA $^{[18]}$, que foram modificados para emissão de pósitrons, Os elétrons Auger possui energias abaixo de $1 \mathrm{keV}$ e foram eliminados pelos absorvedores finos usados acima e abaixo das fontes radioativas.

Para o caso do Método do Pico-Soma, tornou-se necessário gerar novas tabelas de resposta para pósitrons no detector $4 \pi$, adicionando-se absorvedores de alumínio em torno da fonte radioativa. As janelas gama foram ajustadas para incluir somente a janela total da energia da absorção $(511+1275=$ $1786 \mathrm{keV})$, que corresponde ao Pico Soma.

Para o caso do Método do Pico Nuclear, como as medidas do LMN foram efetuadas no sistema I foi necessário gerar novas tabelas de resposta para fótons e pósitrons em diferentes distâncias entre o detector de $\mathrm{Nal}(\mathrm{TI})$ e o detector $4 \pi(\mathrm{PC})$. Os valores obtidos para as atividades foram extrapolados para distância infinita. Este procedimento foi seguido para eliminar as coincidências gama-gama entre os fótons de aniquilação e o gama de $1275 \mathrm{keV}$. Neste caso, a janela do 
raio gama foi ajustada para incluir somente o pico total da energia da absorção do raio gama de $1275 \mathrm{keV}$.

Para a análise da Eficiência Gama para $0{ }^{22} \mathrm{Na}$, foi utilizada a figura 2.9, conforme segue abaixo:

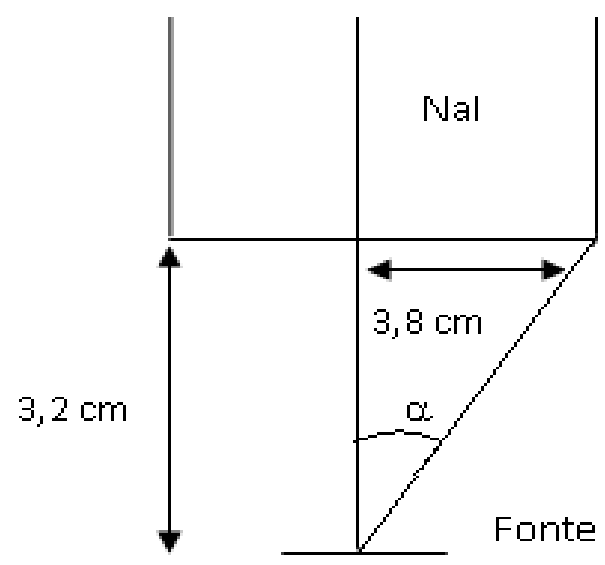

Figura 2.9 - Diagrama para análise da Eficiência Gama para o ${ }^{22} \mathrm{Na}$.

Sabendo-se que:

$$
\Omega=\frac{1}{2}(1-\cos \alpha)
$$

e

$$
\alpha=\operatorname{arctg}(3,8 / 3,2)=49,9^{\circ}
$$

Sendo

$\Omega$ = ângulo sólido

Se tivermos um cristal cintilador $\operatorname{Nal}(\mathrm{TI})$, obteremos $\Omega=0,178$ e se tivermos dois cristais cintiladores $\mathrm{Nal}(\mathrm{TI})$, vamos ter $2 \Omega=0,356$.

Sabendo-se que, para dois cristais cintiladores $\mathrm{Nal}(\mathrm{TI})$ a eficiência total,é dada por:

$\varepsilon_{T_{(512 k \mathrm{kV})}}=0,2293$, para uma radiação gama

$\varepsilon_{T\left(\beta^{+} 1,4 \mathrm{keV}\right)}=0,3397$, para duas radiações gamas

Considerando as eficiências, geométrica e a intrínseca sendo: 
$\varepsilon_{\mathrm{g}} \varepsilon_{\text {in }}=\varepsilon_{\mathrm{T}\left(\mathrm{e}^{+} 1,4 \mathrm{KeV}\right)}=0,3397$, para duas radiações gamas

Obtém para uma radiação gama com dois cristais cintiladores $\mathrm{Nal}(\mathrm{TI})$ :

$\varepsilon_{\text {in(512keV })}=\frac{0,2293}{0,356}=0,644$

Portanto para uma radiação gama de $511 \mathrm{keV}$, teremos:

$\varepsilon_{\mathrm{EF}}=2 \varepsilon_{\mathrm{T}}-\varepsilon_{\mathrm{T}} \varepsilon_{\mathrm{in}}=0,3109$

Uma relação entre a energia entre pósitrons e a eficiência total dos raios gama no $\mathrm{Nal}(\mathrm{TI})$ para fótons de aniquilação foi desenvolvida como segue:

$$
\varepsilon_{\mathrm{T}}=\mathrm{a}_{0}+\mathrm{a}_{1} \frac{1}{\left(1+\mathrm{e}^{\mathrm{z}}\right)}
$$

Onde

$$
z=\frac{\ln \left(E_{0}\right)-\ln \left(E_{1}\right)}{2,3548 F W H M}
$$

$a_{0}$ e $a_{1}$ são os valores totais assintóticos da eficiência do raio gama para a baixa energia $(1,4 \mathrm{keV})$ e alta energia $(1 \mathrm{MeV})$, respectivamente; $E_{0}$ e $E_{1}$ são as energias dos pósitrons na região de baixa energia $(1,4 \mathrm{keV})$ e após emergir do absorvedor da fonte.

A equação (2.55) foi utilizada no MCNPX, para determinar a eficiência total dos raios gama no $\mathrm{Nal}(\mathrm{TI})$, a fim de simular com maior exatidão o efeito da aniquilação dos pósitrons fora da fonte radioativa. $O$ valor $\mathrm{a}_{0}$ foi adotado de modo a considerar a correlação entre os fótons de aniquilação proveniente do mesmo pósitron, que são emitidos em sentidos opostos. Este efeito não é levado em consideração na versão atual de ESQUEMA e a detecção destes fótons de aniquilação é mais provável, porque os dois detectores de $\mathrm{Nal}$ (TI)estão em lados opostos, com relação ao contador proporcional $4 \pi$. $O$ valor $a_{0}$ foi estabelecido verificando o valor experimental da eficiência para o pico de absorção total do gama de $511 \mathrm{keV}$. 


\subsection{Modelagem do Método de Coincidências pela técnica de Monte Carlo.}

\subsubsection{Introdução}

A modelagem do método de coincidências $4 \pi \beta-\gamma$ pela técnica de Monte Carlo envolve diversos aspectos a serem considerados. Inicialmente, é efetuada uma modelagem do arranjo experimental, considerando-se todas as dimensões e materiais envolvidos no sistema. Estes dados são armazenados em um arquivo texto, que serve de entrada para o MCNPX ${ }^{[20]}$. Cada linha deste arquivo corresponde a um tipo de informação. Inicialmente são definidas as células, que corresponde a cada um dos objetos do arranjo experimental. As informações destas primeiras linhas do arquivo contêm: o tipo de material, a densidade e as superfícies que delimitam cada célula.

Alguns objetos podem conter mais de um conjunto de superfícies, como é o caso do detector $4 \pi$ proporcional e o detector de $\mathrm{Nal}(\mathrm{TI})$. O modelo final para o sistema de coincidências contém 50 células e 132 superfícies. Em seguida, têm-se as informações sobre os volumes das células e a importância que se dá para o transporte das radiações em cada uma das células. Para o caso de transporte de elétrons, pósitrons e fótons no detector $4 \pi$, adotou-se importância 1 para elétrons e fótons, em todas as células. Para o caso de transporte de fótons no detector de $\mathrm{Nal}(\mathrm{Tl})$, adotou-se importância 1 apenas para fótons, em todas as células. Em seguida, têm-se as informações sobre as energias, geometria da fonte de radiação e sobre os materiais constituintes de cada célula.

Para a visualização da geometria, utilizou-se o programa VISED, descrito a seguir.

\subsubsection{Programa VISED}

VISED ${ }^{[33]}$, abreviação de VISed EDitor Computer, é um aplicativo distribuído juntamente com o sistema de programas para simulação por Monte Carlo MCNP5/MCNPX ${ }^{[20]}$. Este programa possui uma interface gráfica que permite a criação e edição do arquivo de entrada do MCNP, contendo todas as informações sobre a geometria e materiais do sistema que está sendo simulado. 
Ele permite também observar graficamente, em tempo real, a trajetória das partículas que estão sendo transportadas no sistema, facilitando grandemente a interpretação dos resultados e a detecção de falhas no processo de criação do modelo geométrico para o sistema. No presente trabalho, este aplicativo foi utilizado para efetuar as inclusões e alterações no modelo original de Takeda ${ }^{[19]}$, com o objetivo de torná-lo mais realista. Além disso, serviu para gerar as figuras dos arranjos experimentais, apresentadas no presente trabalho.

Uma limitação do VISED é a impossibilidade de processar o transporte de pósitrons em tempo real. Espera-se que, em versões futuras, esta limitação seja eliminada.

\subsubsection{Geometria Original}

A figura 2.10 mostra o modelo utilizado originalmente para simular o sistema de coincidências $4 \pi \beta-\gamma^{[18]}$. Observa-se que os componentes foram simulados de modo simplificado. Apesar desta simplificação, os resultados obtidos para uma série de radionuclídeos foram satisfatórios, provavelmente porque as energias dos elétrons e fótons envolvidos não foram muito baixas.

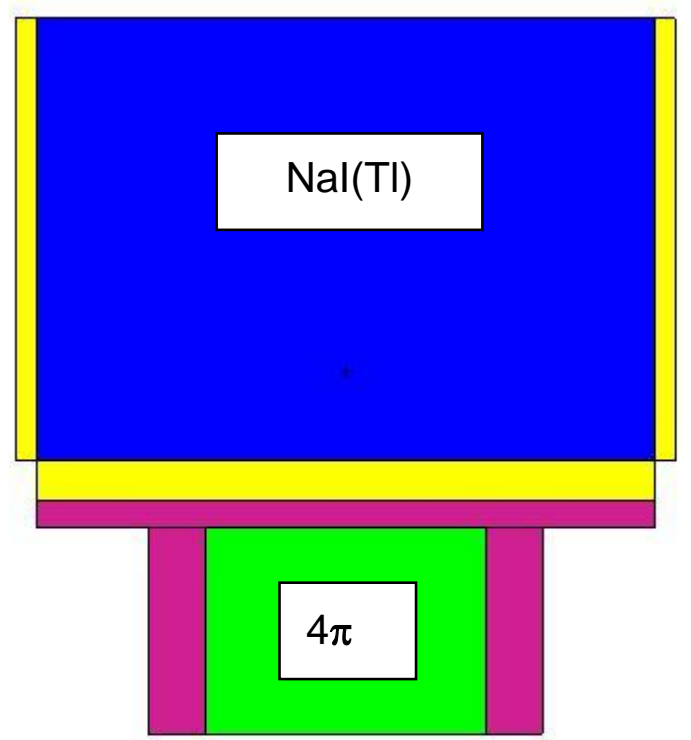

Figura 2.10 - Modelo original do sistema de coincidências $4 \pi \beta-\gamma^{[17]}$. 


\subsubsection{Geometria Modificada}

Posteriormente, Takeda ${ }^{[19]}$ desenvolveu um novo modelo para a descrição do sistema de coincidências, que é apresentado na figura 2.11. Este modelo apresentava-se com suficiente detalhamento do sistema, com exceção da parte interna do detector $4 \pi$, que necessitava melhorias. Este arranjo experimental corresponde ao sistema II, por possuir dois detectores gama de $\mathrm{Nal}(\mathrm{TI})$.

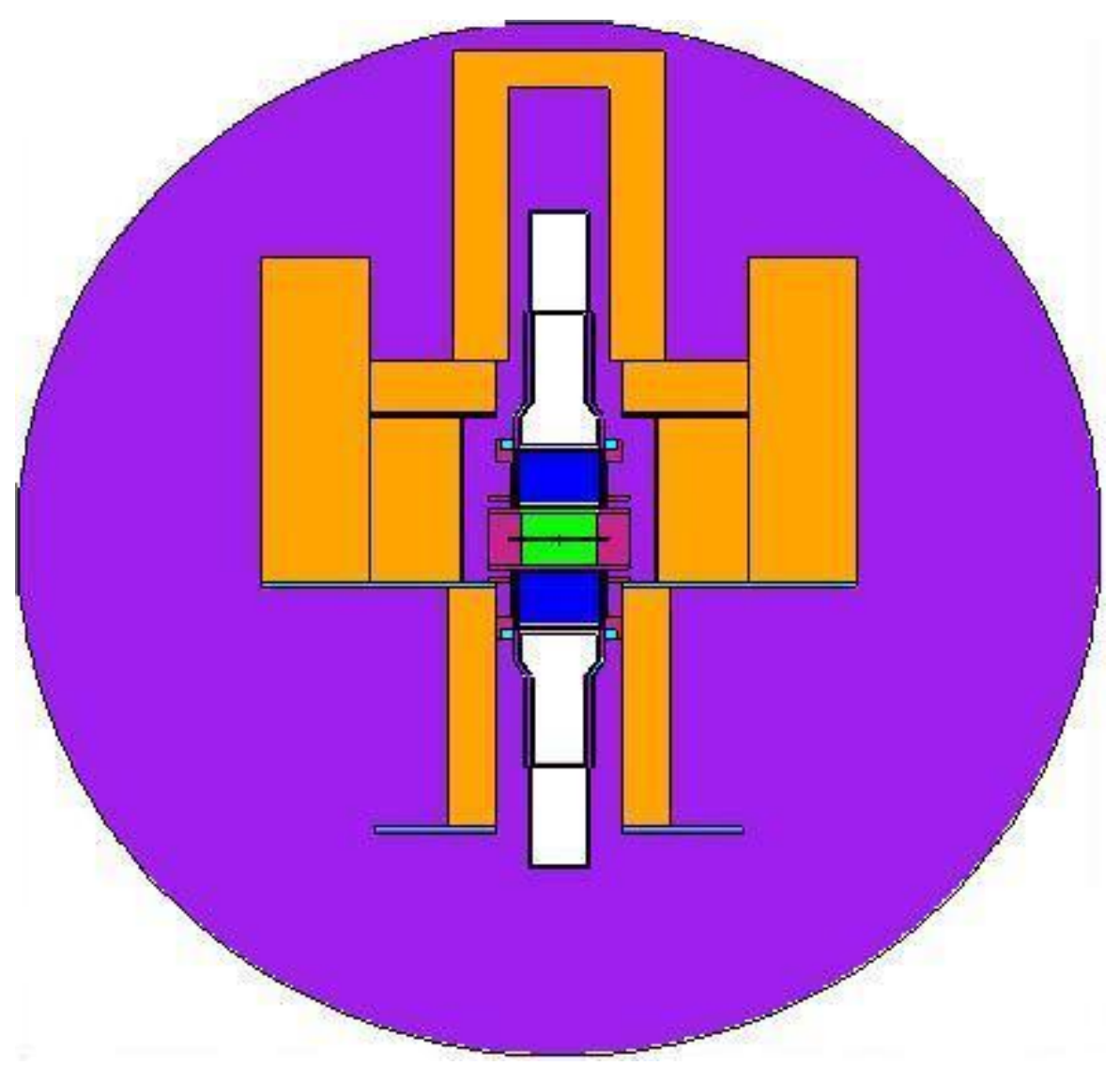

Figura 2.11- Modelo modificado do sistema de coincidências $4 \pi \beta-\gamma$ Sistema II ${ }^{[19]}$.

No presente trabalho, foram introduzidos novos componentes no interior do detector $4 \pi$, a saber:

a) degrau da lingüeta de latão, que sustenta o suporte da fonte radioativa;

b) arandela de aço, que sustenta a fonte radioativa;

c) filme de Collodion sobre a arandela;

d) filme de ouro sobre o Collodion e 
e) fonte radioativa cilíndrica, com $8 \mathrm{~mm}$ de diâmetro e espessura equivalente ao substrato do material residual da fonte, após a evaporação da solução.

Estas características são apresentadas nas figuras $2.12 \mathrm{a}$ e $2.12 \mathrm{~b} . \mathrm{O}$ objetivo destas melhorias foi o de utilizar um modelo o mais próximo possível do arranjo experimental, que se torna necessário principalmente para simular o transporte de elétrons e fótons de baixa energia.

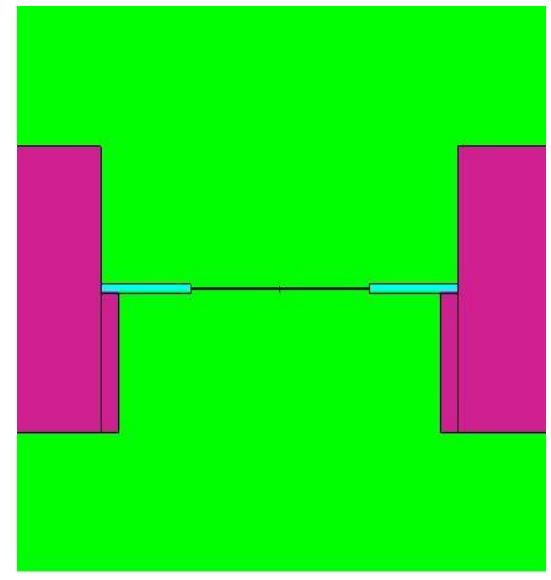

2.12a)

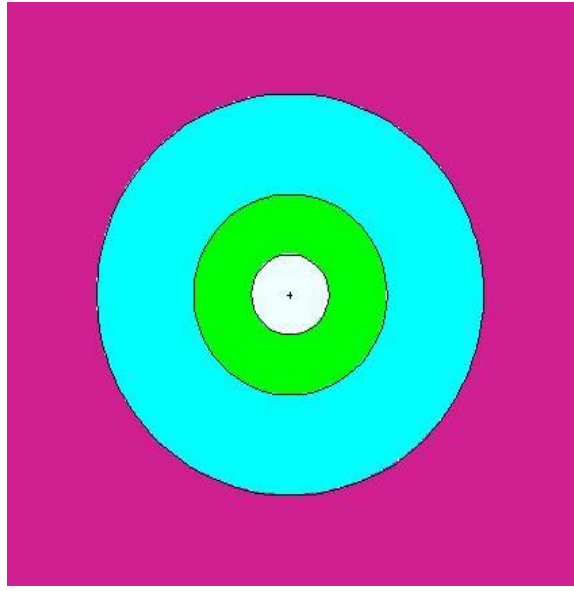

$2.12 b)$

Figura 3.12 - Modelo desenvolvido no presente trabalho, para a parte interna do detector $4 \pi$. Nestas figuras, as cores representam, respectivamente: lilás - lingüeta de latão; verde - gás do detector; azul - arandela de aço e branco o substrato da fonte radioativa. a) vista lateral do conjunto. Nesta figura, a escala na vertical está ampliada por um fator 10, em relação à horizontal. b) vista de cima, indicando os componentes do suporte da fonte radioativa.

Além do sistema de coincidências $4 \pi \beta-\gamma$ apresentado na figura 2.10 e 2.11, o LMN possui outro sistema de coincidências, denominado sistema I, que utiliza apenas um detector de $\mathrm{Nal}(\mathrm{TI})$ para a detecção gama. Este sistema foi utilizado na padronização do radionuclídeo ${ }^{22} \mathrm{Na}$, pelo Método do Pico Nuclear. Por esta razão foi efetuada, no presente trabalho, uma alteração da geometria apresentada na figura 2.10, gerando o arranjo da figura 2.13. 


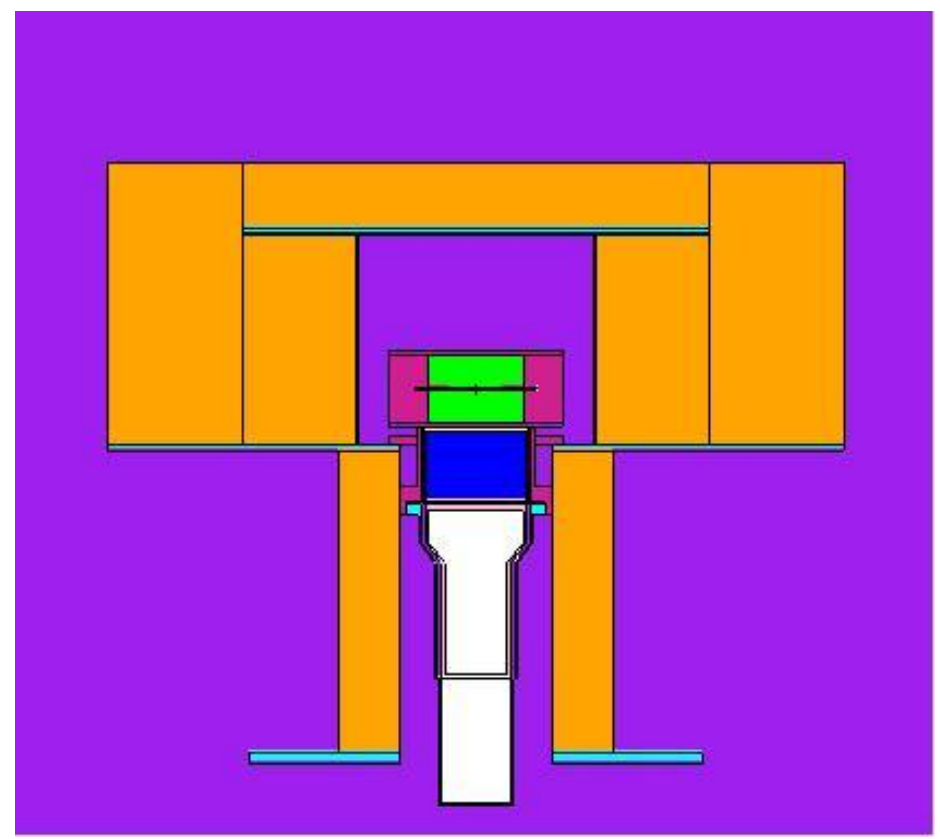

Figura 3.13- Modelo modificado do sistema de coincidências $4 \pi \beta-\gamma$, sistema I.

\subsubsection{Programas Desenvolvidos para Análise de Dados}

Para agilizar o processamento do código MCNPX e gerar as tabelas de respostas necessárias ao programa ESQPOS ${ }^{[19]}$, foram desenvolvidos vários programas de computador no presente trabalho, em linguagem FORTRAN, por meio do sistema Fortran Powerstation Versão $4.0^{[34]}$. Estes programas estão descritos a seguir.

\subsubsection{Programas ELETRONX E FOTONX}

O objetivo destes programas foi o de, a partir do arquivo de entrada para o programa MCNPX, desenvolvido por meio do aplicativo VISED, gerar todos os arquivos de entrada para as demais energias, além do arquivo de lote ( ${ }^{*}$.bat), que permite o processamento do MCNPX para cada um desses arquivos.

O programa ELETRONX foi desenvolvido para o caso de elétrons e pósitrons no detector $4 \pi$, com a geração de 196 arquivos, cobrindo a faixa de energia desde 1,4 keV até 4,0 MeV, em escala tipo degrau, ou seja: intervalos de 0,2 keV entre 1,4 keV e $10 \mathrm{keV}$; intervalos de 2,5 keV entre $10 \mathrm{keV}$ e $200 \mathrm{keV}$; intervalos de $50 \mathrm{keV}$ entre $200 \mathrm{keV}$ e $4000 \mathrm{keV}$. O vetor de energias 
correspondentes a 1,4 keV possui 102 intervalos em escala tipo degrau, ou seja: de 0 a $1000 \mathrm{eV}$ espaçados em intervalos de $10 \mathrm{eV}$, e de $1000 \mathrm{eV}$ a $1400 \mathrm{eV}$, espaçados em intervalos de $20 \mathrm{eV}$.

O programa FOTONX foi desenvolvido para o caso de fótons no detector de $\mathrm{Nal}(\mathrm{TI})$ e no detector $4 \pi$, gerando 740 arquivos, cobrindo a faixa de energia desde $48 \mathrm{keV}$ até $3036 \mathrm{keV}$, em escala linear, com espaçamento de 4 $\mathrm{keV}$ entre cada um. $\mathrm{O}$ vetor de energias correspondentes a $48 \mathrm{keV}$ possui 12 intervalos igualmente espaçados de $4 \mathrm{keV}$ cada um.

Para realizar o trabalho com o $\mathrm{Na}^{22}$, as funções de resposta teóricas de cada detector foram calculadas utilizando o MCNPX ${ }^{[31]}$. Foi desenvolvida uma descrição detalhada dos detectores e dos absorvedores em torno da fonte. Dois modelos geométricos foram criados: um para o método do Pico Soma e outro para o método do Pico Nuclear, em razão da diferença entre o número de detectores de $\mathrm{Nal}(\mathrm{TI})$ envolvidos em cada um deles. Uma escala da energia de $1,4 \mathrm{keV}$ até $4,0 \mathrm{MeV}$, foi selecionada para pósitrons no detector $4 \pi$, com um total de 298 intervalos de energia, em escala tipo degrau.

Para os raios gama a faixa de energia foi de $48 \mathrm{keV}$ a $3 \mathrm{MeV}$, em 752 intervalos uniformes de energia. Os cálculos adicionais foram executados para obter a resposta para os fótons de aniquilação detectados no $\mathrm{Nal}(\mathrm{TI})$, nas condições de diferentes absorvedores, e distâncias diferentes entre o detector $\mathrm{Nal}(\mathrm{TI})$ e o contador $4 \pi(\mathrm{PC})$. Os números de histórias foram respectivamente, $5 \times 10^{4}$ e $10^{6}$, para pósitrons e raios gama.

A função de Fermi foi modificada igualmente para pósitrons de acordo com a literatura ${ }^{[22]}$. Uma dificuldade em simular a emissão de pósitrons reside no processo da aniquilação. Quando não há nenhum absorvedor em torno da fonte radioativa, o pósitron tende a aniquilar fora da fonte, principalmente no gás ou no interior das paredes do contador proporcional.

Entretanto, a presença de absorvedores faz a aniquilação ocorrer mais perto ou eventualmente entre a fonte e o absorvedor. Este efeito muda a eficiência do raio gama para fótons de aniquilação no detector Nal. O código ESQUEMA muda a eficiência beta, quando é colocados absorvedores acima e abaixo da fonte radioativa, conseqüentemente haverá uma dependência da 
eficiência do raio gama no detector $\mathrm{Nal}(\mathrm{TI})$ com a energia do pósitron em função de Fermi e com a espessura do absorvedor.

\subsubsection{Programas MCOUT1 E MCOUT2}

O objetivo destes programas foi o de, a partir dos arquivos de saída gerados pelo programa MCNPX, gerar as tabelas de resposta dos detectores do sistema de coincidência $4 \pi \beta-\gamma$ para elétrons, fótons e pósitrons, necessárias para utilização pelo programa ESQPOS ${ }^{[19]}$.

O programa ESQPOS foi desenvolvido por Takeda para a simulação de desintegração do radionuclídeo em estudo e da curva de extrapolação para a obtenção da atividade da fonte radioativa. A versão 2.0 foi desenvolvida em base ao programa ESQUEMA ${ }^{[18]}$, com o acréscimo de algumas melhorias com o objetivo de calcular a eficiência do detector $4 \pi$ para fótons $\left(\varepsilon_{\beta \gamma}\right)$ e aumentar 0 número de intervalos de energia das tabelas de resposta para os detectores do sistema de coincidência.

O programa ESQPOS2, foi criado efetuando uma melhoria no programa ESQPOS ${ }^{[18]}$ para, alterar a função de Fermi para pósitrons. O programa ESQPOS3, foi criado efetuando uma melhoria no programa ESQPOS2, com inclusão de função sigmoidal para a eficiência gama de aniquilação.

\subsubsection{Programas DGAMA}

O objetivo deste programa foi o de, a partir do arquivo de entrada para o programa MCNPX, desenvolvido por meio do aplicativo VISED, gerar os arquivos de entrada para diferentes distâncias entre o detector de $\mathrm{Nal}(\mathrm{TI})$ e 0 detector $4 \pi$, por meio do Sistema I, apresentado na figura 2.13. Este procedimento foi necessário para gerar as tabelas de respostas para fótons no $\mathrm{Nal}(\mathrm{TI})$ necessárias para a análise do ${ }^{22} \mathrm{Na}$, pelo Método do Pico Nuclear (vide seção 2.3.3). Foram geradas as tabelas de eficiência gama de pico e eficiência gama total para as distâncias de $1 \mathrm{~cm}$ a $15 \mathrm{~cm}$. 
Para reduzir o tempo de processamento foram determinadas faixas de energias de interesse entre $1022 \mathrm{keV}$ e $1274 \mathrm{keV}$, que incluem as energias do decaimento do ${ }^{22} \mathrm{Na}$ que são: 1274,582 keV e 511,003 keV.

\subsubsection{Programa EALUM}

O objetivo deste programa foi, a partir do arquivo de entrada para o programa MCNPX, gerar os arquivos e entradas, desenvolvido por meio do aplicativo VISED, para fótons, variando o número de absorvedores de Alumínio (Al) e Mylar para o Sistema II, apresentado na figura 2.11 Foi realizado este procedimento para determinação da eficiência no Nal(TI) no pico $511 \mathrm{keV}$ (aniquilação) e para diversas energias de pósitrons emitidos da fonte, em duas condições: sem absorvedor e com 10 absorvedores, que corresponde ao método do Pico Soma. Os resultados obtidos foram utilizados para o programa ESQPOS2, para obter o parâmetro $h$, que é a probabilidade da emissão de pósitrons. 


\section{$3 \quad$ RESULTADOS OBTIDOS E DISCUSSÃO}

Neste capítulo são apresentados os resultados obtidos, utilizando a metodologia de padronização de radionuclídeos pelo método da coincidência $4 \pi \beta$ $\gamma$

\subsection{Padronização do ${ }^{60} \mathrm{Co}$}

A curva de extrapolação da eficiência é apresentada na figura 3.1. Os valores de atividade e parâmetro de eficiência são apresentados na tabela 3.1. Observa-se uma boa concordância entre os dados experimentais e a previsão teórica por Monte Carlo, indicando que o procedimento seguido para a modelagem pode ser considerado satisfatório.

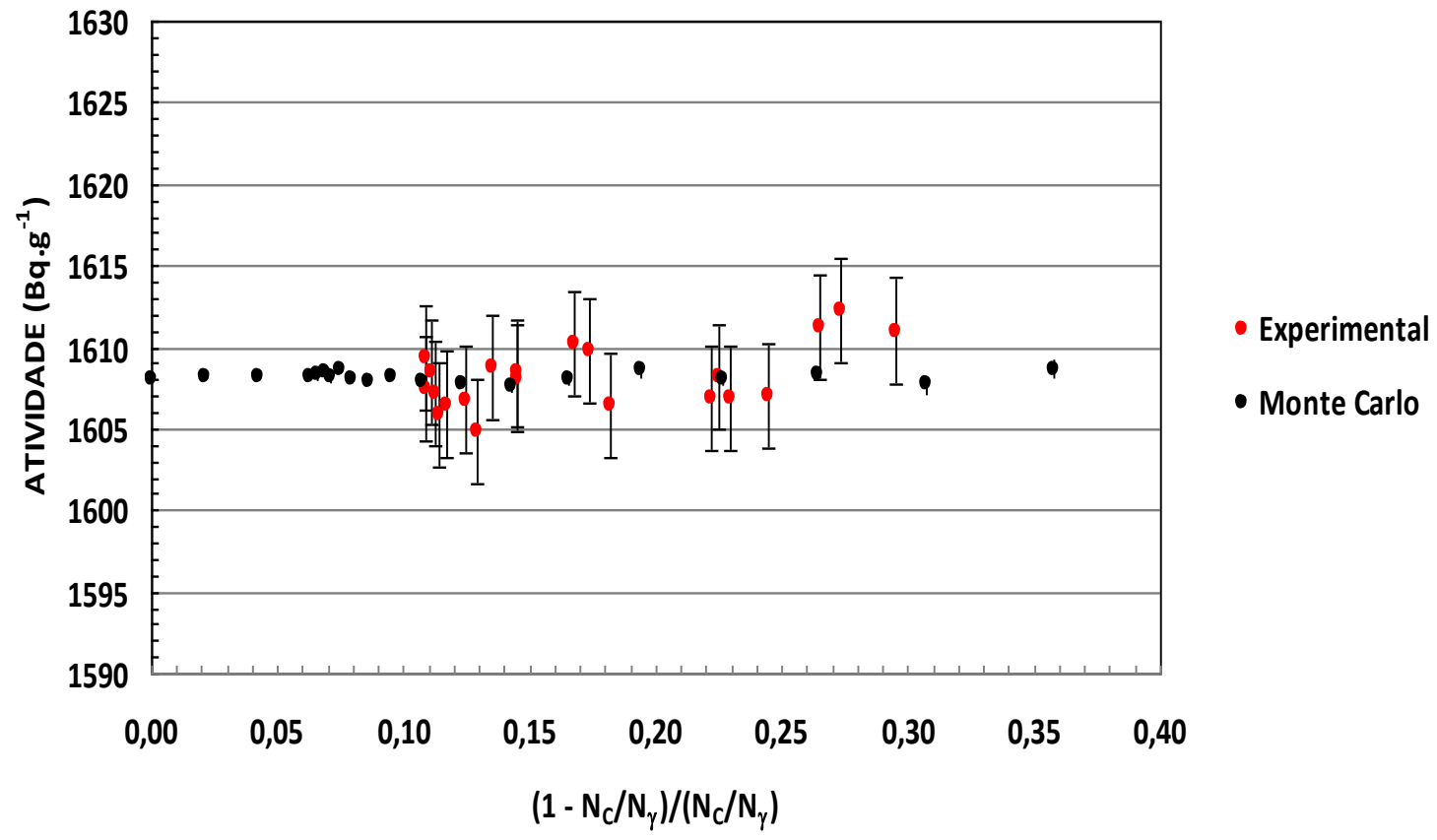

Figura 3.1 - Curva de Extrapolação entre a atividade observada e o parâmetro de ineficiência para ${ }^{60} \mathrm{Co}$. 
Tabela 3.1 - Medida do ${ }^{60} \mathrm{Co}$ - fonte 14109 - método coincidência $4 \pi \beta-\gamma$-sistema II.

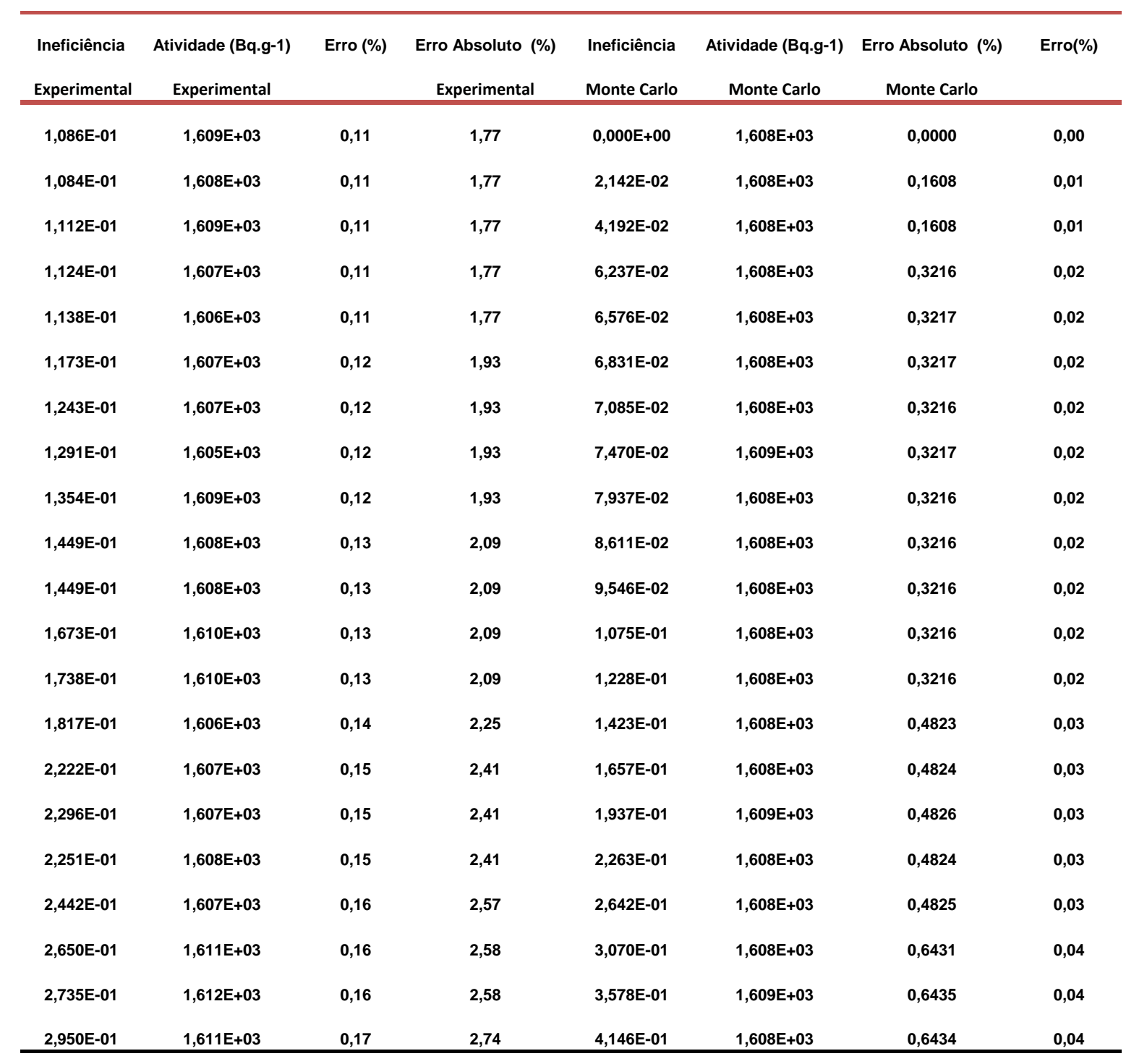

A figura 3.2 mostra o comportamento da curva de eficiência do detector $4 \pi$ para fótons $\left(\varepsilon_{\beta \gamma}\right)$, obtida por meio do código MCNPX. Esta figura foi obtida, utilizando o modelo final para a geometria do arranjo experimental, sem absorvedores sobre a fonte radioativa. Estes resultados foram obtidos com $10^{4}$ histórias por energia, em intervalos de $4 \mathrm{keV}$, e reunidos em grupos de 10, totalizando $40 \mathrm{keV}$ para cada intervalo.

Observa-se um excelente acordo com os valores experimentais obtidos por Moura ${ }^{[10]}$, apresentados na figura 3.3, conforme comparação efetuada entre a parte experimental (tabela 3.1 e resultados de Moura) para a região acima de $300 \mathrm{keV}$. Um aspecto interessante é o aumento da eficiência, para baixas energias, chegando a valores próximos a 93\% em 4,0 keV. Esta informação torna- 
se importante para a análise de radionuclídeos contendo fótons de baixa energia, tais como raios- $X$ provenientes de radionuclídeos que decaem por captura eletrônica.

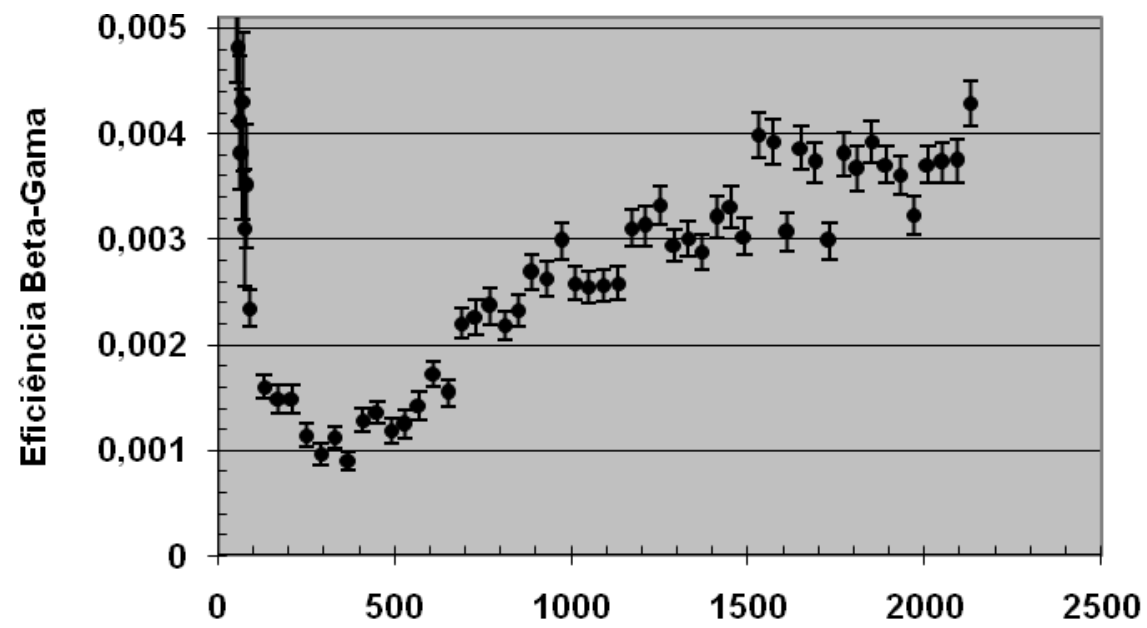

Energia Gama (keV)

Figura 3.2 - Eficiência do detector $4 \pi$ para fótons $\left(\varepsilon_{\beta \gamma}\right)$, obtida pelo programa MCNPX.

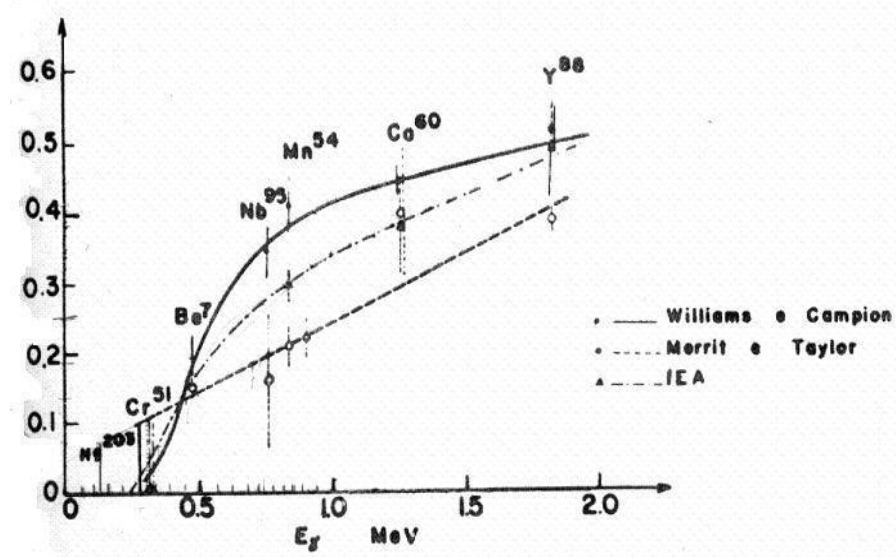

Figura 3.3 - Eficiência (em \%) do detector $4 \pi$ para fótons $\left(\varepsilon_{\beta \gamma}\right)$ obtidos por Moura $^{[10]}$.

A figura 3.4 mostra o espectro diferencial de energia depositada no detector $4 \pi$ para pósitrons, correspondentes às energias de 1,4 keV, $10 \mathrm{keV}, 100$ $\mathrm{keV}$ e $1000 \mathrm{keV}$. Observa-se que o comportamento da energia depositada é muito 
diferente do observado para elétrons, em razão da deposição de energia pelos gamas de aniquilação. Como o total de energia desses gamas atinge $1022 \mathrm{keV}$, a energia depositada pode ser muito maior que a energia do pósitron.

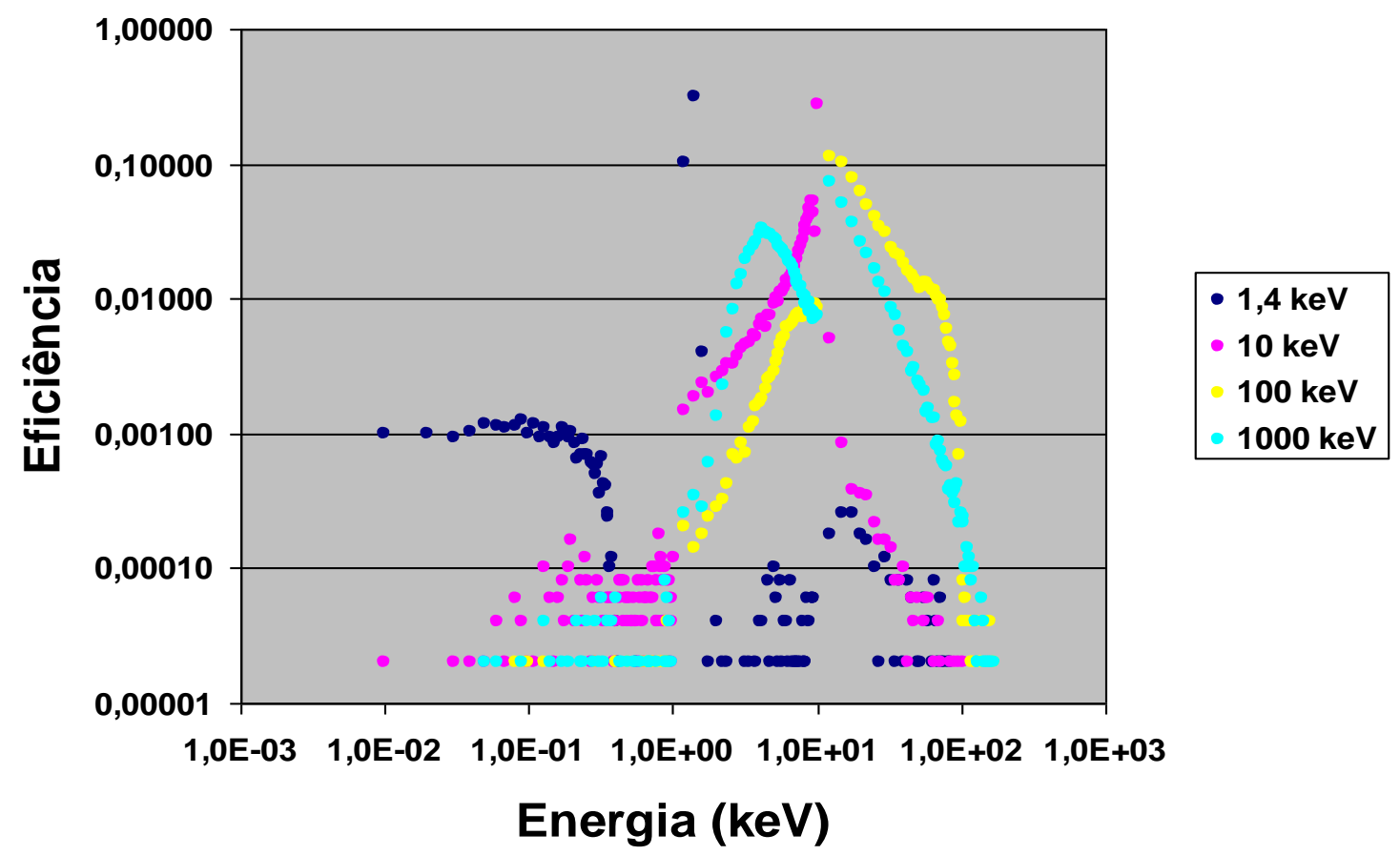

Figura 3.4 - Espectro diferencial de energia depositada no detector $4 \pi$ para pósitrons, determinados pelo programa MCNPX.

\subsection{Padronização do ${ }^{18} \mathrm{~F}$}

Utilizando-se $\mathrm{O}$ esquema da figura 2.6 para $\circ{ }^{18} \mathrm{~F}$, $\mathrm{O}$ programa ESQPOS3 foi processado, gerando o espectro gama para o $\mathrm{Nal}(\mathrm{TI})$ apresentado na figura 3.5. Nota - se claramente o aparecimento do pico de aniquilação em 511 keV, e o Pico Soma em 1022 keV. Nesta figura, considerou-se que este gama tenha sido produzido no interior da fonte radioativa. 


\section{Espectro gama do ${ }^{18} \mathrm{~F}$ no Nal(TI) - Monte Carlo}

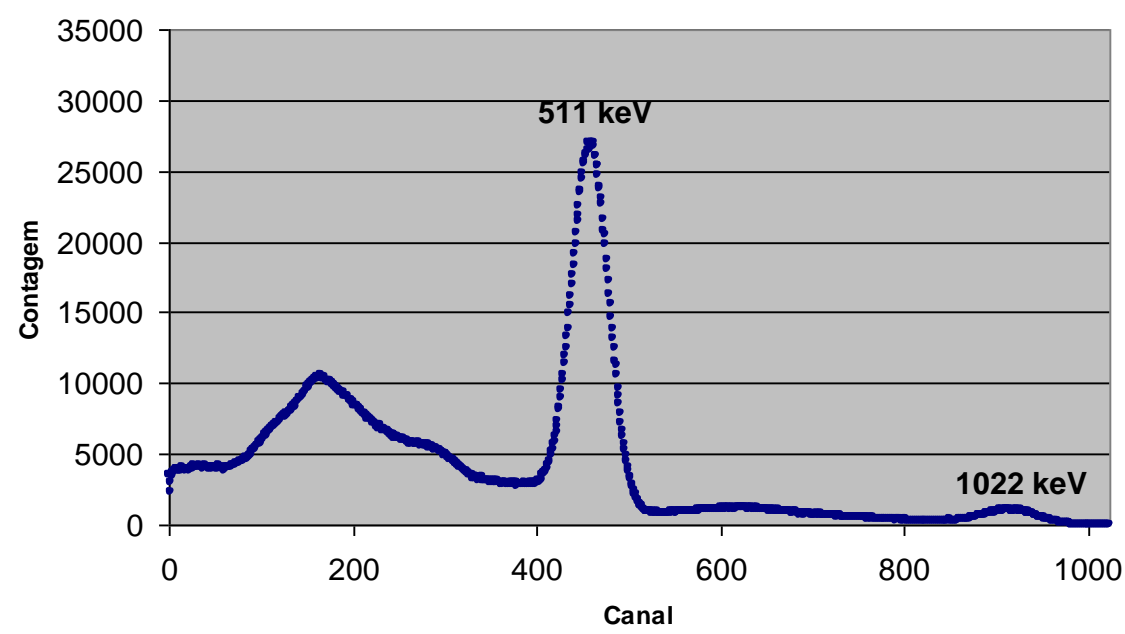

Figura 3.5 - Espectro gama no $\mathrm{Nal}(\mathrm{TI})$ previsto pelo programa ESQPOS2, para $0{ }^{18} \mathrm{~F}$.

Como complemento destes estudos foi efetuado uma determinação experimental da curva de extrapolação para $0{ }^{18} \mathrm{~F}$, nas instalações do LMN, utilizando-se o sistema II. Estes dados foram comparados com a curva teórica prevista pelo método de Monte Carlo. Conforme as tabelas 3.2 e 3.3, e os gráficos da curva de extrapolação 3.6 e 3.7, respectivamente para o Pico Soma e para o Gama de Aniquilação.

Tabela 3.2 - Medida do ${ }^{18} \mathrm{~F}$, para gerar a curva de extrapolação para o Pico Soma e Monte Carlo - método coincidência $4 \pi \beta-\gamma$ - sistema II.

\begin{tabular}{cccccc}
\hline $\begin{array}{c}\text { Ineficiência } \\
\text { Experimental }\end{array}$ & $\begin{array}{c}\text { Atividade (kBq-g-1) } \\
\text { Experimental }\end{array}$ & $\begin{array}{c}\text { Ineficiência } \\
\text { Erro(\%) }\end{array}$ & $\begin{array}{c}\text { Atividade (kBq-g-1) } \\
\text { Monte Carlo }\end{array}$ & Monte Carlo & Erro(\%) \\
\hline $\mathbf{0 , 0 8}$ & $\mathbf{4 , 4 9 E + 0 5}$ & $\mathbf{0 , 2 4}$ & $\mathbf{0 , 0 0}$ & $\mathbf{4 , 4 9 E + 0 5}$ & $\mathbf{0 , 0 1}$ \\
$\mathbf{0 , 1 5}$ & $\mathbf{4 , 4 3 E + 0 5}$ & $\mathbf{0 , 2 9}$ & $\mathbf{0 , 0 0}$ & $\mathbf{4 , 4 9 E + 0 5}$ & $\mathbf{0 , 0 1}$ \\
$\mathbf{0 , 0 9}$ & $\mathbf{4 , 4 6 E + 0 5}$ & $\mathbf{0 , 3 0}$ & $\mathbf{0 , 0 1}$ & $\mathbf{4 , 4 9 E + 0 5}$ & $\mathbf{0 , 0 3}$ \\
$\mathbf{0 , 0 4}$ & $\mathbf{4 , 4 8 E + 0 5}$ & $\mathbf{0 , 3 2}$ & $\mathbf{0 , 0 5}$ & $\mathbf{4 , 4 9 E + 0 5}$ & $\mathbf{0 , 0 6}$ \\
$\mathbf{0 , 0 2}$ & $\mathbf{4 , 5 2 E + 0 5}$ & $\mathbf{0 , 3 4}$ & $\mathbf{0 , 1 2}$ & $\mathbf{4 , 4 9 E + 0 5}$ & $\mathbf{0 , 0 8}$ \\
$\mathbf{0 , 0 2}$ & $\mathbf{4 , 5 3 E + 0 5}$ & $\mathbf{0 , 4 0}$ & $\mathbf{0 , 2 2}$ & $\mathbf{4 , 5 0 E + 0 5}$ & $\mathbf{0 , 1 1}$ \\
$\mathbf{0 , 0 2}$ & $4,48 E+05$ & $\mathbf{0 , 5 2}$ & $\mathbf{0 , 3 2}$ & $\mathbf{4 , 4 9 E + 0 5}$ & $\mathbf{0 , 1 4}$ \\
$\mathbf{0 , 0 1}$ & $4,48 E+05$ & $\mathbf{0 , 5 5}$ & $\mathbf{0 , 4 5}$ & $\mathbf{4 , 5 0 E + 0 5}$ & $\mathbf{0 , 1 6}$ \\
$\mathbf{0 , 0 3}$ & $4,51 E+05$ & $\mathbf{0 , 4 9}$ & $\mathbf{0 , 5 7}$ & $\mathbf{4 , 5 0 E + 0 5}$ & $\mathbf{0 , 1 8}$ \\
$\mathbf{0 , 0 3}$ & $\mathbf{4 , 5 4 E + 0 5}$ & $\mathbf{0 , 4 3}$ & $\mathbf{0 , 7 0}$ & $\mathbf{4 , 5 0 E + 0 5}$ & $\mathbf{0 , 1 9}$ \\
\hline
\end{tabular}


Pico Soma

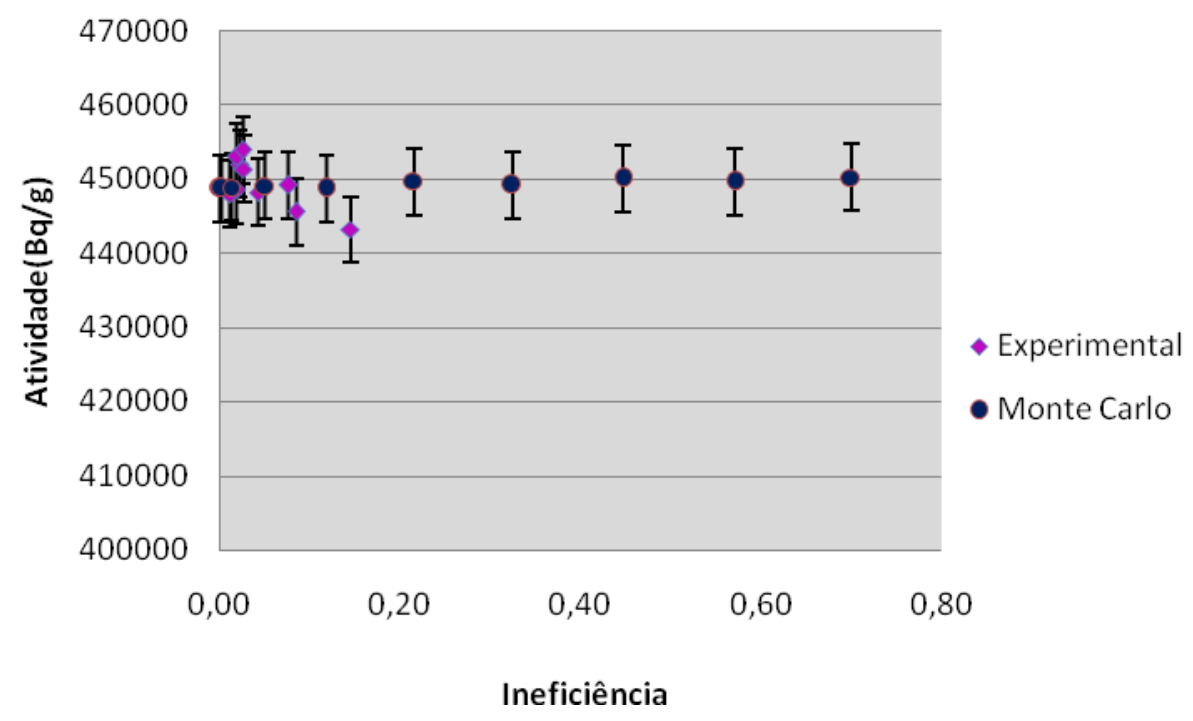

Figura 3.6 - Curva de Extrapolação entre a atividade observada e o Parâmetro, de ineficiência para o Pico Soma.

Tabela 3.3 - Medidas do ${ }^{18} \mathrm{~F}$, para gerar a curva de extrapolação para o Gama de Aniquilação e Monte Carlo - método coincidência $4 \pi \beta-\gamma$-sistema II.

\begin{tabular}{|c|c|c|c|c|c|}
\hline Ineficiência & Atividade (kBq-g- & & Ineficiência & Atividade (kBq-g-1) & \\
\hline Experimental & Experimental & Erro(\%) & Monte Carlo & Monte Carlo & Erro(\%) \\
\hline 0,08 & 4,52E+05 & $\mathbf{0 , 2 0}$ & 0,00 & 4,46E+05 & 0,00 \\
\hline 0,14 & 4,42E+05 & 0,21 & 0,00 & 4,46E+05 & 0,00 \\
\hline 0,08 & 4,44E+05 & 0,21 & 0,01 & 4,46E+05 & 0,01 \\
\hline 0,04 & 4,46E+05 & 0,22 & 0,05 & 4,46E+05 & 0,01 \\
\hline 0,02 & $4,50 E+05$ & 0,23 & 0,12 & 4,46E+05 & 0,02 \\
\hline 0,01 & $4,50 E+05$ & 0,24 & 0,22 & 4,46E+05 & 0,03 \\
\hline 0,01 & 4,44E+05 & 0,27 & $\mathbf{0 , 3 3}$ & 4,47E+05 & 0,03 \\
\hline 0,01 & 4,46E+05 & $\mathbf{0 , 3 0}$ & 0,45 & 4,47E+05 & 0,04 \\
\hline 0,01 & 4,44E+05 & $\mathbf{0 , 3 0}$ & 0,57 & 4,47E+05 & 0,04 \\
\hline 0,01 & 4,47E+05 & $\mathbf{0 , 3 0}$ & 0,70 & $4,48 E+05$ & 0,05 \\
\hline
\end{tabular}




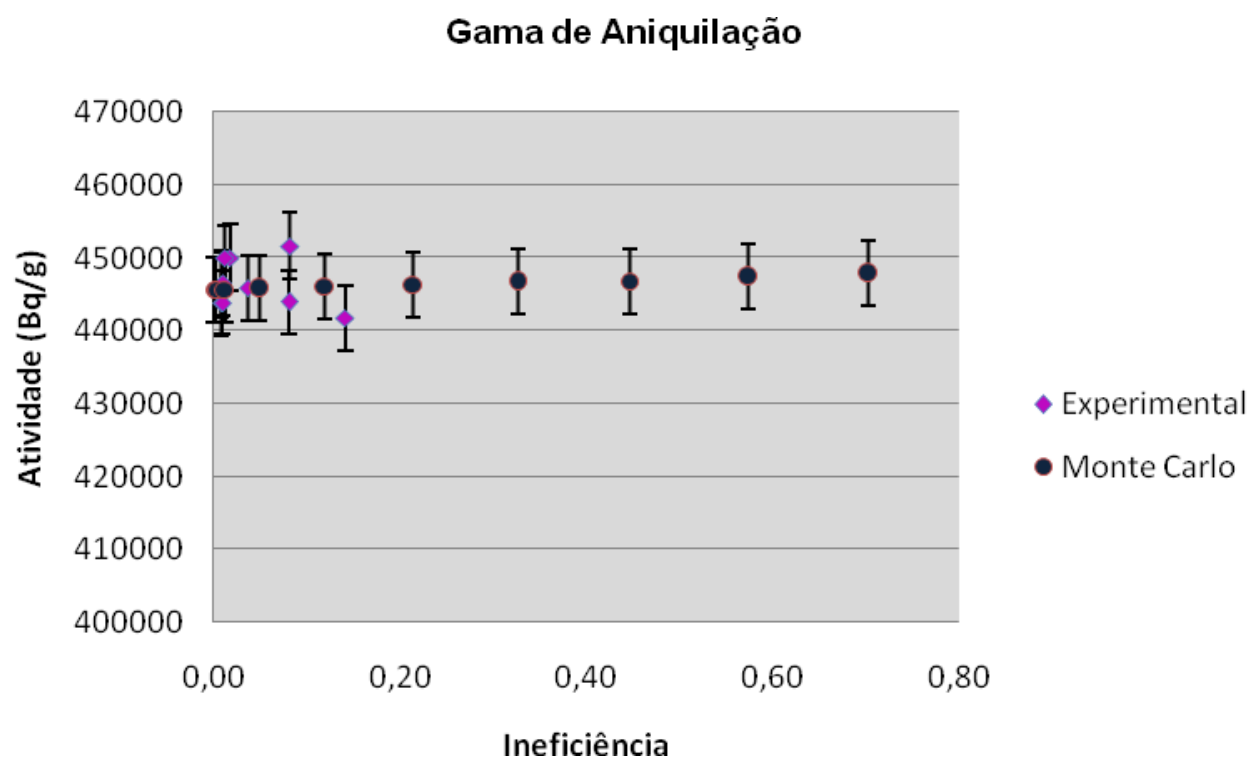

Figura 3.7 - Curva de Extrapolação entre a atividade observada e o parâmetro de ineficiência para o Pico Nuclear.

Verifica-se que as curvas de extrapolação da eficiência apresentada nas figuras 3.6 e 3.7, possuem uma boa concordância entre os dados experimentais e a previsão teórica por Monte Carlo, indicando-se que os procedimentos seguidos para a modelagem podem ser considerados satisfatórios.

\subsection{Padronização do ${ }^{22} \mathrm{Na}$}

Utilizando-se o esquema da figura 2.8 para $0{ }^{22} \mathrm{Na}$, o programa ESQPOS2 foi processado, gerando o espectro gama para o $\mathrm{Nal}(\mathrm{TI})$ apresentado na figura 3.8. Nota-se claramente o aparecimento do pico de aniquilação em 511 keV, o pico soma em $1022 \mathrm{keV}$, o pico gama nuclear em $1275 \mathrm{keV}$ e o pico soma (aniquilação + nuclear) em $1786 \mathrm{keV}$. Estas características indicam que o modelo para o esquema de desintegração pode ser considerado satisfatório. 


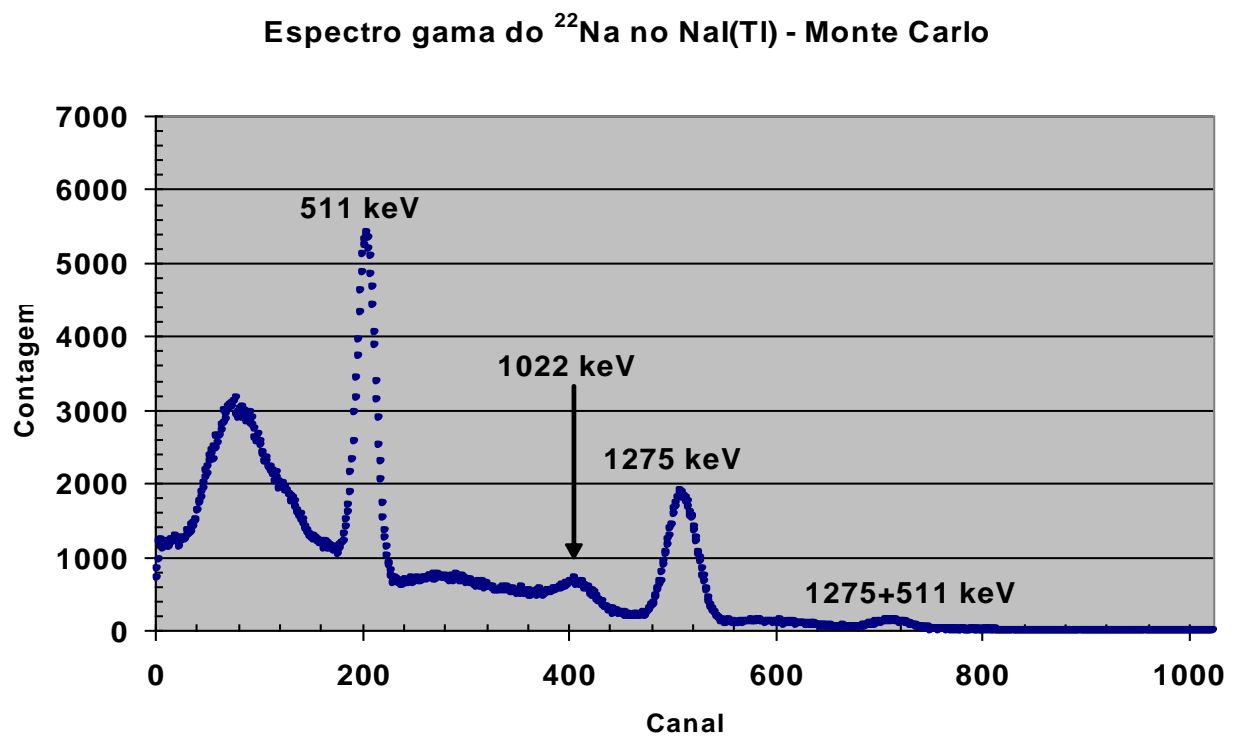

Figura 3.8 - Espectro gama no $\mathrm{Nal}(\mathrm{TI})$ previsto pelo programa ESQPOS 2, para o ${ }^{22} \mathrm{Na}$.

Com estes novos cálculos, foi possível determinar o comportamento da curva de extrapolação para diferentes pontos de aniquilação dos pósitrons. Sem a presença de absorvedores, os pósitrons tendem a se aniquilar longe da fonte, sendo que muitos irão se aniquilar nas paredes do detector $4 \pi$. Como conseqüência, a eficiência do $\mathrm{Nal}(\mathrm{TI})$ para os gamas de aniquilação sofrerá alterações, com relação ao espectro apresentado na figura 3.8, que foi determinada considerando a posição da fonte radioativa como origem do gama de aniquilação.

Na tabela 3.4, são apresentadas a eficiência Gama no Pico de $511 \mathrm{keV}$ e Eficiência Gama total no $\mathrm{Nal}(\mathrm{Tl})$, e as figuras 3.9 e 3.10 representam os espectros das respectivas eficiências, geradas pelo MCNPX, em função das energias emitidas pelos pósitrons da fonte, na condição sem absorvedor, e a tabela 3.5, e as figuras 3.11 e 3.12 obtidas com dez absorvedores. O comportamento segue aproximadamente a forma dada pela equação (2.56). Os valores de $a_{0}$ e do $a_{1}$ resultaram em 0,34 e 0,07 , respectivamente, usando os dois cristais de $\mathrm{Nal}(\mathrm{TI})$. 
Tabela 3.4- Dados gerados pelo programa MCNPX, contendo a eficiência Gama no pico de 511 keV e eficiência Gama total, sem absorvedor.

\begin{tabular}{|c|c|c|c|c|c|c|}
\hline $\begin{array}{c}\text { Energia } \\
\text { Pósitrons (keV) }\end{array}$ & $\begin{array}{l}\text { Eficiciência } \\
\text { Gama Total }\end{array}$ & Erro (\%) & $\begin{array}{l}\text { Pontos } \\
\text { Ajustados }\end{array}$ & $\begin{array}{c}\text { Eficiência } \\
\text { Gama } 511 \text { keV (cor) }\end{array}$ & Erro (\%) & $\begin{array}{l}\text { Pontos } \\
\text { Ajustados }\end{array}$ \\
\hline 1,4 & $3,40 \mathrm{E}-01$ & 0,75 & 0,34 & $1,00 \mathrm{E}-01$ & 1,72 & 0,10 \\
\hline 3 & $3,38 \mathrm{E}-01$ & 0,75 & 0,34 & 9,61E-02 & 1,76 & 0,10 \\
\hline 10 & $3,46 \mathrm{E}-01$ & 0,75 & 0,34 & 1,01E-01 & 1,71 & 0,10 \\
\hline 30 & $3,56 \mathrm{E}-01$ & 0,73 & 0,36 & $1,18 \mathrm{E}-01$ & 1,58 & 0,12 \\
\hline 50 & 3,87E-01 & 0,69 & 0,38 & 1,53E-01 & 1,37 & 0,15 \\
\hline 100 & 4,01E-01 & 0,66 & 0,40 & 1,67E-01 & 1,30 & 0,17 \\
\hline 300 & 4,11E-01 & 0,65 & 0,41 & $1,75 \mathrm{E}-01$ & 1,27 & 0,17 \\
\hline 1000 & 4,11E-01 & 0,65 & 0,41 & $1,68 \mathrm{E}-01$ & 1,30 & 0,17 \\
\hline
\end{tabular}

EFIC. GAMA TOTAL

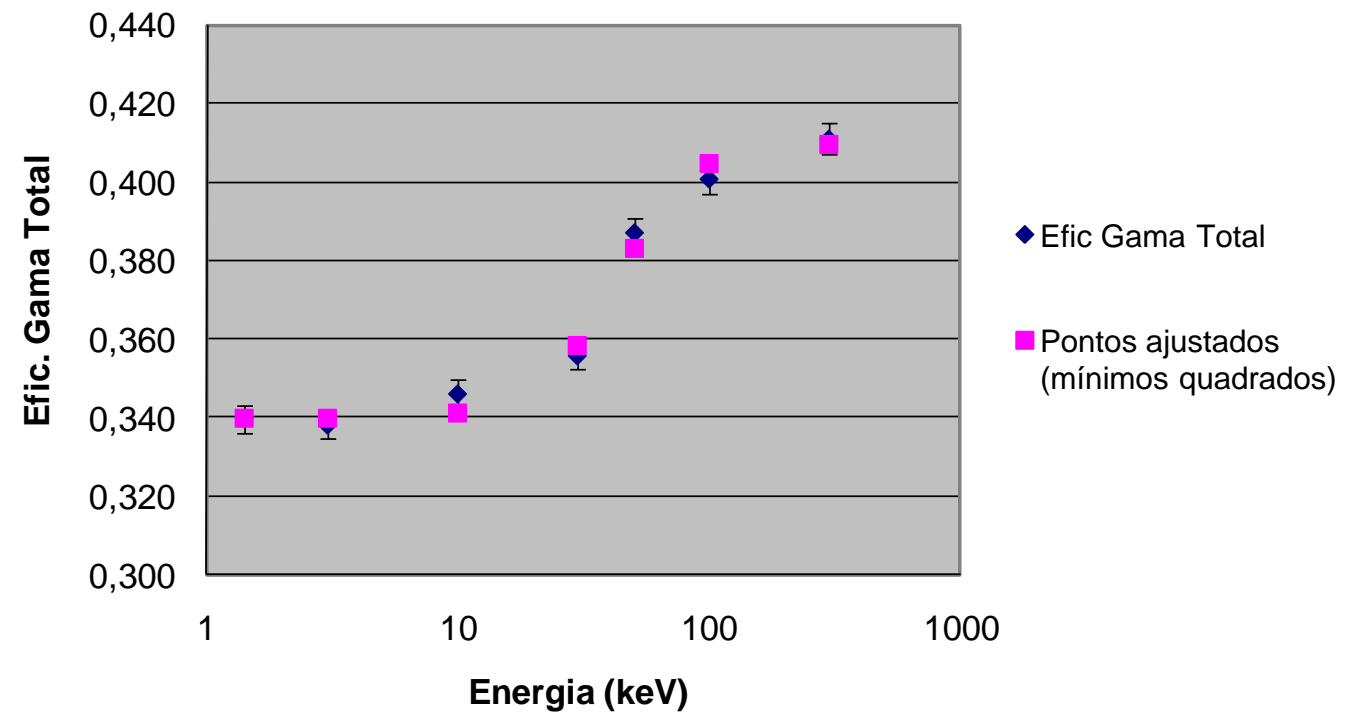

Figura 3.9 - Espectro da eficiência gama total em função da energia, sem absorvedor. 


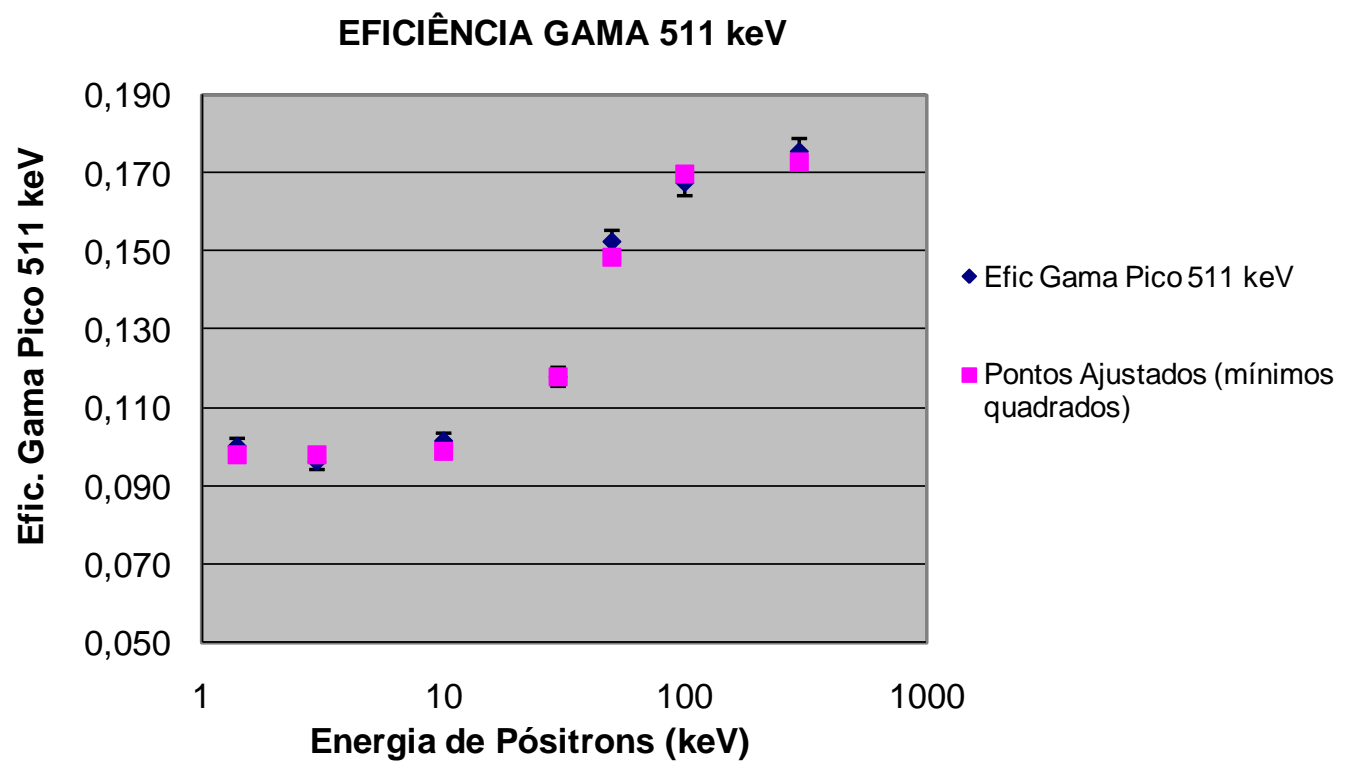

Figura 3.10 - Comportamento da eficiência gama Pico em 511 keV em função da energia, sem absorvedor.

Tabela 3.5 - Dados gerados pelo programa MCNPX, contendo a eficiência Gama no pico de $511 \mathrm{keV}$ e eficiência Gama total, com dez absorvedores.

\begin{tabular}{|c|c|c|c|c|}
\hline $\begin{array}{c}\text { Energia } \\
\text { pósitrons (keV) }\end{array}$ & $\begin{array}{l}\text { Eficiência } \\
\text { Gama Total }\end{array}$ & Erro (\%) & $\begin{array}{c}\text { Eficiência } \\
\text { Gama } 511 \text { keV }\end{array}$ & Erro (\%) \\
\hline 1,4 & $4,30 \mathrm{E}-01$ & 0,51 & 6,33E-02 & 1,72 \\
\hline 10 & 4,33E-01 & 0,51 & 6,33E-02 & 1,72 \\
\hline 20 & $4,32 \mathrm{E}-01$ & 0,51 & $6,30 \mathrm{E}-02$ & 1,73 \\
\hline 30 & $4,40 E-01$ & 0,50 & 6,39E-02 & 1,71 \\
\hline 50 & 4,39E-01 & 0,51 & 6,64E-02 & 1,68 \\
\hline 100 & $5,32 E-01$ & 0,42 & 1,02E-01 & 1,33 \\
\hline 300 & 5,67E-01 & 0,39 & 1,04E-01 & 1,31 \\
\hline 3000 & 5,66E-01 & 0,39 & 9,98E-02 & 1,34 \\
\hline
\end{tabular}




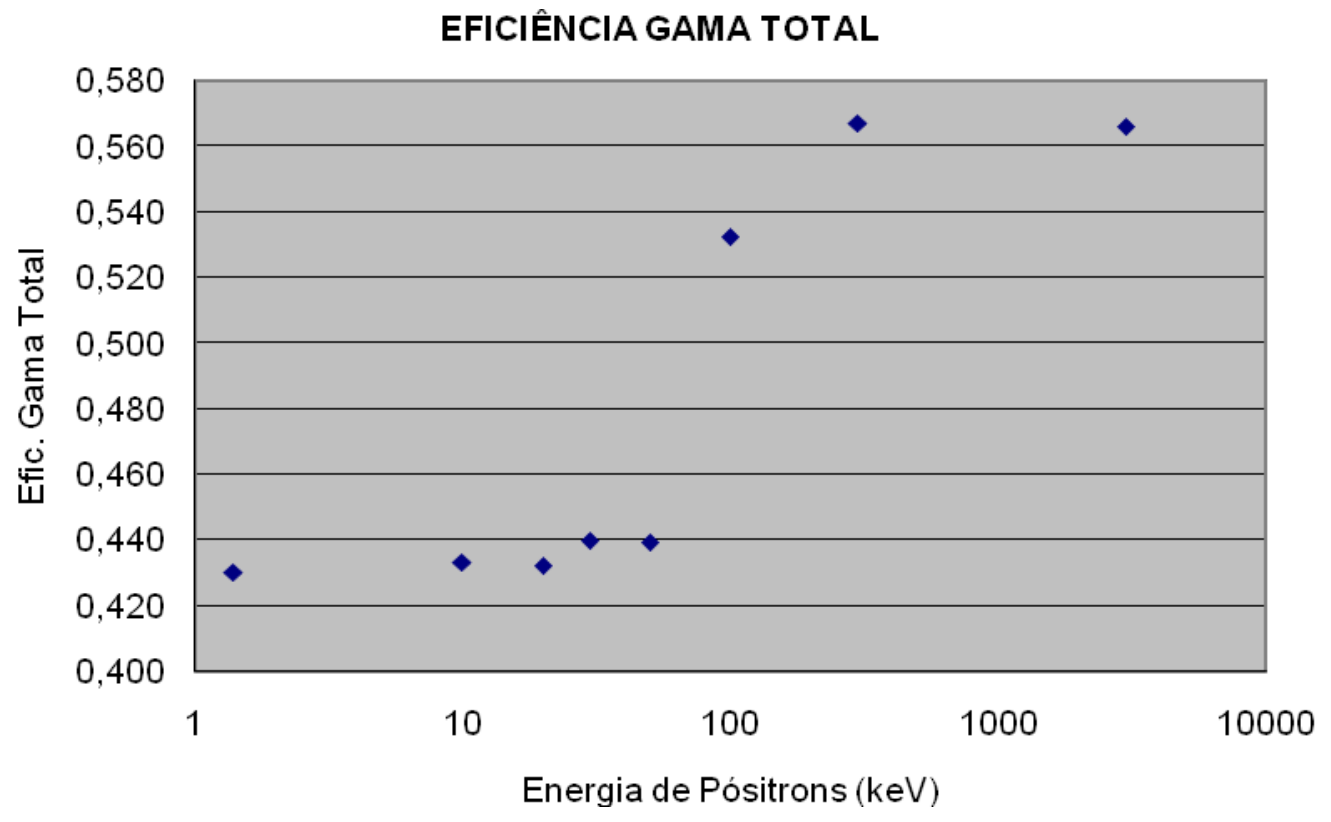

Figura 3.11 - Comportamento da eficiência gama total em função da energia, para dez absorvedores.

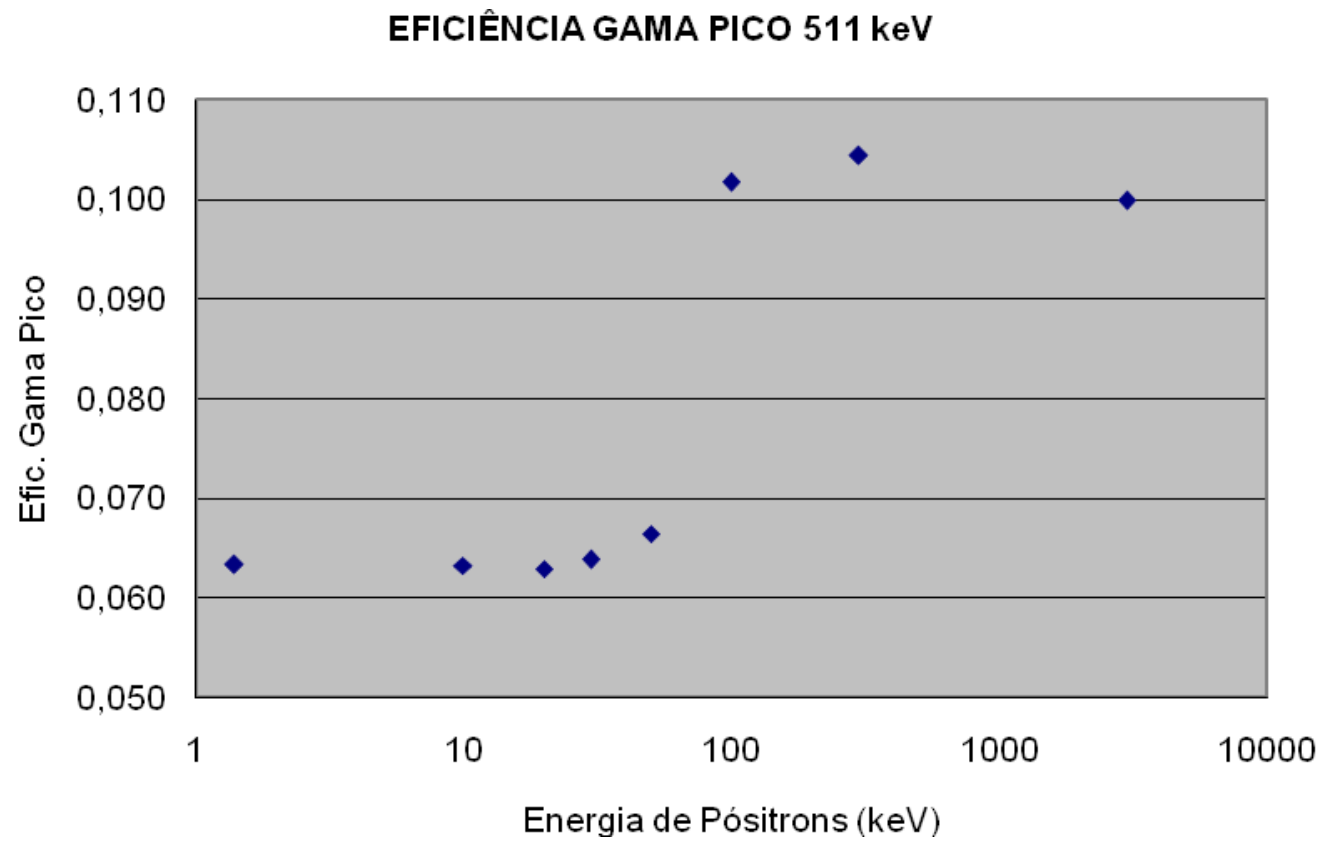

Figura 3.12 - Comportamento da eficiência gama de pico em função da energia, para dez absorvedores.

A figura 3.13 mostra a curva de extrapolação experimental obtida por meio do método do Pico-Soma, variando a espessura do absorvedor colocado 
acima e abaixo da fonte radioativa. Os pontos experimentais têm uma tendência aproximadamente linear com inclinação positiva, causada pela variação na eficiência do raio gama do $\mathrm{Nal}(\mathrm{TI})$ para fótons de aniquilação, produzidos próximos ou distantes da fonte radioativa. Próximo à fonte, a eficiência do raio gama tende a ser mais baixa, em razão do ângulo sólido menor entre o ponto da aniquilação e o detector do $\mathrm{Nal}(\mathrm{TI})$. Pelo Método de Monte Carlo os pontos calculados estão bem próximos dos pontos experimentais.

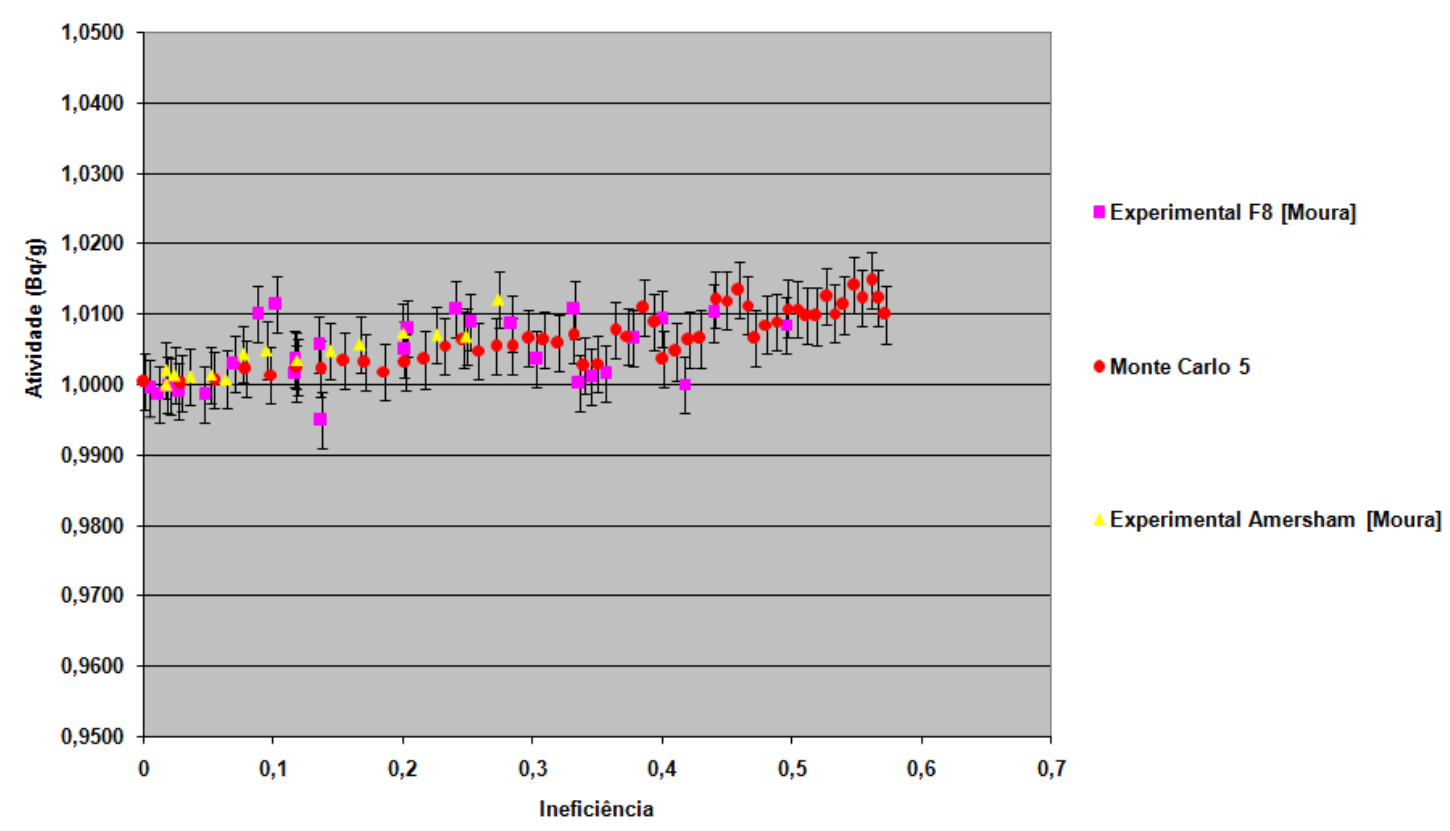

Figura 3.13 - Curva de Extrapolação para o Pico-Soma: comparação das curvas entre os dados experimentais e método de Monte Carlo.

A figura 3.14 mostra a curva da extrapolação obtida para o método do Pico Nuclear. Diversas fontes radioativas foram medidas a diferentes distâncias entre a fonte e o detector de $\mathrm{Nal}(\mathrm{TI})$. Os resultados são apresentados juntamente com o cálculo de Monte Carlo. Observa-se um excelente acordo entre os valores teóricos e experimentais. 


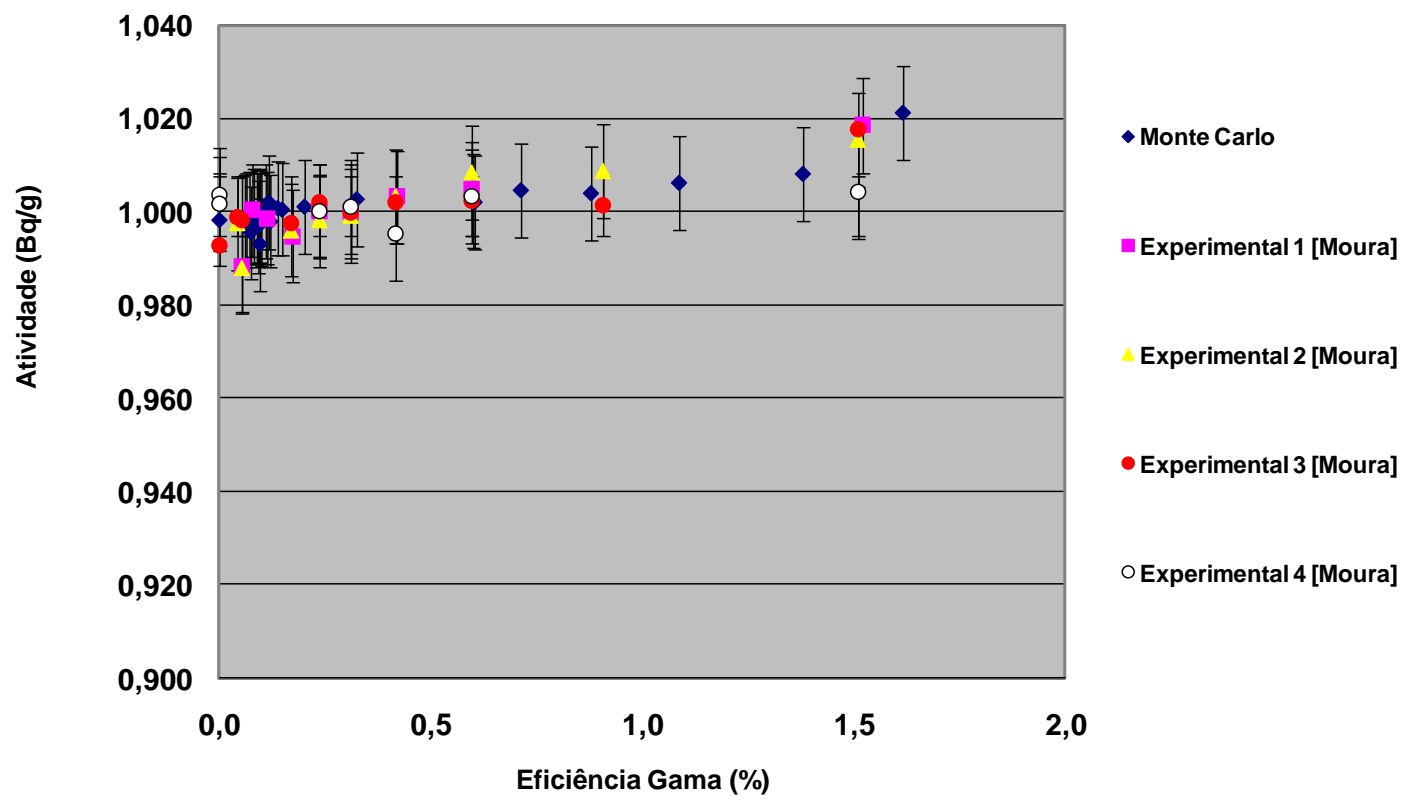

Figura 3.14 - Curva de Extrapolação para o Pico-Nuclear: comparação dos pontos obtidos para os dados experimentais e pelo método de Monte Carlo.

Embora as flutuações, no Pico Nuclear, seja em alguns casos maiores do que as barras de erro estimadas pela propagação, o comportamento total segue aproximadamente a forma da curva prevista por Monte Carlo. Através desta curva foi possível obter a atividade média da solução que resultou, em: $685,0 \mathrm{kBq} \cdot \mathrm{mg}^{-1}$ compatível com o valor original, que é de 682,4 kBq.mg ${ }^{-1[26]}$. Com este novo valor da atividade, obtido por meio do cálculo de Monte Carlo, a razão entre $\mathrm{e} / \mathrm{\beta}^{+}$,resultou em: 0,1039 (21). Este valor pode ser comparado com os encontrados na literatura recente ${ }^{[27]}$, a saber: $0,1075(25)^{[35]}$ (Sýkora e Povinec, 1986), 0,1050 (29) ${ }^{[36]}$ (Kunze et al., 1990) e 0,1084 (27) ${ }^{[27]}$ (Nähle, 2008). 


\section{CONCLUSÕES}

A padronização do ${ }^{60} \mathrm{Co}$, foi realizada no sistema de coincidências $4 \pi \beta-\gamma$ com o propósito de validar a metodologia de cálculo por Monte Carlo, uma vez que este radionuclídeo apresenta um esquema de desintegração simples, meia vida longa, o que possibilita a validação dos programas desenvolvidos. Esta parte também incluiu uma nova determinação da eficiência do detector $4 \pi$ para fótons, que foi comparada com os resultados de Moura ${ }^{[10]}$, apresentando excelente acordo.

Pode-se verificar também que a curva de extrapolação entre a atividade observada e o parâmetro da ineficiência, para o caso do ${ }^{60} \mathrm{Co}$, apresentou uma excelente concordância entre os dados experimentais e a previsão teórica por Monte Carlo. Os resultados podem ser considerados satisfatórios, indicando que a calibração do ${ }^{60} \mathrm{Co}$ possibilitou a validação do novo modelo, para o sistema de coincidências instalado no LMN.

Com o aperfeiçoamento da modelagem do detector proporcional $4 \pi$, introduzindo uma descrição mais detalhada do suporte e do material da fonte radioativa, além de absorvedores colocados em torno da fonte, foram desenvolvidos métodos de padronização para o ${ }^{22} \mathrm{Na}$, no sistema de coincidência $4 \pi \beta-\gamma$, tanto para o sistema I como para o sistema II, e verificamos através dos gráficos que as curvas experimentais, comparadas com o método Monte Carlo (MCNPX), estão em concordância, tanto para método Pico Soma como para o Pico Nuclear, respectivamente.

A metodologia desenvolvida para $0{ }^{22} \mathrm{Na}$ foi aplicada com sucesso na modelagem por Monte Carlo do radionuclídeo ${ }^{18} \mathrm{~F}$, que é um emissor $\beta^{+}$puro, e já havia sido medido anteriormente pelo LMN. Verificamos que as curvas de extrapolação da eficiência possuem uma boa concordância entre os dados experimentais e a previsão teórica por Monte Carlo, indicando que o procedimento seguido para a modelagem foi satisfatório. 
Portanto, a metodologia aplicando o método de Monte Carlo permite um planejamento adequado das medidas para o método de coincidências, principalmente para radionuclídeos com esquema de desintegração complexo, e para o MCNPX, podem ser estimados os cálculos, para outros radionuclídeos que se desintegram pela emissão de pósitrons. 


\section{PERSPECTIVAS FUTURAS}

Como trabalho futuro pode-se sugerir algumas melhorias no código ESQPOS, com o objetivo de aperfeiçoá-lo chegando às condições mais próximas das experimentais e possibilitando realizar comparações com os resultados previstos por Monte Carlo, através de curvas de extrapolação, para outros radionuclídeos com esquema de desintegração complexos, por exemplo, os que decaiam por vários modos de desintegração, tais como $\beta^{-} / \beta^{+} / C E$, simultaneamente.

Para isto, será necessário introduzir duas tabelas de resposta para o detector $4 \pi$ : uma para elétrons e outra para pósitrons. Com estas duas tabelas, não seria necessário adotar-se um esquema de desintegração alternativo, como foram os casos do ${ }^{18} \mathrm{~F} \mathrm{e}{ }^{22} \mathrm{Na}$.

Sugerem-se também a inclusão de raios- $X$ provenientes de processos de conversão interna e de tabelas de eficiência para pósitrons, individuais para cada tipo de absorvedor. Neste caso, para cada energia de pósitron sorteada pelo programa ESQPOS, haveria uma tabela de curva de resposta para o gama de aniquilação correspondente. Isto evitaria ter-se que utilizar uma energia média para os pósitrons e inserir uma resposta específica para o $\mathrm{Nal}$, para a transição de $1022 \mathrm{keV}$. 


\section{APÊNDICE A - PROGRAMA ESQPOS1 $1^{[19]}$}

Este programa calcula $\mathrm{N}_{\beta}{ }^{*} \mathrm{~N} \gamma / \mathrm{Nc}$ e (1-Nc/N $\left.\gamma\right) /(\mathrm{Nc} / \mathrm{N} \gamma)$ para o sistema 4pi-beta-gama - $\mathrm{Nal}(\mathrm{TI})$. Este programa contém 1648 linhas, reproduzidas parcialmente abaixo.

\section{\$DEBUG}

C C Inicio da alteracao: 10/04/2007

C Alteracao intermediaria: 20/05/2007

C Termino da alteracao: em andamento

C CALCULA NB*NG/NC E (1-NC/NG)/(NC/NG) PARA O SISTEMA 4PI-BETAGAMA $(\mathrm{Nal}(\mathrm{TI}))$

C MODIFICACAO DO PROGRAMA ESQUEMAM.FOR PARA CAPTURA ELETRONICA.

C Versao alterada do programa ESQUEM1.FOR para ARGENTINA com inclusao de

C eficiencia beta gama para POS-DOC.

C NCLUSAO DA ENERGIA MINIMA PARA TABELA EFICIENCIA BETA

C INCLUSAO DA TABELA DE RESPOSTAS DO DETECTOR BETA PARA GAMA

C CALCULA TABELA FERMI E IMPLEMENTADO N RAMOS

C BETA, GAMA COM 750 CANAIS VARIANDO DE $4 \mathrm{MeV} \mathrm{e}$

C GAMA EM CASCATA CONSIDERANDO O EFEITO SOMA.

C CALIBRACAO EM CANAL X ENERGIA

C

C

FATOR DE GANHO PARA BETA DIFERENTE DO FATOR DE GANHO PARA FOTON

C CALCULA ENERGIA DOS ELETRONS DE CONVERSAO PARA AS CAMADAS K E L

C POR DIFERENCA ENTRE ENERGIA DO GAMA E ENERGIA DE LIGACAO DO ELETRON

C NA CAMADA CORRESPONDENTE.

C SEGUE ESQUEMA DE DESINTEGRAÇÃO PARA GAMA E ec ATÉ O ESTADO FUNDAMENTAL

C GERA NOVA SEMENTE PARA NUMEROS ALEATORIOS QUANDO TOTAL DE NUMEROS

C ALEATORIOS ESTA PROXIMO DO PERIODO $(2,147 \mathrm{E}+9)$

C V 1.0 - FORTRAN Visual Workbench v 1.00

C 10/04/2007 - Mauro N. Takeda

C CALCULA ESPECTROS BETA, GAMA E COINCIDENCIA

C IMPLEMENTADO RESOLUCAO DO DETECTOR

C VARIAVEIS:

C $\quad$ FOT $=$ FATOR DE OTIMIZACAO $\left(\right.$ FOT $\left.{ }^{\star} E F I C I E N C I A<100 \%\right)$

C DISCE $=$ ENERGIA DO DISCRIMINADOR PARA ENERGIA EMITIDA [MeV]

C DISCD = ENERGIA DO DISCRIMINADOR PARA ENERGIA DEPOSITADA [MeV]

C $\quad F E M B=$ FATOR DE ENERGIA MAXIMA PARA BETA

C $\quad F E M G=$ FATOR DE ENERGIA MAXIMA PARA FOTON

C $\quad$ NCT $=$ NUMERO DE CANAIS TOTAL

C LINCOL $=$ NUMERO DE LINHAS E COLUNAS

C NHIST $=$ NUMERO DE HISTORIAS

C $\quad$ FLAGcol $=$ FLAG PARA ABSORVEDOR DE COLLODION $(0=S E M, 1=$ COM $)$

C $\quad \mathrm{FLAGal}=\mathrm{FLAG}$ PARA ABSORVEDOR DE ALUMINIO $(0=\mathrm{SEM}, 1=\mathrm{COM})$

C $\quad X \mathrm{col}=$ ESPESSURA DO COLLODION $[\mathrm{mg} / \mathrm{cm} 2]$

C Xal = ESPESSURA DO ALUMINIO $[\mathrm{mg} / \mathrm{cm} 2]$

C CNLBGDT $(I)=$ CONTAGEM CANAL BETA COM GAMA DETECTADO

C $\quad$ CNLBGDP $(I)=$ CONTAGEM CANAL BETA COM GAMA DEPOSITADO IMPLICIT REAL*4 (A-H,O-Z)

I NTEGER ${ }^{\star} 4$

CANALFE,CNLSBe,CANALEBD,CANALB,CANALG,CANALC,TRAC,SNUC INTEGER*4 CNLBGDT,CNLBGDP 
DIMENSION EB0(30),PB(30), EBI(298), ENG(30),EFGT(800),BETAi(30)

DIMENSION ERANGE(43),RANGECol(43),RANGEAI(43), EG(752), EKLM(3)

DIMENSION

CANALB(4096),CANALG(4096),CANALC(4096),CANALEBD(4096)

DIMENSION CNLBGDT(4096),CNLBGDP(4096)

DIMENSION CANALFE(4096), CNLSBe(4096), EeL(30,30), GAMAi $(30,30)$

DIMENSION PG(30,30),ALFA(30,30), EFG(800,800), $\operatorname{EeK}(30,30)$, eci $(30,30)$

END DO

IF (HOUR2 .LT. HO) THEN

DHOUR $=(24+$ HOUR2 $)-H 0$

ELSE

DHOUR=HOUR2-HO

END IF

IF (MINUTE2 .LT. MI0) THEN

DMINUTE $=(60+$ MINUTE2 $)-M I 0$

DHOUR=DHOUR -1

ELSE

DMINUTE=MINUTE2-MI0

END IF

IF (SECOND2 .LT. SO) THEN

DSECOND $=(60+S E C O N D 2)-S 0$

DMINUTE=DMINUTE-1

ELSE

DSECOND=SECOND2-S0

END IF

IF (HUND2 .LT. HU0) THEN

DHUND $=(100+H U N D 2)-H U 0$

DSECOND=DSECOND-1

ELSE

DHUND=HUND2-HUO

END IF

WRITE $(9,5030)$ DO,MO,YO,HO,MIO,SO,HUO

5030 FORMAT (1X,//,'INICIO PROCESSAMENTO: ',I2.2,'/',I2.2,'/',I4.4,

* 10X,I2.2,'h ',I2.2,'min ',I2.2,',',I2.2,'seg ',/)

WRITE $(9,5040)$ DHOUR,DMINUTE,DSECOND,DHUND

5040 FORMAT ('TEMPO DE PROCESSAMENTO TOTAL: ',I2.2,'h ',I2.2,

* 'min ',I2.2,',', I2.2,'seg ')

CLOSE (9)

CLOSE (10)

CLOSE (20)

CLOSE (21)

CLOSE (22)

CLOSE (23)

STOP

END

C INICIO SUBROTINAS

SUBROUTINE DATAHORA (YEAR,MONTH,DAY,HOUR,MINUTE,SECOND,HUND) INTEGER ${ }^{\star 2}$ YEAR,MONTH,DAY,HOUR,MINUTE,SECOND,HUND

CALL GETDAT(YEAR,MONTH,DAY)

CALL GETTIM(HOUR,MINUTE,SECOND,HUND)

RETURN

END 


\section{APÊNDICE B - Código do Programa ELETRONX}

Programa para criar arquivo de entrada para MCNP-X

Este programa contém 75 linhas, reproduzidas parcialmente abaixo.

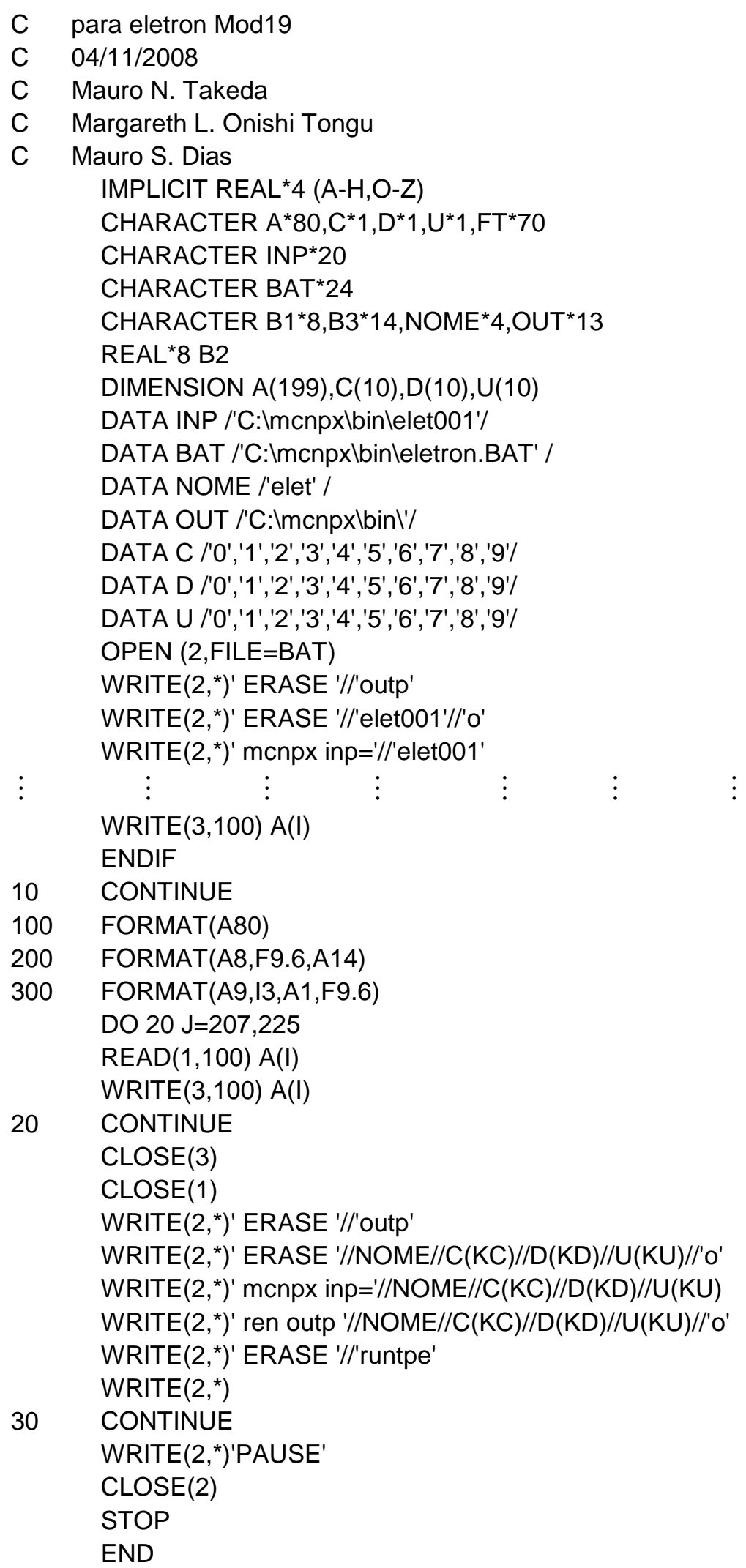




\section{APÊNDICE C- Código do Programa FOTONX}

Programa para criar arquivo de entrada para MCNP-X.

Este programa contém 72 linhas, reproduzidas parcialmente abaixo.

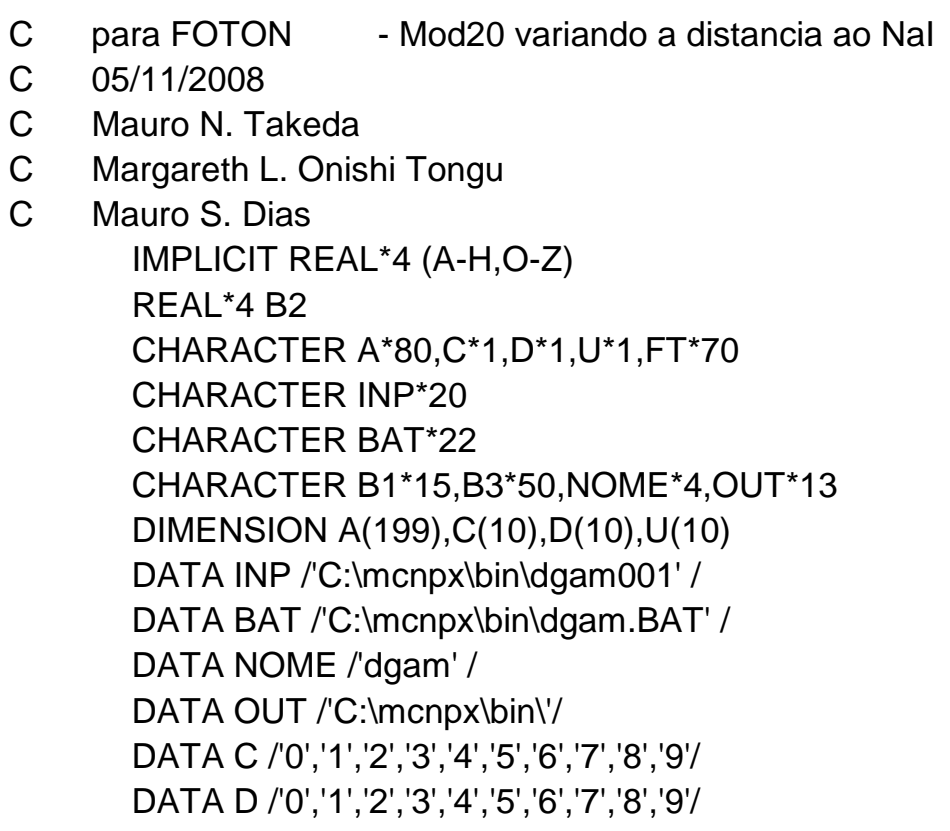

*.OR. I .EQ. 178

*.OR. I .EQ. 171 .OR. I .EQ. 172 .OR. I .EQ. 173

* .OR. I .EQ. 169 .OR. I .EQ. 174 .OR. I .EQ. 175 ) THEN

$\operatorname{READ}(1,200) \mathrm{B} 1, \mathrm{~B} 2, \mathrm{~B} 3$

WRITE $\left({ }^{*},{ }^{*}\right) \mathrm{B} 1, \mathrm{~B} 2, \mathrm{~B} 3$

$\mathrm{B} 2=\mathrm{B} 2-\mathrm{DIST}$

WRITE $\left({ }^{*},{ }^{*}\right) \mathrm{B} 1, \mathrm{~B} 2, \mathrm{~B} 3$

WRITE $(3,200)$ B1,B2,B3

ELSE

$\operatorname{READ}(1,100) \mathrm{A}(\mathrm{l})$

$\operatorname{WRITE}(3,100) A(I)$

ENDIF

10 CONTINUE

100 FORMAT(A80)

200 FORMAT(A15,F6.1,A50)

CLOSE(3)

CLOSE(1)

WRITE $\left(2,{ }^{*}\right)$ ' ERASE '//'outp'

WRITE $\left(2,{ }^{*}\right)^{\prime}$ ERASE '//NOME//C(KC)//D(KD)//U(KU)//'O'

WRITE $\left(2,{ }^{*}\right)^{\prime}$ mcnpx inp='//NOME//C(KC)//D(KD)//U(KU)

WRITE $\left(2,{ }^{*}\right)^{\prime}$ ren outp $1 / / \mathrm{NOME} / / \mathrm{C}(\mathrm{KC}) / / \mathrm{D}(\mathrm{KD}) / / \mathrm{U}(\mathrm{KU}) / / \mathrm{IO}^{\prime}$

WRITE $\left(2,{ }^{*}\right)$ ' ERASE '//'runtpe'

WRITE $\left(2,{ }^{*}\right)$

30 CONTINUE

WRITE $\left(2,{ }^{*}\right)^{\prime} P A U S E '$

CLOSE(2)

STOP

END 


\section{APÊNDICE D - Código do Programa EALUM}

Programa para criar arquivo de entrada para MCNP-X - variando absorvedores Al e Mylar Sistema II.

Este programa contém 88 linhas, reproduzidas parcialmente abaixo.

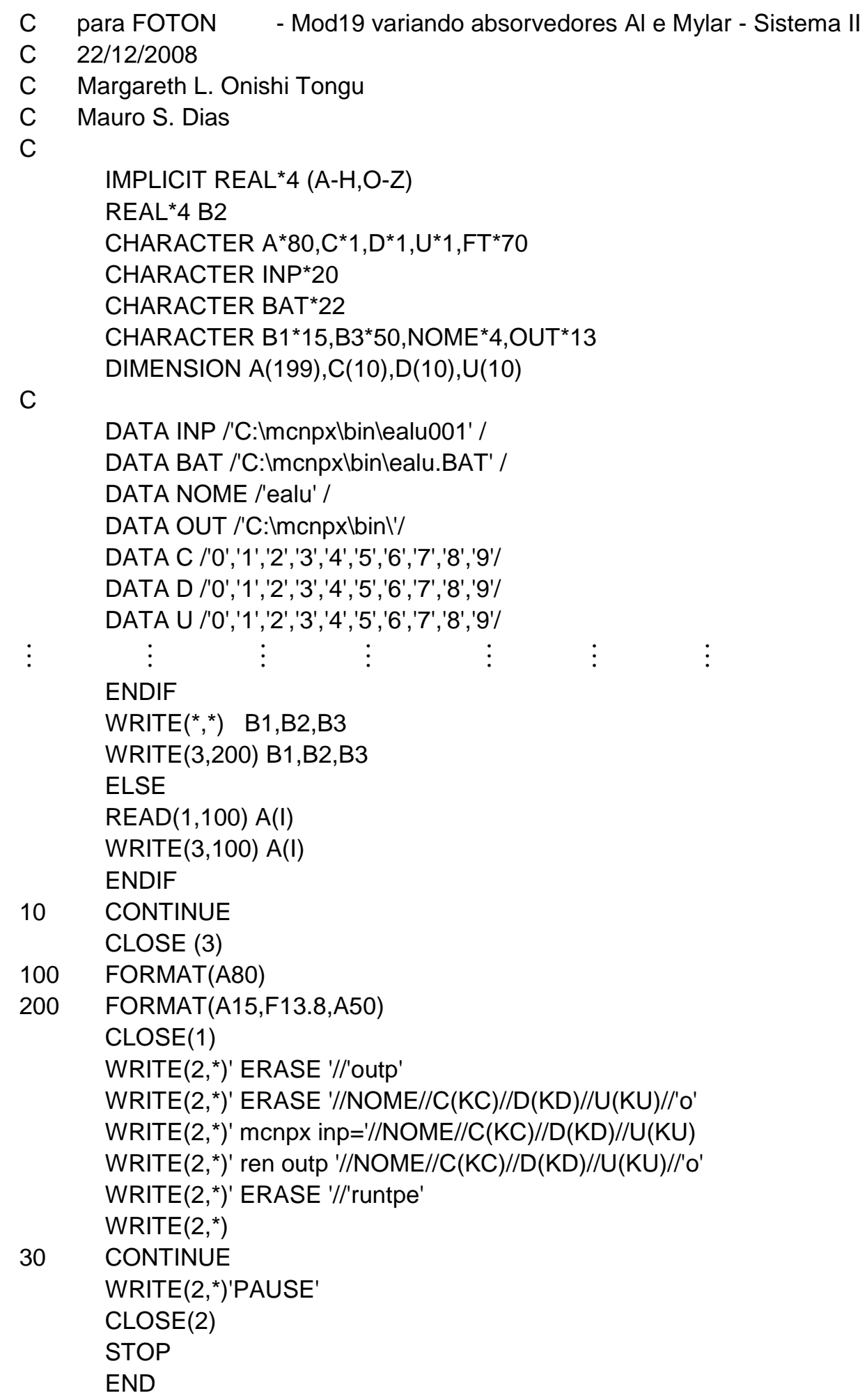




\section{APÊNDICE E - Código do Programa DGAMA}

Analisa saída do MCNPX e gera tabela efigama.dat para MONTEC.

Este programa contém 154 linhas, reproduzidas parcialmente abaixo.

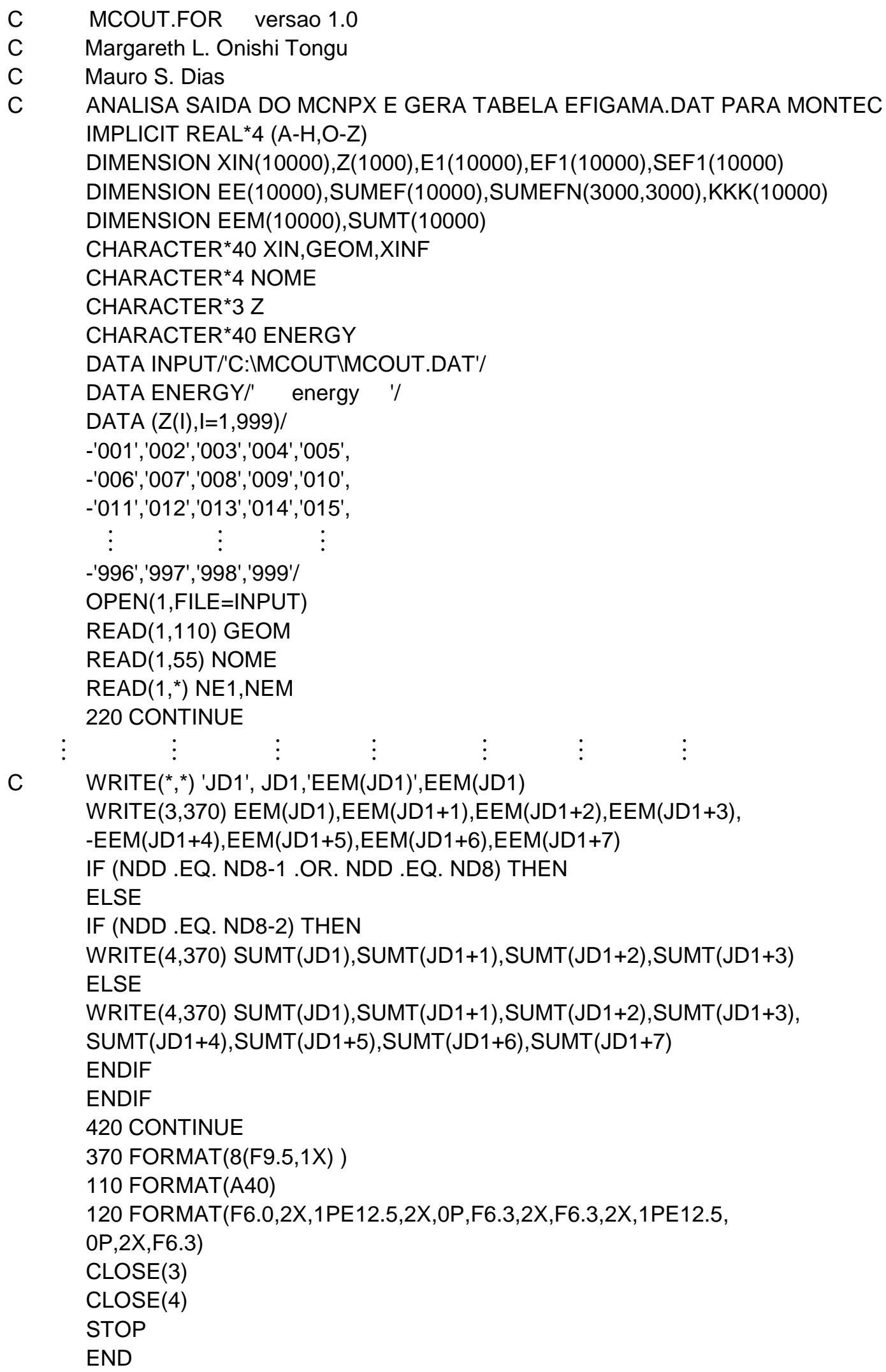




\section{APÊNDICE F - Código do Programa MCOUT1}

Programa para criar arquivo de entrada para MCNP-X para FOTON - Mod20 variando a distancia ao Nal

Este programa contém 96 linhas, reproduzidas parcialmente abaixo.

C Margareth L. Onishi Tongu

C Mauro S. Dias

IMPLICIT REAL*4 (A-H,O-Z)

REAL*4 B2

CHARACTER A*80, $\mathrm{C}^{*} 1, \mathrm{D}^{*} 1, \mathrm{U}^{*} 1, \mathrm{FT}^{*} 70$

CHARACTER INP*20

CHARACTER BAT*22

CHARACTER B $1{ }^{*} 15, \mathrm{~B} 3{ }^{*} 50, \mathrm{NOME}^{*} 4, \mathrm{OUT}^{*} 13$

DIMENSION A(199),C(10),D(10),U(10)

DATA INP /'C:Imcnpx/binldgam001' /

DATA BAT /'C:Imcnpxlbinldgam.BAT' /

DATA NOME /'dgam' /

DATA OUT /'C:Imcnpx|binl'/

DATA C /'0','1','2','3','4','5','6','7','8','9'/

DATA D /'0','1','2','3','4','5','6','7','8','9'/

DATA U /'0','1','2','3','4','5','6','7','8','9'/

DIST $=1$

PASSO $=1$

DIST $=$ DIST - PASSO

OPEN $(2, F I L E=B A T)$

WRITE $\left(2,{ }^{*}\right)$ ' ERASE '//'outp'

WRITE $\left(2,{ }^{*}\right)^{\prime}$ ERASE '//'dgam001'//'o'

WRITE $\left(2,{ }^{*}\right)^{\prime}$ mcnpx inp='//'dgam001'

$\operatorname{WRITE}\left({ }^{*},{ }^{*}\right) \mathrm{B} 1, \mathrm{~B} 2, \mathrm{~B} 3$

WRITE $(3,200)$ B1,B2,B3

ELSE

$\operatorname{READ}(1,100) A(I)$

WRITE $(3,100) A(I)$

ENDIF

10 CONTINUE

100 FORMAT(A80)

200 FORMAT(A15,F6.1,A50)

CLOSE(3)

CLOSE(1)

WRITE $\left(2,{ }^{*}\right)$ ' ERASE '//'outp'

WRITE $\left(2,{ }^{*}\right)^{\prime}$ ERASE '//NOME//C(KC)//D(KD)//U(KU)//'O'

WRITE $\left(2,{ }^{*}\right)^{\prime}$ mcnpx inp='//NOME//C(KC)//D(KD)//U(KU)

WRITE $\left(2,{ }^{*}\right)^{\prime}$ ren outp '//NOME//C(KC)//D(KD)//U(KU)//'O'

WRITE $\left(2,{ }^{*}\right)$ ' ERASE '//'runtpe'

$\operatorname{WRITE}\left(2,{ }^{*}\right)$

30 CONTINUE

WRITE $\left(2,{ }^{*}\right)^{\prime}$ PAUSE'

CLOSE(2)

STOP

END 


\section{APÊNDICE G- Código do Programa MCOUT2}

Código do Programa Analisa saída do MCNPX e Gera Tabela Efibeta.dat para MONTEC. Este programa contém 140 linhas, reproduzidas parcialmente abaixo.

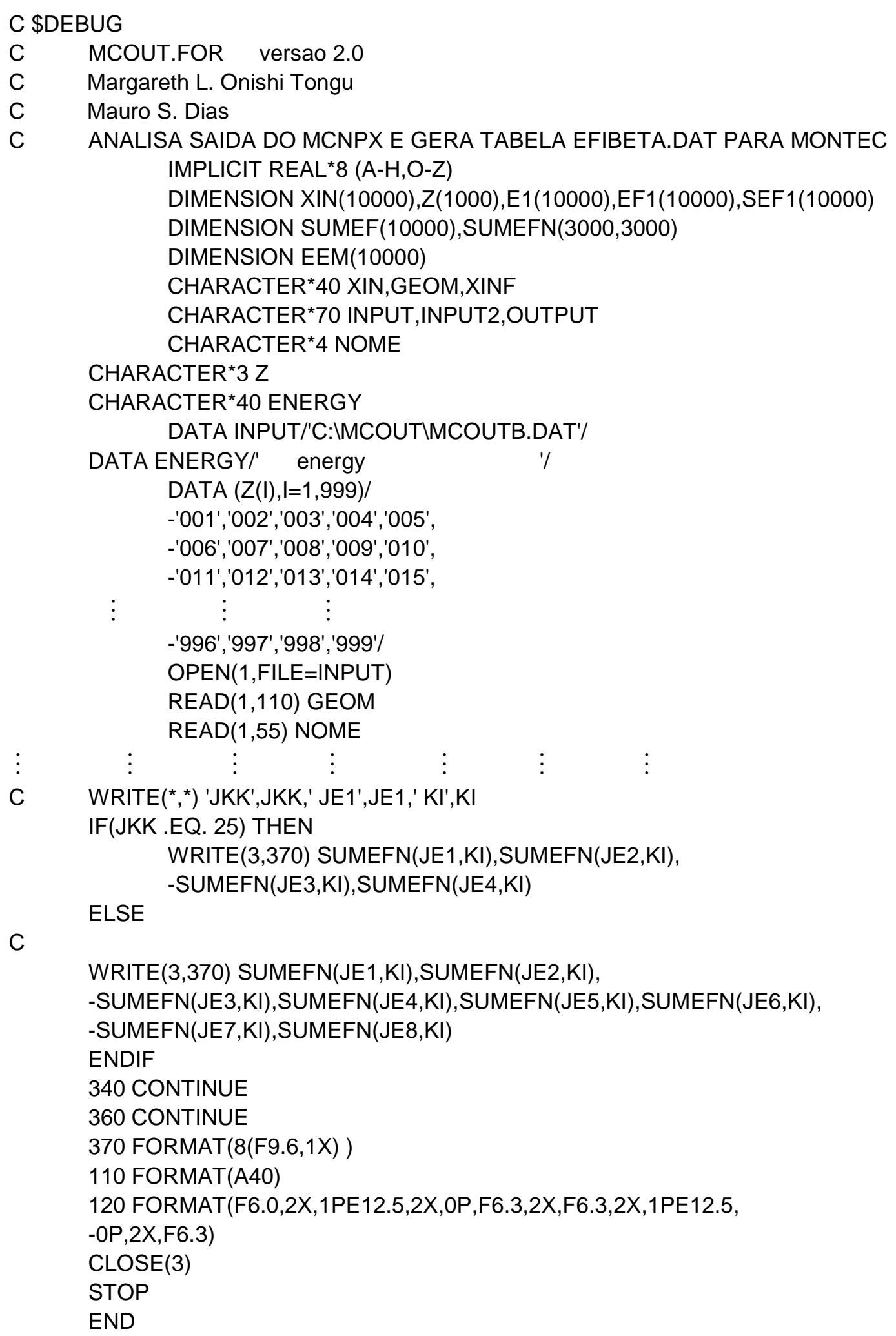




\section{APÊNDICE H - Código do Programa MCOUT3}

Analisa saída do MCNPX e gera tabela Efigamab.dat para MONTEC.

Este programa contém 159 linhas, reproduzidas parcialmente abaixo.

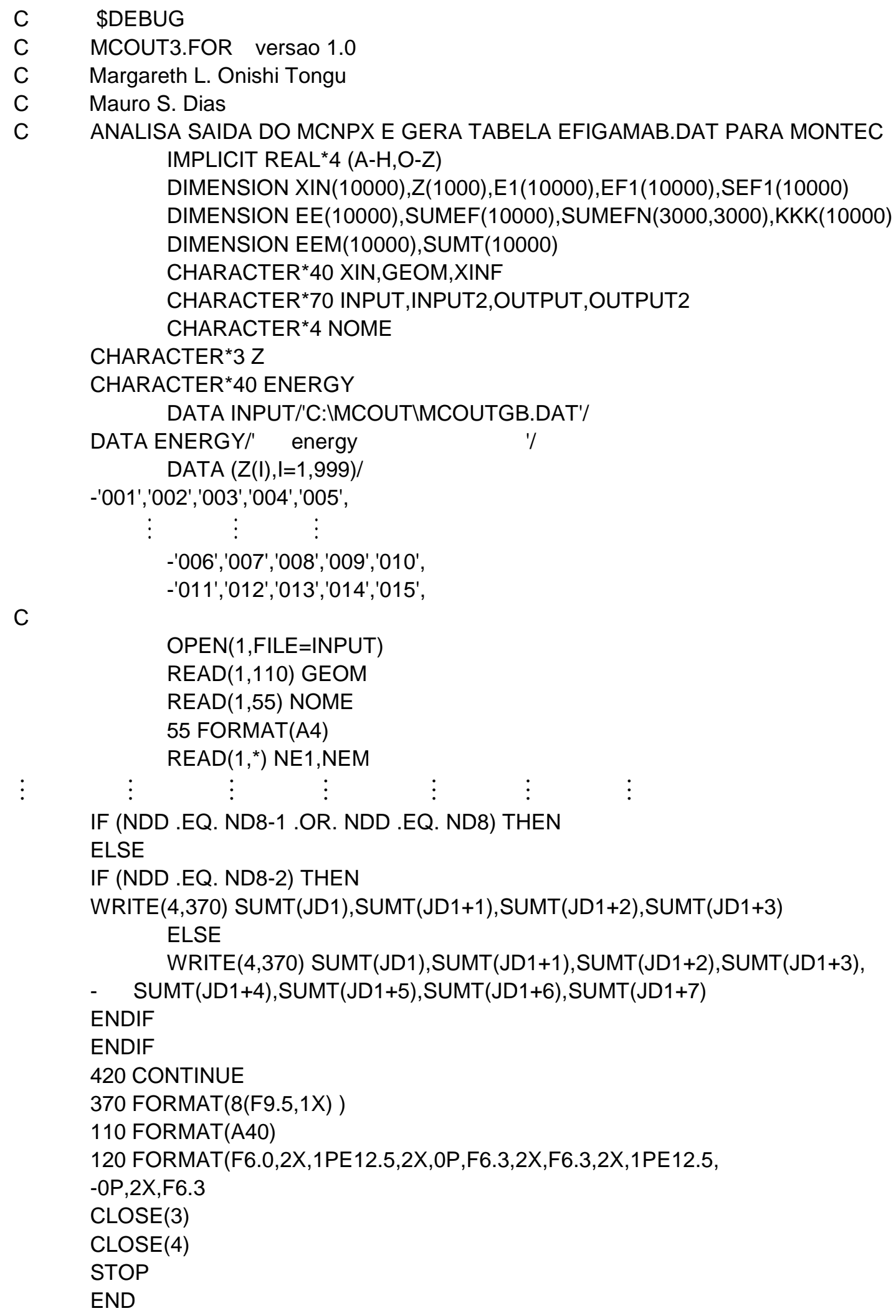




\section{APÊNDICE I - Arquivo Efibeta.dat}

Vetor das eficiências dos elétrons no $4 \pi$ integrada e normalizada, a $1^{a}$ coluna corresponde a energia de $0,0014 \mathrm{MeV}$, a $2^{\mathrm{a}}$ coluna de $0,0016 \mathrm{MeV}$ e assim sucessivamente e as linhas apresentam as eficiências para as energias de 0 até a energia considerada.

$0,0000000,0000100,0000200,0000300,0000400,0000500,0000600,000070$ $0,0000800,0000900,0001000,0001100,0001200,0001300,0001400,000150$ $0,0001600,0001700,0001800,0001900,0002000,0002100,0002200,000230$ $0,0002400,0002500,0002600,0002700,0002800,0002900,0003000,000310$ $0,0003200,0003300,0003400,0003500,0003600,0003700,0003800,000390$ $0,0004000,0004100,0004200,0004300,0004400,0004500,0004600,000470$ $0,0004800,0004900,0005000,0005100,0005200,0005300,0005400,000550$ $0,0005600,0005700,0005800,0005900,0006000,0006100,0006200,000630$ $0,0006400,0006500,0006600,0006700,0006800,0006900,0007000,000710$ $0,0007200,0007300,0007400,0007500,0007600,0007700,0007800,000790$ $0,0008000,0008100,0008200,0008300,0008400,0008500,0008600,000870$ $0,0008800,0008900,0009000,0009100,0009200,0009300,0009400,000950$ $0,0009600,0009700,0009800,0009900,0010000,0012000,0014000,001600$ $0,0018000,0020000,0022000,0024000,0026000,0028000,0030000,003200$

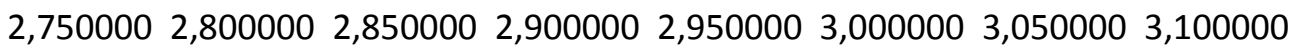
$3,1500003,2000003,2500003,3000003,3500003,4000003,4500003,500000$ $3,5500003,6000003,6500003,7000003,7500003,8000003,8500003,900000$ $3,9500004,000000$

$\begin{array}{cccccccc}0,00000 & 0,00000 & 0,00000 & 0,00000 & 0,00000 & 0,00000 & 0,00000 & 0,00000 \\ 0,00300 & 0,00250 & 0,00210 & 0,00165 & 0,00128 & 0,00099 & 0,00076 & 0,00062 \\ 0,00621 & 0,00527 & 0,00443 & 0,00348 & 0,00271 & 0,00207 & 0,00162 & 0,00130 \\ 0,00947 & 0,00820 & 0,00697 & 0,00551 & 0,00428 & 0,00327 & 0,00256 & 0,00206 \\ 0,01264 & 0,01119 & 0,00962 & 0,00766 & 0,00596 & 0,00455 & 0,00357 & 0,00288 \\ 0,01561 & 0,01413 & 0,01231 & 0,00986 & 0,00771 & 0,00591 & 0,00464 & 0,00374 \\ 0,01829 & 0,01696 & 0,01493 & 0,01208 & 0,00949 & 0,00730 & 0,00573 & 0,00462 \\ 0,02066 & 0,01963 & 0,01748 & 0,01429 & 0,01127 & 0,00870 & 0,00683 & 0,00551 \\ 0,02275 & 0,02215 & 0,01997 & 0,01647 & 0,01305 & 0,01011 & 0,00796 & 0,00641 \\ \vdots & \vdots & \vdots & \vdots & \vdots & \vdots & \vdots & \vdots \\ 1,00000 & 1,00000 & 1,00000 & 1,00000 & 1,00000 & 1,00000 & 1,00000 & 1,00000 \\ 1,00000 & 1,00000 & 1,00000 & 1,00000 & 1,00000 & 1,00000 & 1,00000 & 1,00000 \\ 1,00000 & 1,00000 & 1,00000 & 1,00000 & 1,00000 & 1,00000 & 1,00000 & 1,00000 \\ 1,00000 & 1,00000 & 1,00000 & 1,00000 & 1,00000 & 1,00000 & 1,00000 & 1,00000 \\ 1,00000 & 1,00000 & 1,00000 & 1,00000 & 1,00000 & 1,00000 & 1,00000 & 1,00000 \\ 1,00000 & 1,00000 & 1,00000 & 1,00000 & 1,00000 & 1,00000 & 1,00000 & 1,00000 \\ 1,00000 & 1,00000 & 1,00000 & 1,00000 & 1,00000 & 1,00000 & 1,00000 & 1,00000 \\ 1,00000 & 1,00000 & 1,00000 & 1,00000 & 1,00000 & 1,00000 & 1,00000 & 1,00000 \\ 1,00000 & 1,00000 & 1,00000 & 1,00000 & 1,00000 & 1,00000 & 1,00000 & 1,00000 \\ 1,00000 & 1,00000 & 1,00000 & 1,00000 & 1,00000 & 1,00000 & 1,00000 & 1,00000 \\ 1,00000 & 1,00000 & 1,00000 & 1,00000 & 1,00000 & 1,00000 & 1,00000 & 1,00000\end{array}$




\section{APÊNDICE J - Arquivo Efigama.dat}

Reprodução parcial do vetor das eficiências para gama no Nal(TI), as linhas correspondem as eficiências para as energias do intervalo de 0 a energia considerada.

\begin{tabular}{|c|c|c|c|c|c|c|c|}
\hline & & & & & & & \\
\hline & & & & & & & \\
\hline & & 83 & & & & & \\
\hline 725 & 2888 & 00183 & & 0485 & & & \\
\hline & & 6 & & & & & \\
\hline 3725 & 96 & 12 & 29 & 697 & & & \\
\hline & & & & & & & \\
\hline & 96 & 03 & & & & & 57 \\
\hline & & & & & & & 88 \\
\hline & & 5 & & 82 & & & \\
\hline & 6 & 59 & & 57 & & & \\
\hline & & & & & & & \\
\hline & & & & & & & 78 \\
\hline & & & & & & & \\
\hline & & 0 & & & & & 37 \\
\hline & & & & & & & \\
\hline & & 0 & & & & & \\
\hline & & & & & & & \\
\hline & & & & & & & \\
\hline & & & & & & & \\
\hline • & & & & • & & & \\
\hline & & & & & & & \\
\hline & & & & & & & \\
\hline & & & & & & & \\
\hline & & & & & & & \\
\hline & & & & & & & \\
\hline & & & & & & & \\
\hline & & & & & & & 50 \\
\hline & & & & & & & 000 \\
\hline • & 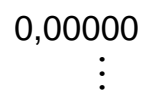 & 000 & 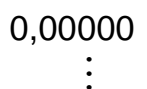 & & 0 & & \\
\hline & & & & & & & \\
\hline & & & & & & & 600 \\
\hline & & 0 & & & & & ,74800 \\
\hline & & 00 & & & 2,77200 & & 78000 \\
\hline & & & & 000 & 2,80400 & & 2,81200 \\
\hline & & & & & & & \\
\hline & & 2,85600 & & & & & 2,87600 \\
\hline & & & & & & & 80 \\
\hline & & & & & & & 2,94000 \\
\hline 9440 & 94800 & 2,95200 & 2,95600 & 2,96000 & 2,96400 & 2,96800 & 2,97200 \\
\hline
\end{tabular}




\section{APÊNDICE K - Código do Programa ESQPOS2 ${ }^{[19]}$}

Calcula $\mathbf{N}_{\beta} \mathrm{N}_{\gamma} / \mathrm{N}_{\mathrm{C}}$ e $\left(1-\mathrm{N}_{\mathrm{C}} / \mathrm{N}_{\gamma}\right) /\left(\mathrm{N}_{\mathrm{C}} / \mathrm{N}_{\gamma}\right)$ para o sistema $4 \pi \beta-\gamma$.

Este programa contém 1662 linhas, reproduzidas parcialmente abaixo.

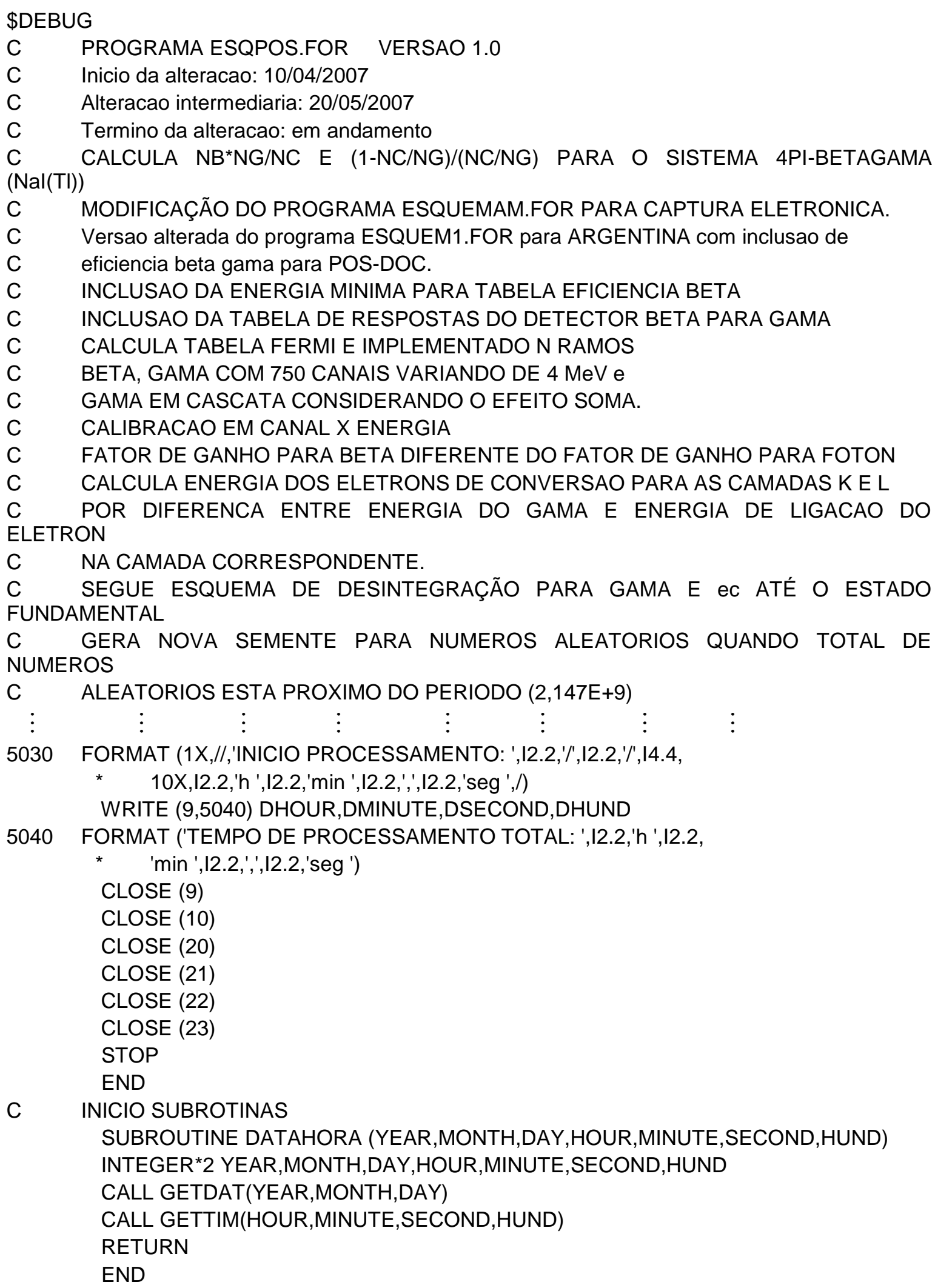




\section{APÊNDICE L - Código do Programa ESQPOS3}

Modificação do programa ESQPOS2 ${ }^{[19]} \mathrm{com}$ inclusão de função sigmoidal para a eficiência gama de aniquilação 13-03-09 (versão para pósitrons).

Este programa contém 1720 linhas, reproduzidas parcialmente abaixo.

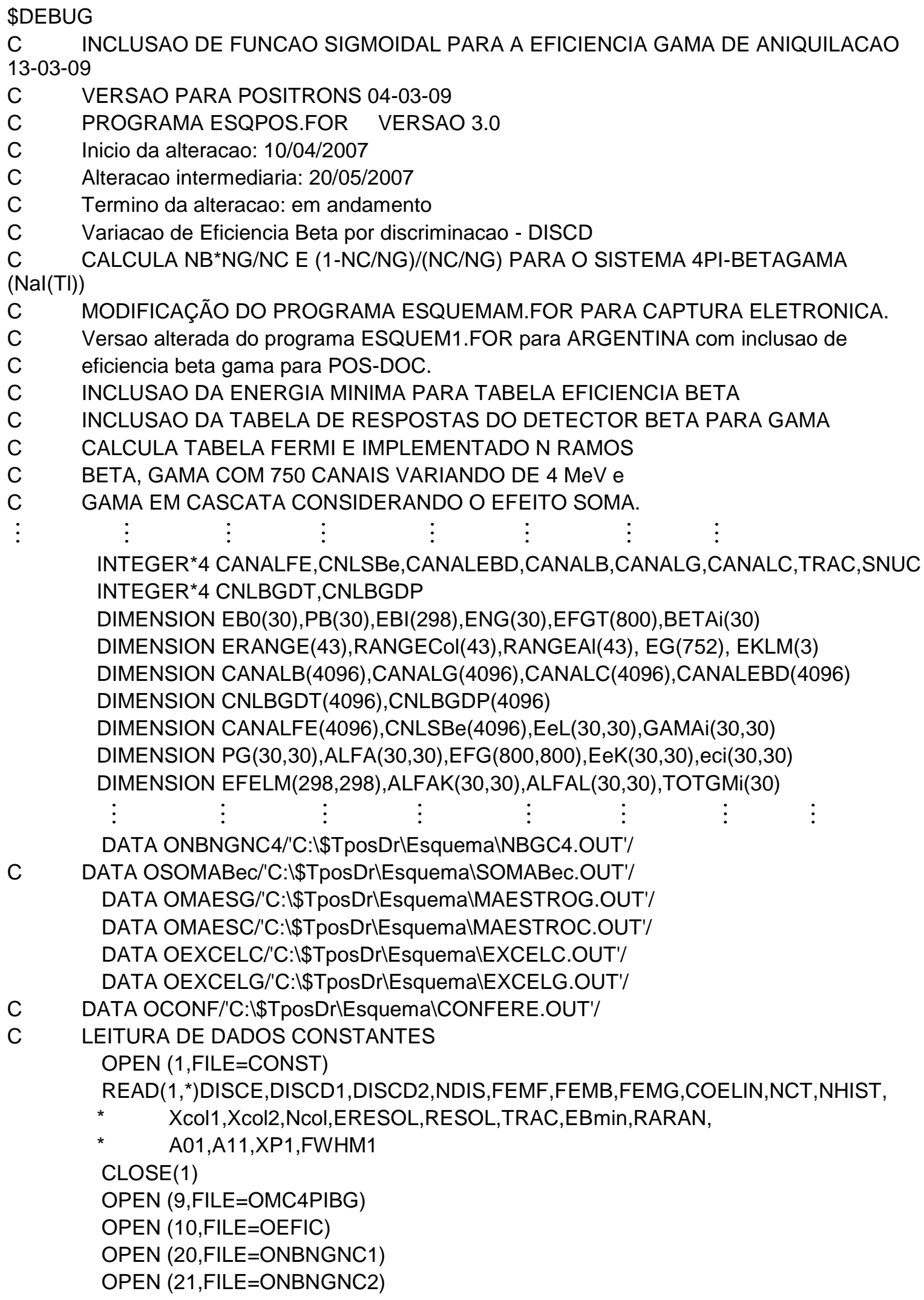




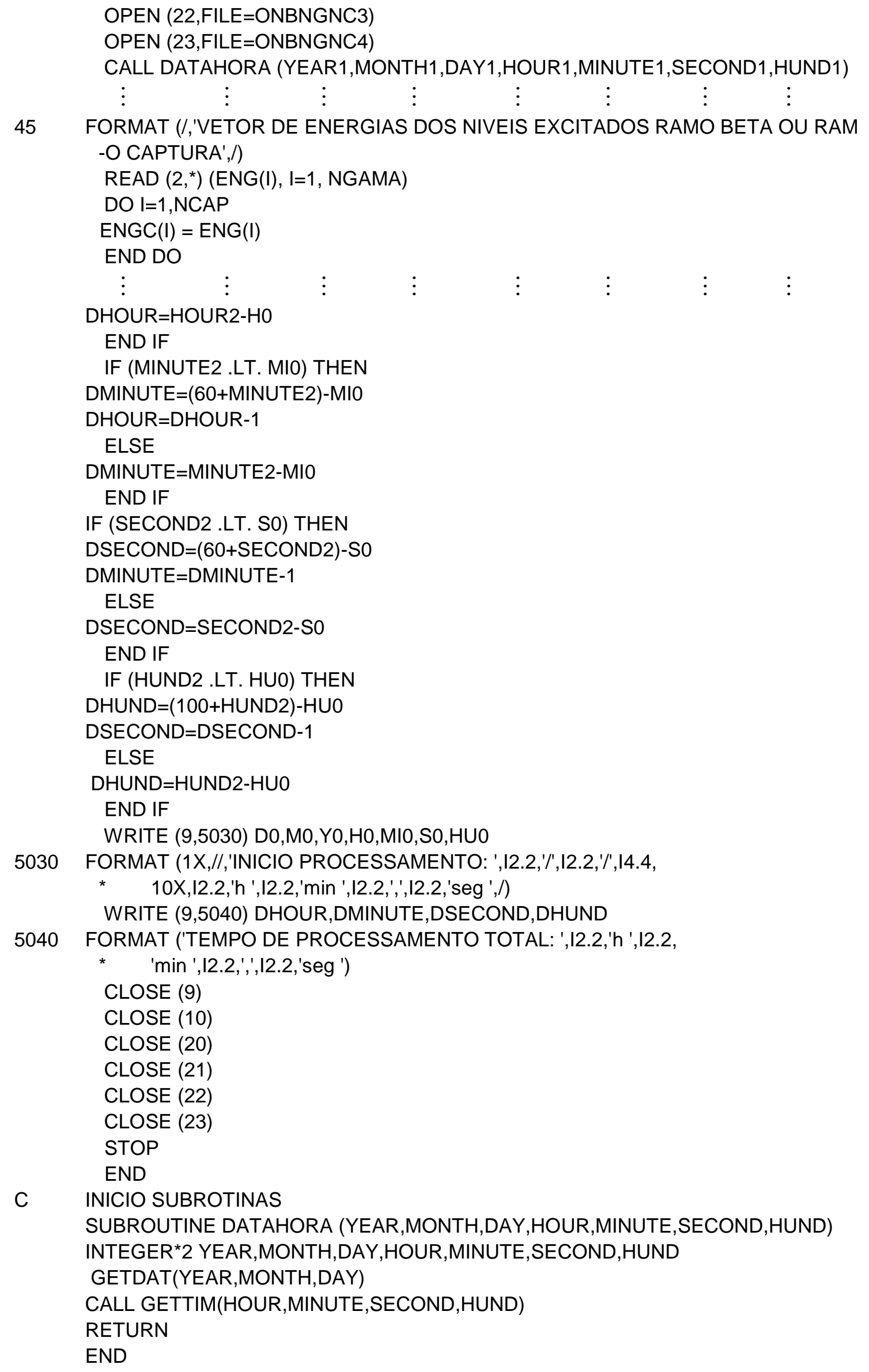




\section{REFERÊNCIAS BIBLIOGRÁFICAS}

[1] CAMPION, P. J., The standardization of radioisotopes by beta-gamma coincidence method using high efficiency detectors. Int. J. Appl. Radiat. Iso., 4, p: 232-248, 1959.

[2] GANDY, A., Mesure absolute de l'activité des radionucléides par la méthode des coincidences beta-gamma à l'aide de détecteurs de grand efficacité - Étude des coincidences instrumentales. Int. Journ. Appl. Radiat. Isot. 11, p: 75, 1961.

[3] GANDY, A., Mesure absolute de l'activité des radionucléides par la méthode des coincidences beta-gamma à l'aide de détecteurs de grand efficacité - Corretions de temps morts. Int. Journ. Appi. Radiat. Isot. 13, p: 501, 1962.

[4] BAERG, A. P., Measurement of radioactivity disintegration rate by the coincidence method. Metrologia, 2 (1), p: 23-32, 1966.

[5] BAERG, A. P., Absolute measurement of radioactivity. Metrologia, $\underline{3}$ (4), p: 105-108, 1967.

[6] BAERG, A. P., The efficiency extrapolation method in coincidence counting. Nuclear Instruments and Methods. 112, p: 143-150, 1973.

[7] HOUTHERMANS, H., MIGUEL, M., 4 $\pi \beta-\gamma$ coincidence counting for the calibration of nuclides with complex decay schemes. Int. J. Appl. Radiat. Isot. 13 p:137-142, 1962.

[8] KAWADA, Y., Extended applications and improvement of the $4 \pi \beta-\gamma$ coincidence method in the standardization of radionuclides. Res. of ETL. Japan, ETL-730, 1972.

[9] TAYLOR, J. G. V., The total internal conversion coefficient of the 279 keV transition following the decay of ${ }^{203} \mathrm{Hg}$ as measured by a new coincidence method. Canad. Journ. Phys., $\underline{40}$ (4) p. 383, 1962.

[10] MOURA, L. P., Método de coincidência generalizado para a medida absoluta da atividade de radionuclídeos - aplicação da determinação do coeficiente de conversão interna da transição de $279 \mathrm{kev}$ do ${ }^{203} \mathrm{TI}$. Tese de Doutorado apresentada à Universidade de Campinas, 1969.

[11] KOSKINAS, M. F.,SILVA E. A., YAMAZAKI I. M., DIAS M.S., Standardization of ${ }^{241} \mathrm{Am}$ solution. Applied Radiation and Isotopes", 64 , p.1238-1241, 2006. 
[12] KOSKINAS, M. F., PIRES C. A., YAMAZAKI I. M., SILVA E. A., DIAS M.S., Standardization of ${ }^{55} \mathrm{Fe}$ by tracing method. Applied Radiation and Isotopes", 66, p.733-736, 2008.

[13] KOSKINAS, M. MOREIRA D. S., TAKEDA M. N., SENEDA J.A., DIAS M.S., Primary standardization of ${ }^{72} \mathrm{Ga}$. Applied Radiation and Isotopes", 64, p. 1225-1228, 2006.

[14] KOSKINAS, M. F., SILVA E. A., YAMAZAKI I. M., DIAS M.S., Disintegration rate measurement of ${ }^{182} \mathrm{Ta}$. Applied Radiation and Isotopes", 66, p. 934-936, 2008.

[15] BACCARELLI A. M., DIAS M.S., KOSKINAS, M. F., BRANCACCIO F. Standardization of ${ }^{18} \mathrm{~F}$ by means of $4 \pi(\mathrm{ps}) \quad \beta-\gamma$ plastic scintillator coincidence system. IEEE Transactions on Nuclear Science, v. 55, ㄲo 3, p. 1767-1773, June 2008.

[16] Dias M.S., Takeda M. N., Koskinas, M. F., Application of Monte Carlo Simulation to the prediction of extrapolation curves in the coincidence technique. Applied Radiation and Isotopes", 64, p.11861192, 2006.

[17] TAKEDA, M. N.; DIAS, M. S.; KOSKINAS, M. K. Application of Monte Carlo simulation to ${ }^{134} \mathrm{Cs}$ standardization by means of $4 \pi$ beta-gamma coincidence system. IEEE Transactions on Nuclear Science, EUA, v. 52, № 5, p. 1716-1720, 2005.

[18] TAKEDA, M. N., Aplicação do Método de Monte Carlo no estudo da padronização de radionuclídeos com esquema de desintegração complexo em sistema de coincidência $4 \pi \beta-\gamma$. Tese de Doutoramento, Universidade de São Paulo, 2006.

[19] TAKEDA, M. N., Otimização de um programa de Monte Carlo para a padronização de radionuclídeos com esquema de desintegração complexos em sistema de coincidências $4 \pi \beta-\gamma$. Projeto de Pesquisa de Pós-Doutorado, Laboratório de Metrologia Nuclear, IPEN, 2007.

[20] MCKINNEY, W.G., et al., 2006. MCNPX overview. Proceedings of the 2006. HSSW, FNAL, IL, LA-UR-06-6206, September 2006.

[21] ORNL, Monte Carlo N-Particle Transport Code System, MCNP4C. RSICC Computer Code Collection, Oak Ridge National Laboratory. Report CCC-700, 2001.

[22] EVANS R. D., The Atomic Nucleus. Krieger Publishing Company Malabar Florida- McGraw-Hill, Inc., 1955. 
[23] KNOLL,G.F., Radiation Detection And Measurement. Second edition, John Wiley \& Sons, Inc.,1989.

[24] MARMIER P.,SHELDON E., Physics of Nuclei and Particles. Volume I Academic Press - New York and London- 1969.

[25] HARVEY, B.G, Nuclear Chemistry. Prentice-Hall, Inc; Englewood Cliffs, N.J.- 1967 - Prentice-Hall,Inc.

[26] MOURA, L. P., NUEVO-JR., A. B., relatório interno do Laboratório de Metrologia Nuclear. IPEN - Instituto de Pesquisas Energéticas e Nucleares, São Paulo,1972.

[27] NÄHLE O. KOSSERT K., KLEIN R. Activity standardization of ${ }^{22} \mathrm{Na}$. applied radiation and isotopes. 66, p.865-871, 2008.

[28] Table des Radionucleides, LMRI, CEA, 1987.

[29] DIAS, M. S., comunicação pessoal, 2007.

[30] M.J.WOODS, Baker M., Establishing equivalence for activity standards of short-lived radionuclides using NPL secondary standard radionuclide calibrator. Appl. Radiat. Isot., vol 60, 499-504, 2004.

[31] WILLIANS A., Measurement of the ratio of electron capture to positron emission in the decay of Na-22. Nuclear Physics 52 (1964) 324-332; (C) North-Holland Publishing Co. Amsterdan.

[32] ORNL, Monte Carlo N-Particle Transport Code System, MCNP5. RSICC Computer Code Collection, Oak Ridge National Laboratory. Report CCC,2006.

[33] CARTER, L.L.,SCHWARZ, R.A. MCNP Visual Editor Computer Code Manual for Vised. Version 19K, November, 2005. www.mcnpvised.com.

[34] Fortran Powerstation Versão 4.0. 1995.

[35] PAL P. B., GUPTA S.K., VARSHNEY V.P., GUPTA D. K. Continuous slowing down approximation range of $50 \mathrm{kev}$ to $\mathbf{1 0 0} \mathrm{mev}$ positrons. Japanese Journal of Applied Physics, vol. 24, no 8 August, 1985 pp. 10701073.

[36] SÝKORA I., POVINEC P., Measurement of electron capture to positron emission ratios in light and medium nuclides. Nucl. Instrum Methods $B$ 17, 467-471, 1986. 
[37] KUNZE V., SCHMIDT-OTT W.-D., BEHRENS H., Measurement of capture positron decay ratios in $\mathrm{Na}-22$ and $\mathrm{Zn}-65$ and comparison whith theory. z. phys. A 99, 55-64, 1990. 